\title{
RICARDO STEFANI
}

Quimitaxonomia e fitoquímica de espécies da tribo Heliantheae (Asteraceae) e uso de Quimioinformática em elucidação estrutural

Tese apresentada à Faculdade de Filosofia,Ciências e Letras de Ribeirão Preto da Universidade de São Paulo para obtenção do título de Doutor em Ciências.

Área: Química

Orientador: Prof. Dr. Fernando Batista da Costa

Co-Orientador: Prof. Dr. Vicente de Paulo Emerenciano

Ribeirão Preto

2006 


\section{FICHA CATALOGRÁFICA}

Stefani, Ricardo

Quimiotaxonomia e estudo fitoquímico de espécies da tribo Heliantheae (Asteraceae) e uso de quimioinformática em elucidação estrutural.

Ribeirão Preto, 2006.

142 p. : il. ; $30 \mathrm{~cm}$

Tese de Doutorado, apresentada à Faculdade de Filosofia, Ciências e Letras de Ribeirão Preto/USP - Área de concentração: Química.

Orientador: Prof. Dr. Fernando Batista da Costa.

1. Heliantheae. 2. Asteraceae. 3. Lactonas sesquiterpênicas. 4. Elucidação Estrutural. 5. Quimioinformática. 6. Redes Neurais Artificiais. 


\section{AGRADECIMENTOS}

Ao Prof. Dr. Fernando Batista da Costa pela orientação, confiança, amizade, por ter me ensinado muito e contribuido para o meu crescimento científico, pessoal e intelectual.

Ao Prof. Dr. Vicente de Paulo Emerenciano pela co-orientação, confiança, amizade e por ter me ensinado muito sobre Quimioinformática.

A Prof. Dra. Dionéia Camilo Rodrigues de Oliveira por ter me "adotado" enquanto o Prof. Fernando completava o seu pós-doutoramento na Alemanha, pela amizade e também pelas coisas que me ensinou sobre elucidação estrutural e produtos naturais.

A Faculdade de Filosofia Ciências e Letras de Ribeirão Preto e ao departamento de Química da mesma unidade pela oportunidade de realização do curso de doutorado.

A CAPES pela bolsa concedida.

A PCARP pela bolsa moradia.

Ao funcionário Walter Lopes do Laboratório de Farmacognosia/FCFRP pelo auxilio durante a fase experimental e amizade.

A funcionária Virgínia do Laboratório de RMN do departamento de Química/FFCLRP pela obtenção dos espectros de RMN.

Ao Prof. Dr. Noberto Peporine Lopes pela obtenção de espectros de Massa.

Aos amigos Paulo, Sérgio e Nilton, do Laboratório de Farmacognosia, pelos extratos cedidos, auxilio prestado durante os estudos fitoquímicos, pela amizade e convivência.

Ao Marcus Tulius Scotti pelo auxilio com alguns descritores e redes neurais.

Aos meus pais pelo apoio.

Aos demais amigos do laboratório: Niege, Gustavo, João Paulo, Paula, Ana Silvia, William, Thales, Leonardo, Ana Lúcia, Patrícia, Karin e Juliana pela amizade e bons momentos.

Ao pessoal da moradia da pós-graduação pela amizade, convivência e momentos de descontração. 


\section{RESUMO}

STEFANI, R. Quimitaxonomia e fitoquímica de espécies da tribo Heliantheae (Asteraceae) e uso de Quimioinformática em elucidação estrutural. 2006. Tese (doutorado), Faculdade de Filosofia, Ciências e Letras de Ribeirão Preto, Universidade de São Paulo, Ribeirão Preto, 2006.

A química de produtos naturais sempre foi uma fonte importante de novas substâncias e de substâncias bioativas. No mundo moderno, o homem utiliza os produtos naturais para diversos fins: corantes, edulcorantes, essências, defensivos agrícolas e principalmente medicamentos. Com o desenvolvimento das técnicas de isolamento de substâncias, cresceu a necessidade de organizar as informações obtidas e também a criação de meios para a identificação mais rápida das substâncias isoladas. Esta foi uma das necessidades que fez surgir a Quimioinformática. Quimioinformática é uma disciplina que utiliza os métodos da informática para organizar dados químicos, analisar estes dados e gerar novas informações a partir destes dados. Esta ferramenta tem sido utilizada com sucesso em procura por novas drogas (QSAR/QSPR), elucidação estrutural automatizada de substâncias orgânicas e em cálculos e previsão de propriedades físico-químicas de diversas moléculas.

Os objetivos do presente trabalho foram o estudo fitoquímico de espécies dos gêneros Dimerostemma e Ichthyothere com o intuito de isolar novas substâncias e o desenvolvimento de técnicas envolvendo quimioinformática com o intuito de auxiliar a elucidação estrutural de produtos naturais.

Realizou-se a técnica de microamstragem de tricomas glandulares de diversas espécies pertencentes a gêneros da tribo Heliantheae (Viguiera, Tithonia, Dimerostemma). Através da microamostragem foi possível identificar diversas substâncias presentes nos tricomas glandulares das espécies analisadas. Das duas espécies de Dimerostemma investigadas ( $D$. brasilianum e $D$. rotundifolium) foi possível identificar dois germacrolidos e 
dois eudesmanolidos, enquanto que de Ichthyothere terminalis foi possível a identificação de dois melampolidos, todos eles lactonas sesquiterpênicas. Foram treinadas redes neurais artificiais para a realização da identificação dos esqueletos carbônicos de determinadas substâncias a partir dos dados obtidos através dos espectros de RMN ${ }^{13} \mathrm{C}$, sendo que os resultados obtidos podem ser considerados satisfatórios.

Foi desenvolvido um software para efetuar a identificação automática de substâncias através da comparação com uma biblioteca de padrões que possui dados cromatográficos de 51 lactonas sesquiterpênicas. Esse software, chamado de NAPROSYS, também é capaz de fazer comparação de dados de RMN de amostra com dados de RMN presentes em uma biblioteca de dados, tornando possível a identificação imediata de substâncias presentes na biblioteca e também auxiliar a elucidação estrutural de substâncias que não estão nela presentes. Para testar a eficiência do NAPROSYS, o programa foi utilizado com sucesso para identificar LSTs através da microamostragem de tricomas glandulares. A eficiência do NAPROSYS em identificar dados de RMN de substâncias presentes na biblioteca foi testada com substâncias isoladas do gênero Tithonia e Viguiera que possuem substâncias bem descritas na literatura e já isoladas no nosso laboratório, sendo que os resultados apresentados foram excelentes. Criou-se também dois modelos de redes neurais para prever tempos de retenção de lactonas sesquiterpênicas em cromatografia líquida (QSRR) com o objetivo de melhorar o desempenho do NAPROSYS em análises de dados cromatográficos. Os resultados para este caso, embora coerentes, precisam ser melhorados.

Neste trabalho concluimos que o uso das técnicas clássicas juntamente com as novas técnicas de Quimoinformática pode se tornar uma ferramenta muito eficaz para a elucidação estrutural e busca de substâncias com determinadas propriedades químicas ou mesmo na bioprospecção de novas substâncias bioativas.

Palavras-chaves: Heliantheae, Asteraceae, Lactonas sesquiterpênicas, Elucidação estrutural, Quimioinformática, Redes neurais artificiais. 


\section{ABSTRACT}

STEFANI, R. Chemotaxonomy and phytochemistry of Heliantheae (Asteraceae) species and use of Chemoinformatics in structure elucidation. 2006. Thesis (doctorade), Faculdade de Filosofia, Ciências e Letras de Ribeirão Preto, Universidade de São Paulo, Ribeirão Preto, 2006.

Natural products chemistry has always been an important source for new and bioactive compounds. In modern world, mankind uses natural products to do many tasks: colouring, as essences, as agricultural defensives and many as medicines. Within the development of compound isolation techniques, the need for information organisation has grown. The need for quickly identification of isolated compounds has also grown. This was one of the necessities that made Chemoinformatics emerge. Chemoinformatics is a discipline that uses informatics as a tool to organise, analise and to generate new knowledge from chemical data. This tool has been used with success in automate structure elucidation, drug development (QSAR/QSPR) and to predict chemical-physical data of many molecules.

The aims of the present work were the phytochemical study of species of the genera Dimerostemma and Ichthyothere to isolate new compounds, and the development of chemoinformatics techniques to aid natural products structure elucidation.

The glandular trichome microsampling was made for diverse species of genera from the tribe Heliantheae (Viguiera, Tithonia, Dimerostemma). Many compounds were identified through glandular trichome microsampling. Two germacrolides and two eudesmanolides were identified from Dimerostemma species (D. brasilianum and $D$. episcopale), while from Ichthyothere terminalis two melampolides were identified, all of them being sesquiterpene lactones. Artificial Neural Networks were trained to make skeleton identification from data obtained from ${ }^{13} \mathrm{C}$ NMR and the obtained results can be considered satisfactory.

A software was developed to make automatic compound identification through the comparation with a compound library that possesses data from 51 STLs. This software is called NAPROSYS is also able to compare the NMR data of the sample with the NMR data 
stored into a compound library, making the imediate identification of compounds present into library possible and also help the structure elucidation of unknown compounds. To test NAPROSYS' efficience to identify NMR data of compunds sored into the library was made with compounds isolated from species of Tithonia and Viguiera genera, because these genera has well describe compounds in the literature and that has been isolated in our laboratory, and the obtained results are excellent. Two Artificial Neural Network models were created to predict the retention time of sesquiterpene lactones in liquid cromatography (QSRR) with the aim of improve NAPROSYS performance in cromatographic data analysis. The results for this case, although coherent, can be improved.

The conclusion of this work is that the use of classical techniques with the new techniques of chemoinformatics can be a very efficient tool to make structure elucidation, search for compounds with certain chemical properties and even the search for new bioactive compounds.

Key words: Heliantheae, Asteraceae, Sesquiterpene lactones, Structure Elucidation, Chemoinformatics, Artificial neural networks. 
Os produtos naturais têm sido utilizados para diversas finalidades pelo homem desde a antigüidade. A maior parte destes produtos naturais são micromoléculas de origem vegetal, sendo que muitas já foram isoladas e identificadas. Muitas destas micromoléculas têm importância na medicina (fármacos), na indústria textil (corantes) e alimentícia (edulcorantes) e, também na agricultura (defensivos agrícolas).

Contudo, o potencial dos produtos naturais como fonte de novas drogas é o que mais chama a atenção de pesquisadores em centros de pesquisa, indústrias e mesmo em universidades. A maior parte das drogas existentes no mercado são micromoléculas naturais puras, tais como atropina, morfina, quinina, etc., que foram isoladas e identificadas de plantas medicinais tradicionais. Outras drogas, tais como a aspirina e anestésicos locais, são modificações de micromoléculas naturais. Essas moléculas só puderam ser utilizadas devido ao conhecimento prévio que os povos tinham do uso das plantas que biossintetizam estas moléculas e, atualmente, há um grande interesse na busca de novos produtos naturais bioativos, pois das vinte drogas mais vendidas no mundo em 1999, nove eram produtos naturais ou derivados (Harvey, 2000).

Dentre todas as fontes de produtos naturais conhecidas, as plantas são as mais importantes, sendo que o total estimado de espécies vegetais é em torno de 250.000 espécies e cerca de $10 \%$ já foram estudadas para algum tipo de atividade biológica (Verpoorte, 1998). Todavia, esse número não deve ser interpretado ao "pé-da-letra”, pois muitas espécies vegetais foram estudadas tendo em vista apenas uma classe de substâncias ou um tipo de atividade biológica. Embora o número de espécies estudadas seja limitado, o número de substâncias conhecidas é suficiente para permitir conhecermos que a ocorrência de certos tipos de metabólitos secundários está restrita a algumas famílias, tribos ou mesmo gêneros. Essa, sem dúvida, é um tipo de informação valiosa na busca de novas substâncias bioativas em espécies que ainda não foram estudadas, pois o conhecimento sobre o tipo de metabólito que ocorre em determinada família ou gênero pode ser um guia na busca por substâncias bioativas em determinada espécie. Os dados da 
ocorrência de substâncias naturais em espécies vegetais, podem auxiliar no agrupamento das espécies vegetais em gênero, tribos e famílias, ou seja, podem ser úteis em um trabalho de taxonomia. O ramo que estuda como os dados químicos podem ser aplicados em taxonomia é conhecido como quimiotaxonomia. A quimiotaxonomia pode ser utilizada também como um indicador negativo na busca de novas substâncias bioativas; por exemplo, se não são encontrados substâncias com determinada atividade biológica em espécies relacionadas, pode-se evitar a procura por substâncias com certa atividade biológica nestas espécies.

As espécies vegetais oferecem um enorme potencial para o desenvolvimento de novas drogas (Verpoorte, 1998) e muito pouco da biodiversidade vegetal foi explorada em termos químicos. Muito desse potencial está no Brasil, pois o país possui a maior biodiversidade vegetal do planeta, respondendo por cerca de um quinto do número de espécies vegetais conhecidas (Soejarto, 1996; Castro et al., 1999). Um grande número destas espécies vegetais presentes na flora brasileira são herbáceas ou pequenos arbustos e pertencem às famílias Myrtaceae, Rubiaceae e Asteraceae, sendo que a maioria das espécies pertencem à família Asteraceae (Schilling et al., 2000).

A família Asteraceae é uma das maiores famílias conhecidas dentre as Angiospermas e é agrupada em 3 subfamílias e 17 tribos (Bremer, 1996). À esta família pertencem espécies utilizadas pelo homem há milênios com os maior diversos fins. Dentre estas finalidades, podemos citar a alimentação: alface (Lactuca spp); a medicina: arnica (Arnica montana), picão (Bidens spp), carqueja (Baccharis trimera), guaco (Mikania spp), além de inúmeras espécies ornamentais. Do ponto de vista químico, as espécies da família Asteraceae se caracterizam pela biossíntese de terpenóides, poliacetilenos e flavonóides (Bohlmann, 1990), sendo que dentre os terpenóides destacam-se as lactonas sesquiterpênicas (LSTs). As LSTs são provenientes da via do mevalonato e possui uma grande variedade de esqueletos conhecidos (Fig. 1) e caracterizam-se pela importância quimiotaxonômica (Seaman, 1982) e por apresentarem diversas atividades biológicas 
(Picman, 1986; Passreiter e Isman, 1997). Dentre as diversas atividades biológicas apresentadas pelas LSTs, podemos citar as atividades anti-tumorais, citotóxicas, antibacterianas e anti-inflamatórias.

Uma das tribos onde as LSTs ocorrem com uma variedade enorme de esqueletos é a tribo Heliantheae. Essa tribo é uma das maiores da família Asteraceae, englobando aproximadamente 2.500 espécies 189 gêneros (Bremer, 1996), sendo problemática do ponto de vista taxonômico, uma vez que suas espécies são química e morfologicamente semelhantes a outras espécies estreitamente correlacionadas (Bremer, 1996; Karis e Ryding, 1994). A caracterização dos metabólitos secundários pode auxiliar a classificação taxonômica das espécies desta tribo. O uso mais difundido de caracteres químicos na taxonomia vegetal (quimiotaxonomia vegetal) é em resolução de problemas onde a análise criteriosa de dados biológicos é ambígua (Heywood et al., 1984). dados químicos podem ser utilizados para resolver problemas de classificação vegetal em nível de espécie, gêneros, tribos ou famílias (Hegnauer, 1986). Por terem ampla distribuição na família Asteraceae, e ocorrerem com uma grande variedade de esqueletos carbocíclicos, as LSTs são consideradas como marcadores quimiotaxonômicos desta família, sendo que alguns esqueletos e padrões de substituição estão restritos a algumas tribos ou mesmo gêneros. Dados envolvendo LSTs foram utilizados com sucesso e em estudos taxonômicos envolvendo membros de Asteraceae, inclusive Heliantheae (Spring e Buschmann, 1996).

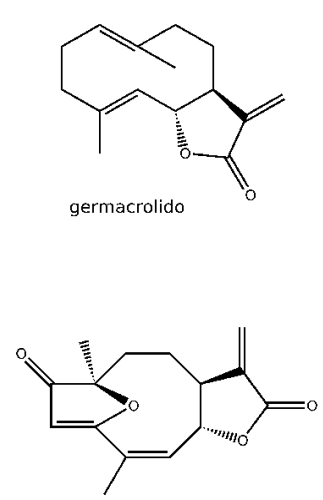

furanoeliangolido
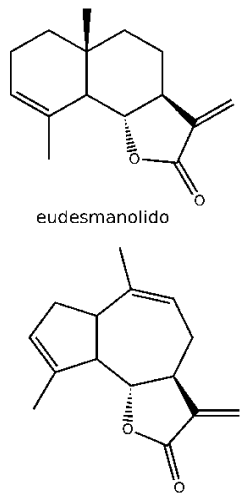

guaianolido

Figura 1 - Alguns tipos de esqueletos de LSTs

Quimitaxonomia e fitoquímica de espécies da tribo Heliantheae (Asteraceae) e uso de Quimioinformática em elucidação estrutural 
Na família Asteraceae, a diversidade dos esqueletos de LSTs e de seus padrões de substituição torna possível agrupar as espécies em gênero, subtribos e tribos. Todavia, essa classificação baseada em dados químicos só é possível se houver uma quantidade suficiente de dados coletados e analisados. Tais dados podem incluir centenas de estruturas químicas e milhares de ocorrências, sendo necessário o uso de ferramentas auxiliares para a análise dos dados. É nesta fase que a quimioinformática pode ser útil, fornecendo os meios necessários para auxiliar no processo de elucidação estrutural, análises quimiotaxonômicas e também em comparação com dados já existentes.

Quimioinformática é um termo que define a aplicação das técnicas de Informática na resolução de problemas envolvendo a Química (Gasteiger, 2006), ou seja, é uma disciplina que estuda como aplicar as técnicas existentes em Informática para auxiliar o químico na resolução de vários problemas, que sem a ajuda de um computador, seriam de difícil resolução. Embora o termo e o reconhecimento como disciplina da quimioinformática sejam recentes, faz mais de 40 anos que vários grupos estudam como aplicar os conhecimentos de Informática em Química. Conforme o número de substâncias conhecidas foi aumentando, era natural que os químicos procurassem por maneiras para organizar as substâncias e propriedades relacionadas a elas que fossem mais eficazes do que os conhecidos handbooks. Assim, surgiram os primeiros métodos para representar uma estrutura química por meio de um computador, dos quais os mais famosos são a representação em linha WLN (Wiswesser Line Notation) (Smith, 1976), a representação em linha SMILES (Simple Molecular Input LinE System) (Weininger, 1989) e a tabela de conectividade (CT) que fora criada para o Chemical Abstract Service (CAS) (Morgan, 1965).

Devido às limitações existentes nos primeiros meios de armazenamento magnético, as notações em linha foram populares por muito tempo, pois permitiam a economia de espaço em disco, um elemento caro e valioso. Contudo, com o desenvolvimento da tecnologia e o barateamento destes meios, as notações em linha foram suplantadas pela representação em tabela de conectividade, que é essencialmente a representação de um 
grafo molecular. Isso torna possível a implementação de algoritmos para procurar subestruturas, comparar, dividir e juntar moléculas. Esses algoritmos, embora confusos a princípio, formaram a base para algo mais ambicioso e que foi alvo de inúmeros grupos pioneiros: a elucidação estrutural automatizada (CASE).

Dentre estes projetos pioneiros, o que mais contribuiu para o desenvolvimento tanto da quimioinformática quanto da elucidação estrutural automatizada foi o DENDRAL (Lindsay et al., 1980) e os algoritmos foram publicados em um livro abordando CASE (Gray, 1986). Para esta tarefa, foram desenvolvido geradores de estruturas, isto é, sistemas que a partir de uma fórmula molecular fornecida, poderiam criar isômeros.

Quando o assunto é elucidação estrutural de substâncias orgânicas, deve-se lembrar que no princípio eram feitas em laboratório reações de degradação e obtenção de derivados das substâncias naturais, o que consumai muito tempo, material e a quantidade de substância isolada deveria ser grande, sendo que essa técnica, não raramente, induzia a erros. Com o advento de técnicas espectroscópicas, houve um avanço nessa área, pois permitiu a elucidação estrutural de substâncias orgânicas sem a necessidade de reações de degradação, diminuindo a quantidade de amostra a ser isolada e o tempo necessário para sua análise. As técnicas de RMN ${ }^{1} \mathrm{H}$ e de ${ }^{13} \mathrm{C}$, incluindo suas variantes bidimensionais, são as técnicas de elucidação estrutural mais poderosas e eficientes para a elucidação de compostos orgânicos atualmente existentes (FERREIRA et al., 2001). Atualmente, obtêm-se um conjunto completo de espectros de RMN para uma amostra em menos de uma hora, tendo-se uma quantidade considerável de amostra. Assim, os sistemas especialistas CASE foram criados para auxiliar a tarefa de interpretar diversos espectros. Várias metodologias foram desenvolvidas visando a criação de sistemas CASE (Lindsay et al., 1980; Dubois e Sobel, 1985; Kalchhauser \& Robien, 1985; Munk \& Christie, 1989; Fromanteau et al., 1993; Faulon, 1994; Strokov \& Lebedev, 1999; Steinbeck, 2001; Nuzillard, 2003; Elyashberg et al., 2004; Korytko et al., 2003; Han \& Steinbeck, 2004). Mesmo após mais de 20 anos de trabalho, ainda não se chegou à uma metodologia, tomando-se um termo emprestado dos 
informatas, "matadora", ou seja, uma metodologia tão eficiente que tornaria todas as outras ultrapassadas. Assim, automatizar totalmente o processo de elucidação estrutural ainda continua sendo um desafio. Existem dados espectroscópicos disponíveis para milhares de moléculas e, muitas vezes, o químico tem que repetir o processo de elucidação estrutural de uma molécula já conhecida, incluíndo-se aí produtos naturais.

Atualmente, a Química de produtos naturais e a elucidação estrutural estão intimamente ligadas, sendo que as técnicas de RMN mono- e bidimensionais são as técnicas mais utilizadas nesta tarefa.

Nos estudos envolvendo produtos naturais, uma das maiores barreiras sempre foi a etapa de elucidação estrutural das substâncias isoladas. Com a popularização de técnicas espectroscópicas, a elucidação estrutural de produtos naturais passou a ser feita por espectroscopistas ou químicos experientes que, em sua maioria, analisam um conjunto de espectros, compara com a literatura, identifica o esqueleto e cadeias laterais, propondo uma estrutura para a substância (Ferreira et al., 2001). Essa tarefa é a mais difícil para o espectroscopista, visto que existe uma variedade enorme de esqueletos para produtos naturais.

Após a obtenção dos espectros, um químico geralmente inicia sua interpretação através da comparação dos sinais obtidos nos espectros com dados disponíveis na literatura. Quando esses dados não estão presentes, ele utiliza a sua experiência e conhecimento sobre espectroscopia e química orgânica para propor uma estrutura que esteja de acordo com o conjunto de dados em questão (Jaspars, 1999). No entanto, esta não é uma tarefa simples, e pode demorar entre poucos dias a alguns meses, dependendo do caso. Graças à automação de instrumentos analíticos, tal como o espectrômetro, o principal problema agora não é a obtenção de dados, mas sim como tratá-los de forma eficiente.

Os métodos mais conhecidos de quimioinformática para realizar este trabalho são os sistemas especialistas e as redes neurais, especialidades da área denominada inteligência 
artificial. As redes neurais são simuladas em computadores através de métodos matemáticos e algoritmos computacionais especialmente projetados para simular o processamento de informações e aquisição de conhecimento do cérebro humano (Cerqueira et al., 2001). Em termos de prospecção de substâncias bioativas, os bancos de dados e redes neurais podem ser utilizados para se prever em quais gêneros ou espécies poderão ser encontradas certas classes de produtos naturais, economizando tempo e custos na procura de substâncias bioativas.

Embora as técnicas computacionais sejam promissoras, muitas vezes, ao trabalhar com produtos naturais, o químico se depara com uma espécie jamais estudada e às vezes há a necessidade de se fazer todo o estudo químico da espécie em questão. Estudos fitoquímicos, tais como isolamento e identificação de micromoléculas, são processos demorados e caros para serem efetuados. Esse fato limitou o uso de dados químicos com vistas à taxonomia até o início da década de 1970, quando então surgiram técnicas e equipamentos que permitiram a rápida análise e identificação de micromoléculas em material vegetal. A cromatografia liquida de alta eficiência (CLAE) foi uma das técnicas desenvolvidas que permitiram esse avanço. A CLAE e as técnicas espectrométricas a ela acopladas, como UV, RMN ou espectometria de massas, permitiram desenvolver métodos mais rápidos e avançados de análise fitoquímica, como por exemplo a microamostragem de tricomas glandulares (Spring, 1989). A obtenção de um perfil fitoquímico, que poderia levar semanas ou mesmo meses empregando-se técnicas clássicas, pode levar apenas dias ou algumas semanas se for utilizada a microamostragem de tricomas glandulares, que basicamente envolve a coleta manual de tricomas de plantas e a análise de seu perfil químico através de CLAE-UV-Vis (Spring, 2000). A maior parte dos membros da tribo Heliantheae (Asteraceae) possui tais tricomas, onde são biossintetizados metabólitos secundários, tais como LSTs em maior escala e também substâncias aromáticas, como flavonóides e cumarinas.

A técnica empregada é a CLAE, um método uniforme, confiável, rápido e eficiente, 
reduzindo tempo e custos, além da pouca quantidade de amostra utilizada quando comparada com a fitoquímica clássica (Spring, 1991). Essa técnica permite a detecção de compostos em concentrações muito pequenas, da ordem de nanogramas, devido à sua própria sensibilidade. A padronização de alguns itens, tais como colunas, solventes e comprimentos de onda na detecção por UV, permite a diferenciação de compostos com comportamentos físico-químicos muito semelhantes e a comparação do perfil químico com uma biblioteca de padrões de substâncias previamente identificadas (Spring, 2000), o que pode ser feito com auxílio de um software, pois quando se tem uma biblioteca pequena com no máximo 100 substâncias, ainda é possível fazer comparações dos parâmetros cromatográficos sem auxilio de software algum, apenas consultado tabelas. Todavia, esse processo se torna inviável quando a biblioteca possui centenas ou milhares de substâncias, sendo indispensável o uso de computadores.

Os computadores podem ser úteis também para a criação de modelos estatísticos que permitam prever o comportamento cromatográfico de determinada substância. Tais modelos se baseiam no princípio de que o tempo de retenção de um soluto em uma determinada condição está relacionada com sua estrutura e propriedades físico-químicas. Essas propriedades e a estrutura da substância podem ser descritas através de formas matemáticas chamadas de descritores, que por sua vez podem ser utilizados posteriormente na criação de modelos de previsão de tempos de rentenção, sendo que este processo é conhecido como QSRR (Quantitative Structure Retention Relationship) (Kalinszan, 1993). Essa técnica pode ser utilizada para obter várias informações, tais como: mecanismos de interação entre entre a fase móvel e fase estacionária (Nord et al, 1998), otimização de condições cromatográficas (Baczek e Kaliszan, 2003), correlação com possível atividade biológica, uma vez que os mesmos descritores utilizados em QSRR podem ser utilizados em QSAR (Nord et al, 1998).

QSRR podem ser utilizados em uma biblioteca de substâncias para virtual screening para procurar substâncias com determinado comportamento cromatográfico ou então 
simular a separação de determinada misturas de substâncias, com o objetivo de melhorar uma biblioteca de substâncias para química combinatorial (Schefzick et al., 2004). Estudos envolvendo QSRR também podem ser utilizados em elucidação estrutural, uma vez que o tempo de retenção previsto para uma estrutura proposta pode ser comparado com o tempo de retenção de uma substância desconhecida e se esse tempo for muito diferente, a proposta de estrutura pode ser descartada. A abordagem de QSRR aliada a uma biblioteca de padrões em CLAE pode ser uma ferramenta muito útil no auxílio à elucidação estrutural de substâncias desconhecidas de forma rápida e sem a necessidade de recorrer à técnicas de isolamento das substâncias. Além disso, a grande vantagem de estudos que envolvem QSRR é que a cromatografia fornece uma grande quantidade de dados precisos e que podem ser reproduzidos com segurança. 
Os objetivos deste trabalho são:

a) Quimiotaxonomia e estudo fitoquímico de algumas espécies da tribo Heliantheae;

b) O Desenvolvimento de modelos computacionais para auxiliar o processo de quimiotaxonomia e a identificação de LSTs utilizando-se CLAE;

c) o desenvolvimento de técnicas computacionais para auxiliar o processo de elucidação estrutural de produtos naturais; 


\subsection{Materiais e equipamentos utilizados}

\subsubsection{Materiais utilizados para CLV (Comatografia liquida a vácuo)}

-Colunas cromatográficas de vidro com diâmetro de 4 a $10 \mathrm{~cm}$, com comprimento variável, dependendo da massa de amostra a ser aplicada;

-Sílica gel 60H como fase estacionária, Merck (Art. 7736) 100-200 mesh ASTM;

-Solventes orgânicos destilados como eluentes;

-Rotaevaporadores (marca Fisatom, modelo 820) foram utilizados para a concentração dos extratos e frações recolhidas das colunas cromatográficas.

\subsubsection{Materiais utilizados para CCD (Cromatografia em camada delgada)}

-Placas cromatográficas de vidro com diferentes dimensões $(5,10$ ou $20 \mathrm{~cm})$, dependendo da aplicação e número das amostras a serem analisadas;

-Sílica gel $60 \mathrm{GF}_{254}$ como adsorvente, Merck (Art. 7730), com espessura na placa de $0,25 \mathrm{~mm}$

-Solventes orgânicos destilados como eluentes;

-Lâmpada de luz UV com 254 nm e 336 nm de comprimento de onda (Mineralight LAMP, modelo UVGL-25) como revelador físico;

$-\mathrm{H}_{2} \mathrm{SO}_{4}$ concentrado, vanilina sulfúrica ou anisaldeído sulfúrico como reveladores químicos.

Quimitaxonomia e fitoquímica de espécies da tribo Heliantheae (Asteraceae) e uso de Quimioinformática em elucidação estrutural 


\subsubsection{Materiais utilizados para cromatografia líquida em coluna sob baixa pressão (flash)}

-Coluna cromatográfica de vidro com diâmetro de 2,5 cm e 45 cm de comprimento;

-Sílica gel 60 com tamanho de partícula de 0,060 a 0,200 mm (230-400 mesh), marca Merck (Art. 9385);

-Solventes orgânicos destilados como eluentes, com fluxo de eluição de $5 \mathrm{~cm}^{3} / \mathrm{min}$.

\subsubsection{Materias utilizados para a coleta dos tricomas glandulares}

-Lâmina de vidro com dimensões de 1,5 por 5,0 cm;

-Lupa bifocal marca Olympus, modelo SZ-60;

-Tubos tipo Eppendorf com capacidade para 1,5 mL;

-Agulhas de dissecação;

-Solventes orgâncos grau HPLC para dissolver as glândulas (Metanol ou Acetonitrila); -Microcentrífuga marca Sanyo, linha microcentaur mod. MSB010.

\subsubsection{Materiais utilizados para CLAE (Cromatografia líquida de alta eficiência)}

-Cromatógrafo líquido Shimadzu, modelo SLC-10 Avp com detetor de arranjo de diodos Shimadzu (UV-DAD) modelo SPD-M10Avp, injetor automático de amostras modelo SIL10AD, coletor automático de frações modelo FRC-10A e sistema controlador 
computadorizado com software Class VP versão 5.02;

-Coluna cromatográfica analítica de fase reversa C-18 com comprimento de $25 \mathrm{~cm}$ e 0,46 cm de diâmetro com tamanho de partícula de $5 \mu \mathrm{m}$, marca Shimadzu;

-Solventes orgânicos grau HPLC como eluentes (Acetonitrila ou Metanol), marcas Malinkrodt ou J.T Baker.

-Água MilliQ

\subsubsection{Materiais utilizados para codificação dos softwares}

-Microcomputador de arquitetura IBM/PC x86 contendo processador Intel Pentium 42.8 GHz; 256 MB RAM, HD 80 GB;

-GNU/Linux (SuSe Linux 9.3), kernel versão 2.6.11, GNOME 2.10.0 sob XWindow;

-Compilador C++ GNU 3.3 (gcc 3.3.5) (Stallman et al., 2003);

-Java Run Time Environment (JRE) versão 1.5.0.

\subsubsection{Materiais utilizados para treinamento das redes neurais}

- Software Weka

- Sonnia

- Adriana.Code 


\subsection{Métodos}

\subsubsection{Levantamento bibliográfico das espécies investigadas}

O levantamento bibliográfico das espécies investigadas foi feito através de busca em sistemas on-line tais como Scirus (www.scirus.com), ScienceDirect (www.sciencedirect.com) e portal CAPES (www.periodicos.capes.gov.br). Foram utilizadas na busca as seguintes palavras-chave: Chemotaxonomy, Asteraceae, Compositae, Sesquiterpene Lactones, Heliantheae, eudesmanolide, guaianolide, heliangolide, melampolide e germacranolide. Também foi utilizada uma revisão sobre a família Asteraceae da autoria de Kåre Bremer (Bremer, 1994).

\subsubsection{Coleta do material vegetal}

Após a escolha das espécies vegetais a serem investigadas, o material vegetal foi coletado pela taxonomista botânica Mara Magenta do IB/USP em vários locais diferentes. Uma exsicata de cada população vegetal foi levada para o nosso laboratório, a fim de que pudessem ser investigadas quimicamente.

\subsubsection{Seleção das espécies a serem investigadas}

Quimitaxonomia e fitoquímica de espécies da tribo Heliantheae (Asteraceae) e uso de Quimioinformática em elucidação estrutural 
Com base nos critérios apresentados anteriormente, foram selecionadas espécies de diversos gêneros da tribo Heliantheae: Angelphytum, Calea, Ichthyothere, Dimerostemma, Thithonia e Viguiera. As espécies selecionadas foram: Ichthyothere terminalis, Calea hispida, Dimerostemma brasilianum, Dimerostemma vestitum, Dimerostemma rotundifolium, Dimerostemma epsicopaleae, Angelphytum cf. arnotii, Angelphytum tenuifolium, Tithonia diversofolia, Viguiera robusta.

\subsubsection{Microamostragem dos tricomas glandulares}

Coletou-se sob lupa bifocal e com agulha de dissecação cerca de 60 tricomas glandulares das folhas ou apêndices das anteras de cada uma das espécies a investigadas e que ainda não tinham sido analisadas através de microamostragem. Os tricomas coletados foram solubilizados em tubos Eppendorf contendo $30 \mu \mathrm{L}$ de $\mathrm{MeOH}$. Após a coleta dos tricomas, completou-se o volume com mais $30 \mu \mathrm{L}$ de água e sonicou-se durante 2 minutos para a liberação dos metabólitos contidos nos tricomas. A solução foi centrifugada durante 3 minutos a 10.000 rpm em microcentífuga para a preciptação de possíveis materias sólidos presentes na amostra.

Para se obter o perfil dos metabólitos presentes nos tricomas glandulares, fez-se duas injeções da solução obtida em CLAE com detecção simultânea em dois comprimentos de onda distintos, sendo 225 e 265 nm respectivamente, em dois sistemas isocráticos, sendo $\mathrm{MeOH} / \mathrm{H}_{2} \mathrm{O}$ 1:1 (sistema 1) e $\mathrm{MeCN} / \mathrm{H}_{2} \mathrm{O}$ 35:65 (sistema 2). O tempo de eluição foi de 60 minutos e fluxo de $1 \mathrm{~mL} / \mathrm{min}$ para o sistema 1 e de $1,3 \mathrm{~mL} / \mathrm{min}$ para o sistema 2 . Os perfis cromatográficos obtidos das espécies foram comparados entre si e com uma biblioteca de padrões existente em nosso laboratório.

Quimitaxonomia e fitoquímica de espécies da tribo Heliantheae (Asteraceae) e uso de Quimioinformática em elucidação estrutural 


\subsubsection{Estudo fitoquímico de Dimerostemma brasilianum}

$300 \mathrm{~g}$ das partes aéreas de $D$. brasilianum foram secos em estufa de ar circulante e posteriormente moídas. Após este processo, o pó foi extraído exaustivamente com dicloremetano (DCM) à temperatura ambiente, obtendo-se após a evaporação do solvente, $15 \mathrm{~g}$ de extrato bruto seco, que foram fracionados conforme a Figura 2. Esse extrato bruto foi ressuspenso em uma solução $\mathrm{MeOH} / \mathrm{H}_{2} \mathrm{O}$ na proporção de $4: 1$ por $24 \mathrm{~h}$. O produto foi filtrado, obtendo-se uma massa final de $12.5 \mathrm{~g}$ após a evaporação do solvente. O extrato foi posteriormente particionado com $n$-hexano e clorofórmio, obtendo-se frações de $3,5 \mathrm{~g}$ e 4,8 g respectivamente. A fração clorofórmica foi posteriormente submetida a CLV em gradiente crescente de polaridade com $n$-hexano e acetato de etila (AcOEt), sendo recolhidas 9 frações de $500 \mathrm{~mL}$ cada (Tabela 1).

Tabela 1 - Fracionamento em CLV da fase clorofórmica do extrato bruto de $D$. brasilianum

\begin{tabular}{lll}
\hline Fração & Fase Móvel & Massa \\
\hline DB Fr. 1 & Hexano 100\% & $98 \mathrm{mg}$ \\
DB Fr 2 & Hexano:AcOEt $5 \%$ & $235 \mathrm{mg}$ \\
DB Fr 3 & Hexano:AcOEt $10 \%$ & $255 \mathrm{mg}$ \\
DB Fr 4 & Hexano:AcOEt $20 \%$ & $335 \mathrm{mg}$ \\
DB Fr 5 & Hexano:AcOEt 30\% & $450 \mathrm{mg}$ \\
DB Fr. 6 & Hexano:AcOEt 50\% & $830 \mathrm{mg}$ \\
DB Fr. 7 & Hexano:AcOEt 70\% & $640 \mathrm{mg}$ \\
DB Fr. 8 & Hexano:AcOEt $90 \%$ & $208 \mathrm{mg}$ \\
DB Fr. 9 & AcOEt 100\% & $250 \mathrm{mg}$ \\
\hline
\end{tabular}

Quimitaxonomia e fitoquímica de espécies da tribo Heliantheae (Asteraceae) e uso de Quimioinformática em elucidação estrutural 


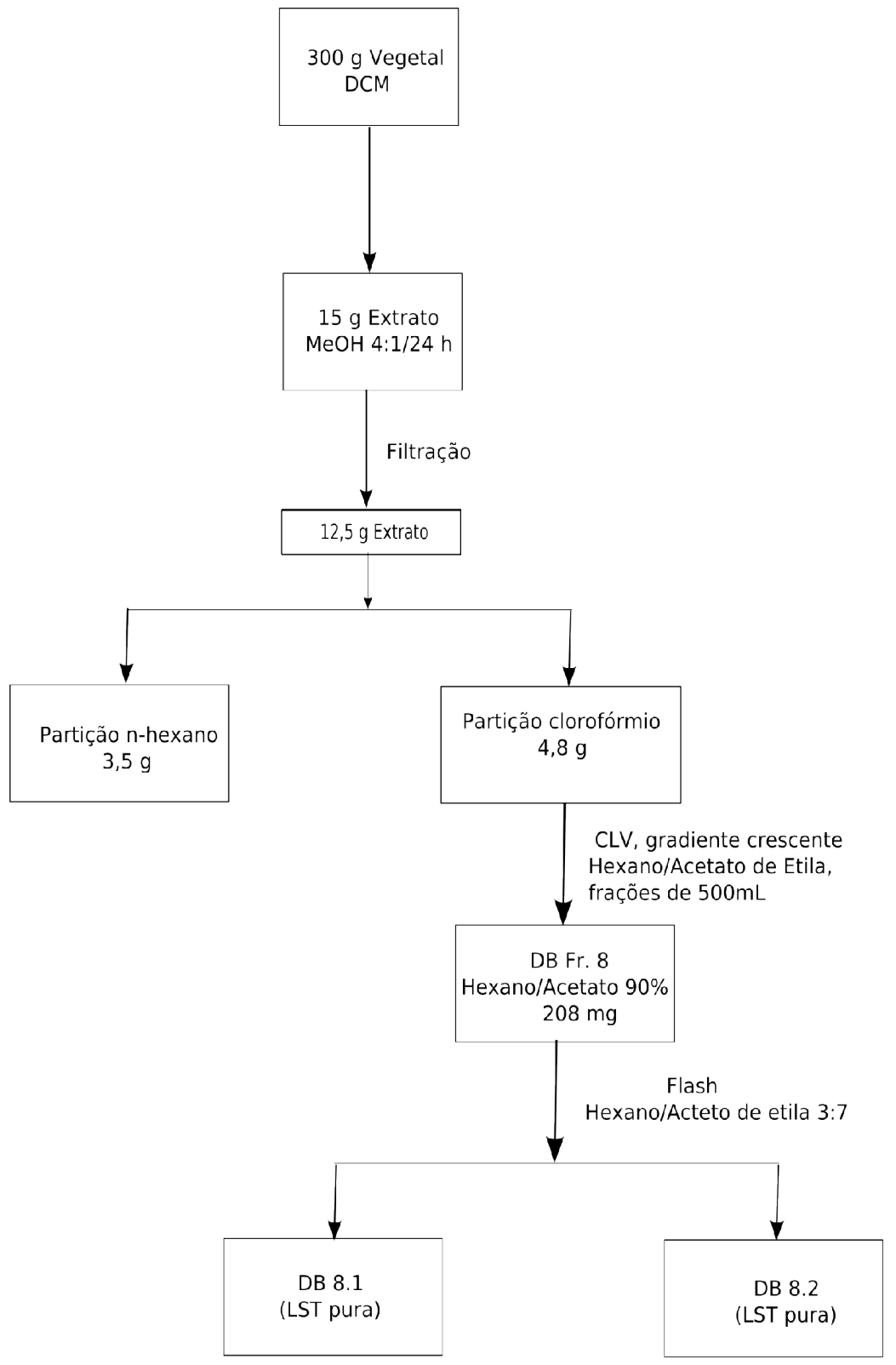

Figura 2 - Fracionamento do extrato bruto de $D$. brasilianum

As fraçoes obtidas foram monitoradas através de espectroscopia na região do infravermelho (IV) e o espectro da fração 8 mostrou fortes bandas de absorção em $1770 \mathrm{~cm}^{-}$ 1, típico de lactonas. A fração 8 foi submetida à cromatografia flash utilizando-se como fase móvel Hexano:AcOEt 3:7, sendo recolhidas 20 frações que foram monitoradas por CCDC e as que possuiam perfil semelhante, foram agrupadas conforme a tabela 2. 
Tabela 2 - Fracionamento em coluna "flash" da fração DB Fr. 8

\begin{tabular}{lll}
\hline Fração & Frações reunidas & Massa \\
\hline DB Fr. 8.1 & $1-8$ & $40 \mathrm{mg}$ \\
DB Fr 8.2 & 9 & $4 \mathrm{mg}$ \\
DB Fr 8.3 & $10-13$ & $17 \mathrm{mg}$ \\
DB Fr 8.4 & $14-17$ & $27 \mathrm{mg}$ \\
DB Fr 8.5 & $18-20$ & $19 \mathrm{mg}$ \\
\hline
\end{tabular}

As frações reunidas foram submetidas à análise por RMN ${ }^{1} \mathrm{H}$ e as frações DB Fr. 8.1 e DB Fr. 8.2 eram LSTs puras.

\subsubsection{Estudo fitoquímico de $D$. rotundifolium}

Após a microamostragem dos tricomas glandulares de $D$. rotundifolium fez-se o extrato de lavagem foliar de 16,3 g de material vegetal seco com DCM, obtendo-se $1 \mathrm{~g}$ de extrato bruto seco que foi fracionado conforme a Figura 4. Esse extrato bruto foi ressuspenso em uma solução $\mathrm{MeOH} / \mathrm{H}_{2} \mathrm{O}$ na proporção de $4: 1$ por $24 \mathrm{~h}$. $\mathrm{O}$ produto foi filtrado, obtendo-se uma massa final de $630 \mathrm{mg}$ do extrato bruto seco. Esse extrato foi então submetido a uma separação através de CLV, utilizando-se $25 \mathrm{~g}$ de sílica gel $60 \mathrm{H}$ como fase estácionária e mistura de hexano e AcOEt em gradiente crescente de polaridade como fase móvel, sendo coletados $500 \mathrm{~mL}$ para cada fração (Tabela 6). 
Tabela 6 - Fracionamento em CLV da fase clorofórmica do extrato bruto de $D$. rotundifolium

\begin{tabular}{lll}
\hline Fração & Fase Móvel & Massa \\
\hline DR Fr. 1 & Hexano 100\% & $30 \mathrm{mg}$ \\
DR Fr 2 & Hexano:AcOEt 10\% & $70 \mathrm{mg}$ \\
DR Fr 3 & Hexano:AcOEt $30 \%$ & $108 \mathrm{mg}$ \\
DR Fr 4 & Hexano:AcOEt 50\% & $191 \mathrm{mg}$ \\
DR Fr 5 & Hexano:AcOEt 70\% & $112 \mathrm{mg}$ \\
DR Fr. 6 & Hexano:AcOEt 100\% & $20 \mathrm{mg}$ \\
\hline
\end{tabular}

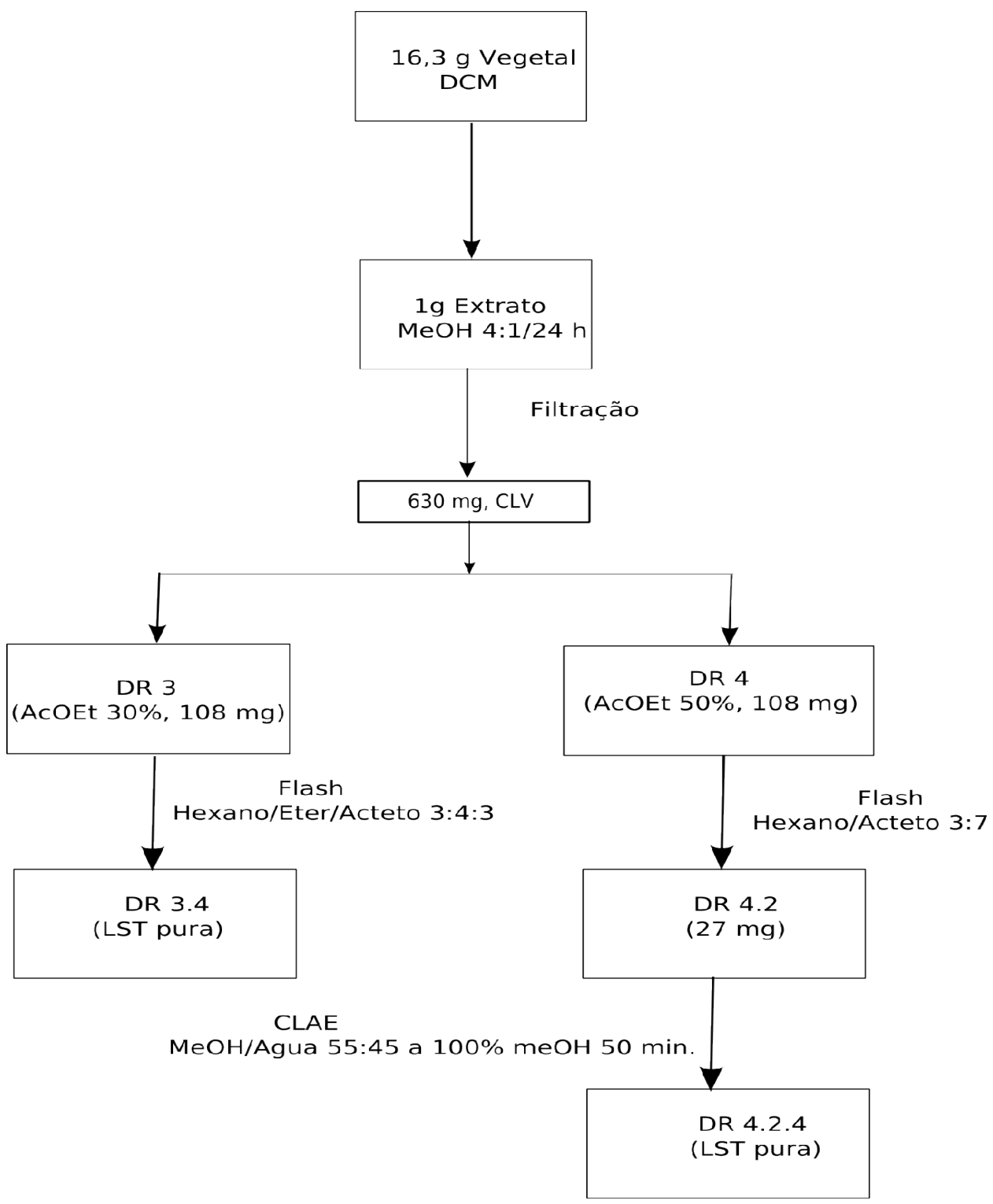

Figura 3 - Fracionando do extrato bruto de $D$. rotundifolium 
Cada fração coletada foi submetida à espectroscopia na região do IV e os espectros das frações DR 3 (AcOEt 30\%, 108 mg), 4 (AcOEt 50\%, $191 \mathrm{mg}$ ) e 5 (AcOEt 70\%, $112 \mathrm{mg}$ ) apresentaram bandas de absorção em torno de $1760 \mathrm{~cm}-1$, característicos de $\gamma$-lactonas $\alpha, \beta$-insaturadas. Decidiu-se então iniciar o trabalho com a fração DR 3, a qual foi submetida a novas etapas de fracionamento. Esta fração foi separada através de cromatografia líquida sob baixa pressão (flash), utilizando-se como fase móvel Hex:Eter:AcOEt na proporção de 3:4:3, sendo obtidas 25 frações que foram monitoradas por CCD. Aquelas com perfil semelhante foram reunidas (Tabela 7).

Tabela 7 - Fracionamento em coluna "flash" da fração DR 3

\begin{tabular}{lll}
\hline Fração & Frações reunidas & Massa final \\
\hline DR 3.1 & $1-8$ & $23 \mathrm{mg}$ \\
DR 3.2 & $9-14$ & $20 \mathrm{mg}$ \\
DR 3.3 & $14-18$ & $35 \mathrm{mg}$ \\
DR 3.4 & $19-25$ & $15 \mathrm{mg}$ \\
\hline
\end{tabular}

As frações resultantes foram analisadas através de CLAE (fase móvel $\mathrm{MeOH} / \mathrm{H}_{2} \mathrm{O}$ 55:45, fluxo $1 \mathrm{~mL} / \mathrm{min}$ ) e verificou-se que a fração 3.4 estava pura. A fração foi então submetida à análise $\mathrm{RMN}{ }^{1} \mathrm{H}$ e ${ }^{13} \mathrm{C}$.

A fração DR 4 também foi submetida à cromatografia flash, utilizando-se como fase móvel uma mistura de Hexano:AcOEt na proporção de 3:7. Foram recolhidas 25 frações que foram monitoradas por CCDC e reunidas (Tabela 8).

Tabela 8 - Fracionamento em coluna "flash" da fração DR 4

\begin{tabular}{lll}
\hline Fração & Frações reunidas & Massa \\
\hline DR 4.1 & $1-6$ & $37 \mathrm{mg}$ \\
DR 4.2 & $7-10$ & $29 \mathrm{mg}$ \\
DR 4.3 & $11-16$ & $87 \mathrm{mg}$ \\
DR 4.4 & $17-22$ & $38 \mathrm{mg}$ \\
DR 4.5 & $23-25$ & $9 \mathrm{mg}$ \\
\hline
\end{tabular}

Quimitaxonomia e fitoquímica de espécies da tribo Heliantheae (Asteraceae) e uso de Quimioinformática em elucidação estrutural 
Os componentes da fração DR 4.2, por sua vez, também foram separados em CLAE, utilizando-se um gradiente de fase móvel $\left(\mathrm{MeOH} / \mathrm{H}_{2} \mathrm{O}\right.$ 45:55 a 100\% MeOH em 50 min, fluxo $1 \mathrm{~mL} / \mathrm{min})$, obtendo-se seis subfrações, sendo que a fração codificada como DR 4.2 .4 (4 mg) estava pura e foi submetida a análise por RMN mono e bidimensionais $\left({ }^{1} \mathrm{H},{ }^{13} \mathrm{C}, \mathrm{COSY}\right.$, HMBC, HMQC).

\subsubsection{Estudo fitoquímico de I. terminalis}

Fez-se o extrato de lavagem foliar com DCM de 32,8 g de material vegetal seco, obtendo-se 805 mg de extrato bruto seco, que foi particionado conforme a Figura 5. Esse extrato foi ressuspenso em uma solução $\mathrm{MeOH} / \mathrm{H}_{2} \mathrm{O}$ na proporção de $4: 1$ por $24 \mathrm{~h}$. O produto foi filtrado, obtendo-se uma massa final de $410 \mathrm{mg}$ do extrato bruto seco. Esse extrato foi então submetido a uma separação através de CLV, utilizando-se $15 \mathrm{~g}$ de sílica gel $60 \mathrm{H}$ como fase estacionária e mistura de Hexano:AcOEt em gradiente crescente de polaridade como fase móvel, sendo coletados $200 \mathrm{~mL}$ para cada fração (Tabela 9).

Tabela 9 - Fracionamento em CLV da fase clorofórmica do extrato bruto de I. terminalis

\begin{tabular}{lll}
\hline Fração & Fase Móvel & Massa \\
\hline IT 1 & Hexano 100\% & $42 \mathrm{mg}$ \\
IT 2 & Hexano:AcOEt $10 \%$ & $38 \mathrm{mg}$ \\
IT 3 & Hexano:AcOEt $30 \%$ & $87 \mathrm{mg}$ \\
IT 4 & Hexano:AcOEt $40 \%$ & $127 \mathrm{mg}$ \\
IT 5 & Hexano:AcOEt $50 \%$ & $159 \mathrm{mg}$ \\
IT 6 & Hexano:AcOEt $70 \%$ & $130 \mathrm{mg}$ \\
IT 7 & AcOEt 100\% & $105 \mathrm{mg}$ \\
\hline
\end{tabular}

Quimitaxonomia e fitoquímica de espécies da tribo Heliantheae (Asteraceae) e uso de Quimioinformática em elucidação estrutural 


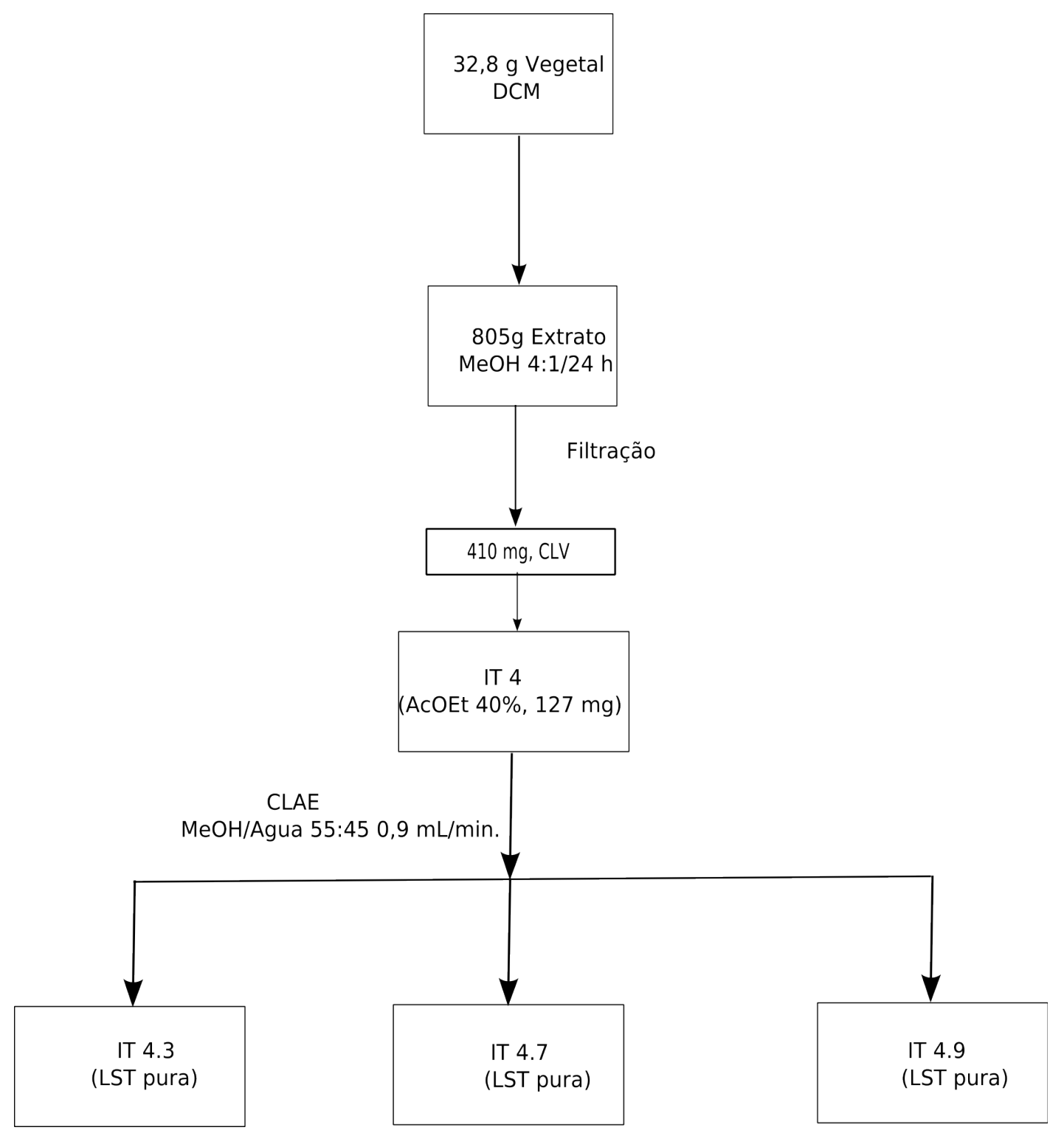

Figura 4 - Fracionamento do extrato bruto de I. terminalis

Cada fração coletada foi submetida à espectroscopia na região do IV e o espectro da fração IT 4 (AcOEt 40\%, 127 mg) apresentou banda de absorção em torno de 1760 cm-1. Decidiu-se por fazer a separação dos componentes da fração IT 4, a qual foi submetida a novas etapas de fracionamento. O motivo desta fração ter sido a única fração trabalhada é que ela era a única cujo espectro na região do IV mostrou bandas características de $\gamma$ lactonas $\alpha, \beta$-insaturadas. Uma vez que esta é a única classe de compostos que nos interessa neste trabalho, não houve motivo para trabalhar-se com as demais frações. 
A fração IT 4 foi posteriormente submetida à CLAE em sistema isocrático ( $\mathrm{MeOH} / \mathrm{H}_{2} \mathrm{O}$ 45:55, fluxo 0,9 mL/min), sendo coletadas 10 frações, das quais as frações IT 4.3 (10 mg), IT 4.7 (8 mg) e IT 4.9 (6 mg) estavam puras e foram submetidas a análise por RMN.

\subsubsection{Obtenção dos espectros de RMN ${ }^{13} \mathrm{C}$ dos extratos brutos}

Fez-se a lavagem dos tricomas glandulares das folhas de algumas espécies selecionadas com DCM (Tabela 10).

Tabela 10 - Obtenção dos extratos e espectros de RMN ${ }^{13} \mathrm{C}$

\begin{tabular}{lll}
\hline Espécie & $\begin{array}{l}\text { Massa do material } \\
\text { vegetal seco }(\mathbf{g})\end{array}$ & Massa do extrato $(\mathbf{m g})$ \\
\hline Tithonia diversifolia & $5 \mathrm{~g}$ & $47 \mathrm{mg}$ \\
Viguiera robusta & $2 \mathrm{~g}$ & $15 \mathrm{mg}$ \\
Dimerostemma rontudifolium & $1 \mathrm{~g}$ & $10 \mathrm{mg}$ \\
\hline
\end{tabular}

Após os extratos serem ressuspensos em uma mistura de $\mathrm{MeOH}: \mathrm{H}_{2} \mathrm{O}$ 8:2 para precipitação dos compostos mais apolares, os extratos foram secos e submetidos à espectroscopia de RMN ${ }^{13} \mathrm{C}$ para obter-se espectros de RMN ${ }^{13} \mathrm{C}$ BB, DEPT 90 e DEPT 135.

\subsubsection{Desenvolvimento e funcionamento do NAPROSYS}

O NAPROSYS é um programa desenvolvido na linguagem java (Gosling, 2000) e usa a biblioteca CDK (Chemistry Development Kit) (Steinbeck et al., 2003) para as 
operações de gerenciamento de moléculas, procura de subestruturas e visualização 2D/3D das moléculas. O uso de CDK permite o rápido desenvolvimento de qualquer programa voltado para química utilizando-se a linguagem java. Toda a base de dados de $\mathrm{RMN}{ }^{13} \mathrm{C}$ que o NAPROSYS utiliza foi importada do SISTEMAT e gerenciada através do servidor SQL MySQL (http://www.mysql.com), que possui distribuição gratuita pela rede.

Devido ao fato do NAPROSYS ser utilizado tanto para o gerenciamento de dados cromatográficos quanto de dados de RMN, durante o desenvolvimento optou-se por dividir o programa em dois módulos distintos: NAPROSYS-LC e NAPROSYS-NMR. O módulo NAPROSYS-LC é responsável pelo gerenciamento e processamento de dados cromatográficos, enquanto o módulo NAPROSYS-NMR é responsável pelo gerenciamento e processamento de dados de RMN. Um diagrama da arquitetura do banco de dados do NAPROSYS pode ser visto na Figura 6.

A tabela principal contém um campo id, que é uma chave primária associada a cada composto presente na base de dados (Figura 6). O nome sistemático e comum das substâncias, os dadoss cromatográficos e uma cadeia de caracteres no formato MDL estão armazenados nesta tabela. Os dados cromatográficos necessários para a caracterização de compostos utilizando-se este software são os seguintes: os tempos de retenção relativos (trr) ao padrão interno 2,5-dimetilfenol (DMP) nos sistemas de solventes $\mathrm{MeOH}: \mathrm{H}_{2} \mathrm{O}$ (trr1) e MeCN: $\mathrm{H}_{2} \mathrm{O}$ (trr2), a absorbância máxima no UV $\lambda_{\max }$ (fornecido por detetor DAD) e as razões entre as absorbâncias no UV em 225 e 265 nm ( $\left(_{225 / 265}\right)$. Tais dados são essenciais para a caracterização indireta dos compostos através da comparação com dados cromatográficos de compostos previamente identificados. Os deslocamentos químicos de RMN de cada LST são armazenados na tabela RMN13C_DATA (Figura 6). 


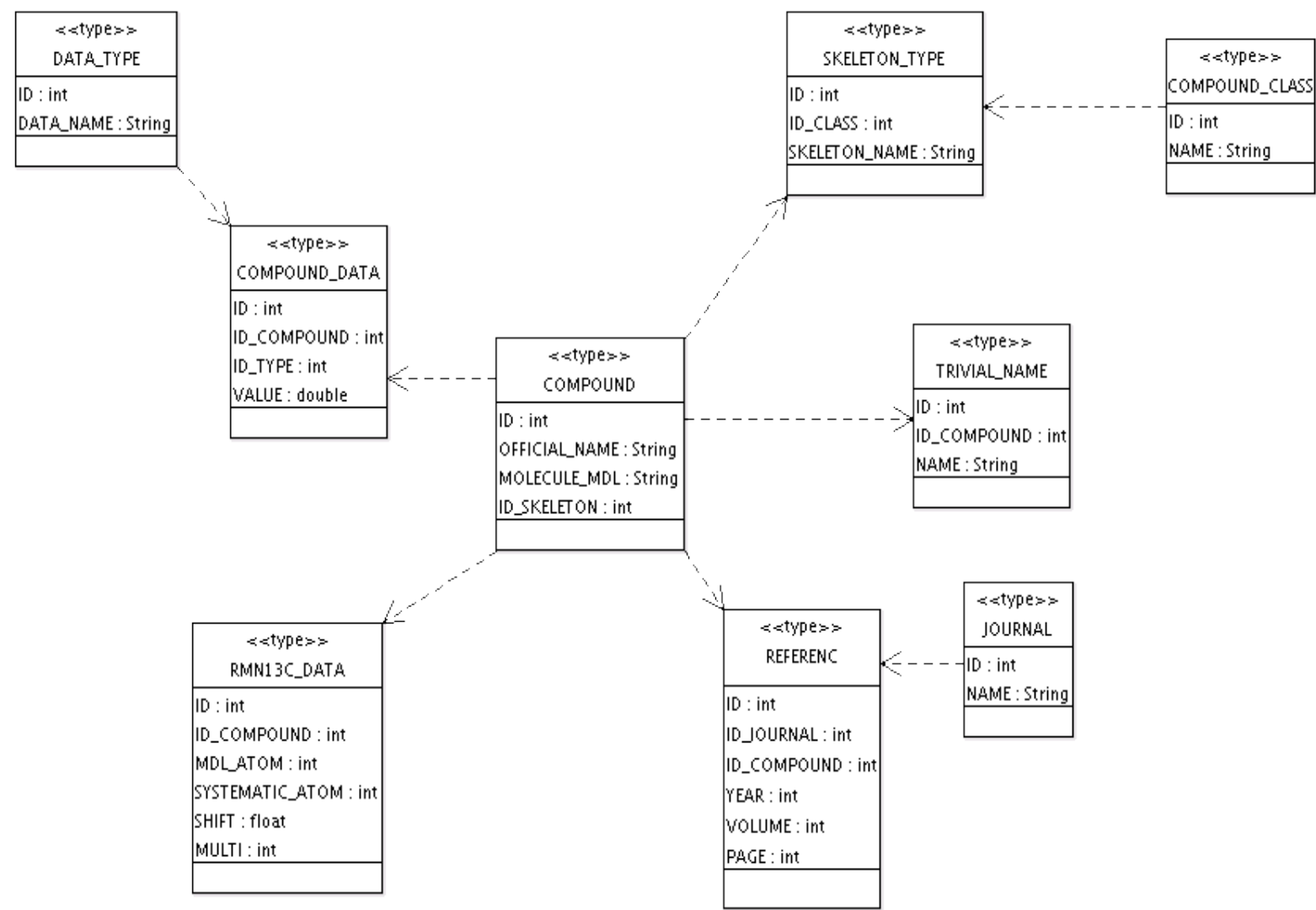

Figura 5 - Diagrama UML do banco de dados utilizado pelo NAPROSYS

Para fazer a caracterização de LSTs, os seguintes dados coletados dos cromatogramas devem ser fornecidos ao programa: os tempos de retenção em minutos nos dois sistemas de fase móvel (MeOH: $\mathrm{H}_{2} \mathrm{O}$ e $\left.\mathrm{MeCN}: \mathrm{H}_{2} \mathrm{O}\right)$ dos picos selecionados, o tempo de retenção do padrão interno, a razão $A_{225 / 265}$ e o valor de $\lambda_{\max }$ no espectro de UV. O programa utiliza os valores do tempo de retenção do padrão interno e dois picos para calcular automaticamente o valor do tempo de retenção relativo (trr1 e trr2).

Para a análise de dados de $\mathrm{RMN}{ }^{13} \mathrm{C}$, o programa opera basicamente através de um melhoramento no algoritmo de Munk (Shelley e Munk, 1982). Na nossa implementação deste algoritmo, a seqüência de dados a ser fornecida para o programa é a seguinte:

a) Os deslocamentos químicos presentes no espectro de $\mathrm{RMN}{ }^{13} \mathrm{C}$ e suas multiplicidades,

b) A margem de erro inicial admitida pelo programa (padrão $=0,5 \mathrm{ppm}$ )

c) O número mínimo de sinais de $\mathrm{RMN}{ }^{13} \mathrm{C}$ para procura em subestrutura 
(padrão $=10)$.

O algoritmo procura no banco por substâncias cujos átomos de carbonos possuam deslocamentos químicos e multiplicidades compatíveis com o espectro problema. Essa procura leva em conta a margem de erro de deslocamento químico, sendo que esta margem significa a diferença que será tolerada, para mais ou para menos, entre os dados de RMN presentes no banco e os dados do espectro problema. Primeiramente são selecionadas todas as substâncias que possua algum dado de RMN compatível com o espectro problema. Após esta fase, é feita uma nova seleção onde ficam apenas as substâncias que possuem pelo menos o número mínimo de sinais necessário para procura de subsestruturas.

O NAPROSYS possui ainda um módulo de previsão de tempos de retenção de LSTS que foi desenvolvido através de regressão linear múltipla e dados disponíveis na nossa biblioteca de padrões.

\subsubsection{Treinamento das redes neurais}

As redes neurais artificiais podem ser definidas como caixas pretas que recebem uma série de dados de entrada e a partir de tais dados produzem uma saída ou resposta. Embora esta definição possa ser suficiente para quem quer apenas utilizar um programa baseado em redes neurais, ela pode ser considerada incompleta e inconvincente por quem quer desenvolver métodos baseados em redes neurais. Então, o que é uma rede neural, algumas vezes também chamada de redes neuronais ?

As redes neurais são um método computacional que simulam o funcionamento do cérebro humano e são capazes de aprender através de exemplos. Para simular o funcionamento do cérebro, as redes neurais artificiais (RNA) simulam também os neurônios, chamados perceptrons, e as sinapses, que são chamadas de pesos. Devido à característica 
que as redes neurais possuem para generalizar, esta metodologia têm recebido crescente atenção dos químicos (Gasteiger e Zupan, 1999). Os neurônios e as sinapses são simulados no computador através do uso de variáveis (posições de memória), cujos valores são atualizados através de funções matemáticas conhecidas como funções de ativação. A maneira como os neurônios e sinapses estão organizadas em uma RNA é conhecida como arquitetura da rede. A escolha de uma arquitetura correta é importante, pois algumas arquiteturas são melhores quando aplicadas em problemas envolvendo classificação e outras em problemas envolvendo previsão.

As arquiteturas de RNA mais utilizadas em problemas envolvendo química são as redes Kohonen, utilizadas para resolver problemas envolvendo classificação e backpropagation (BP), utilizadas para resolver problemas envolvendo previsão. Entretanto, iindependentemente da arquitetura aplicada, é obrigatório em uma RNA a presença de pelo menos uma camada de neurônio ligadas por sinapse. O tipo de RNA de retropropagação são os tipos que envolvem múltiplas camadas (Figura 6).

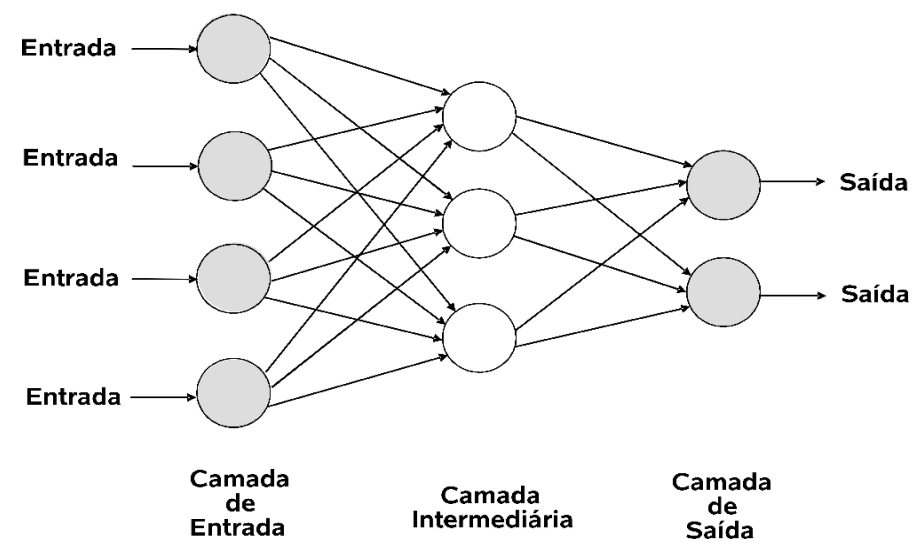

Figura 6 - Arquitetura de uma RNA de múltiplas camadas

Um olhar atento sobre a figura acima, demonstra que cada neurônio pode ter mais do um peso ligado a ele, ou seja, pode possuir assim como um neurônio biológico, várias sinapses. Considerando que cada estímulo tenha um valor $s_{i}$ e que e é passado para o neurônio seguinte por uma sinapse que tenha um peso (valor) $w_{i}$ e que esses pesos podem 
mudar a cada momento, a resposta notal da rede em uma dado momento Net, será a somatório do propduto dos estímulas $\left(s_{i}\right)$ pelos pesos $\left(w_{i}\right)(E q .1)$

$$
\text { net }=\Sigma s_{i} W_{i}(\text { Eq. 1) }
$$

Durante o treinamento da rede, que nada mais é do que vários ciclos de ajuste dos valores dos pesos e de saída dos perceptrons, os valores dos pesos $w_{i}$ vão sendo mudados a cada ciclo (epoch) para a rede convergir, isto é, provocar o menor erro possível. Essa mudança no valor dos pesos é feita através do que é conhecido como função de ativação da rede, sendo que existem vários tipo de funções, das quais as mais conhecidas e utilizadas são as funções sigmóidais (redes multicamadas) e função competiva (redes de uma só camada, classificação).

A função sigmóidal, definida abaixo (Eq. 2), pode ser ajustada através da mudança dos parâmetros $\alpha$ (intervalo de mudança dos pesos) e $\xi$ (momento, ou seja, quando o ajuste irá efetivamente começar). Esse ajuste pode conduzir a uma melhor ou pior convergência da resposta da rede. A maneira como esses parâmetros serão ajustados depende do problema a ser resolvido.

$$
\text { Out }_{j}=1 /\{1+\exp [-\alpha(\text { Net }-\xi)]\} \text { Eq. (2) }
$$

Para as redes conhecidas como redes competitivas, muito utilizadas em classificação e cujo tipo mais popular é o tipo Kohonen, a função de treino é diferente da função sigmóidal. O objetivo de tais redes é mapear objetos de um espaço $m$ dimensional para um espaço $n$ dimensional. Nas redes do tipo Kohonen existem duas camadas: a camada de entrada e a camada de saída, sendo que apenas uma delas é a camada ativa. Essa camada ativa é prganizada como uma grade bidimensional, onde os dados com características semelhantes são agrupados próximos uns aos outros. Neste tipo de rede, o neurônio com

Quimitaxonomia e fitoquímica de espécies da tribo Heliantheae (Asteraceae) e uso de Quimioinformática em elucidação estrutural 
peso mais semelhante ao valor de entrada é selecionado e todos dos dados com valores semelhantes são colocados próximos. A função de treino para uma rede kohonen éw mostrada na equação a seguir:

$$
y_{j}=\sum_{i}\left(w_{j i}-x_{i}\right)^{2}
$$

Onde $y_{j}$ o valor de saída da rede, $w_{i j}$ é o valor do peso (sinapses) dos neurônios e $x_{i}$ é o valor de um dado de entrada. Assim, a grade, também chamda de mapa, vai se organizando a cada ciclo e valores semelhantes vão ficando próximos uns dos outros. A figura 8 mostra como a arquitetura de uma rede kohonen é organizada.

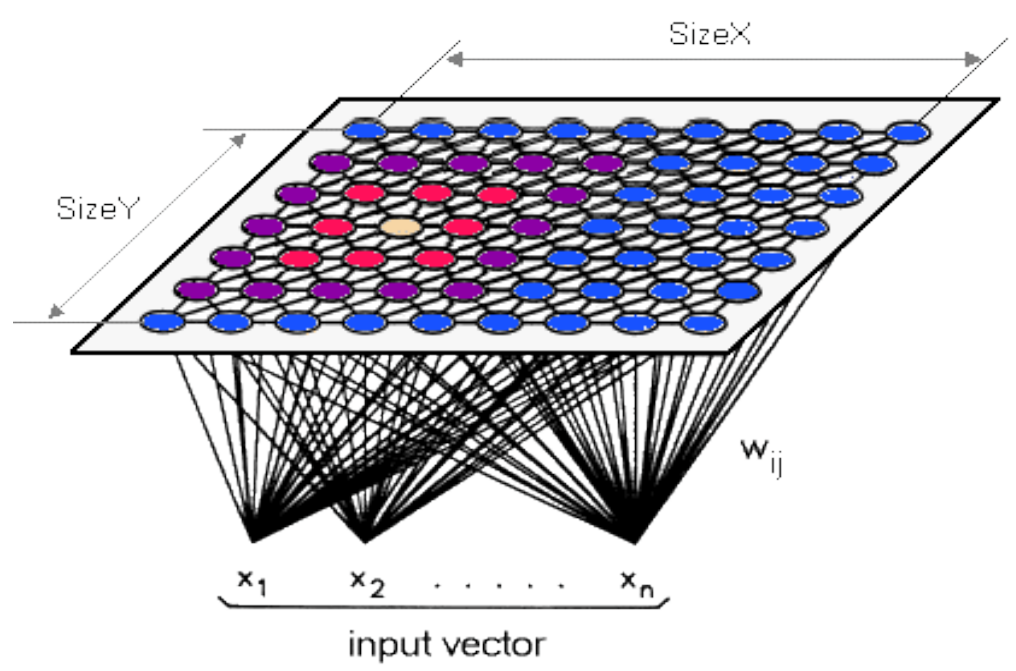

Figura 7 - Arquitetura de uma rede Kohonen.

Como podemos ver, existem várias arquiteturas de redes e cada uma se aplica a um problema específico. Assim, quando utilizamos RNA neste trabalho, escolhemos sempre a arquitetura de redes que julgamos mais apropriada para resolver determinado problema. 


\subsubsection{Análise quimiotaxonômica através de redes neurais}

Para fazer-se a análise quimiotaxonômica das subtribos da tribo Heliantheae, desenvolveu-se uma rede neural do tipo SOM (Self Organized Map) com o software MatLab e SOMTOOLBOX (Vesanto, 1998). O mapa resultante, de uma dimensão de 6x6, é um mapa quadrado. Para o treinamento da rede, foram selecionadas 93 espécies dos gêneros a seguir: Calea, Dimerostemma, Espeletia, Helianthis, Heliomeris, Smallanthus, Polymnia, Tithonia, Viguiera e Zaluzania. Criou-se uma tabela com colunas correspondentes a cada esqueleto estudado de LSTs: germacrolido, heliangolido, furanoeliangolido, eudesmanolido, melampolido, guaianolido e pseudoguaianolido. Nas colunas e linhas correspondentes a cada espécie, marcou-se "1" para a presença de substâncias pertencentes ao esqueleto correspondente e "0" para a ausência. O objetivo final da rede era agrupar os gêneros pela freqüência com que determinados esqueletos aparecem no gênero. Assim, gêneros com semelhanças químicas ficariam próximos uns dos outros, mostrando assim a utilidade da rede para a classificação de plantas com base em seu perfil químico de LSTs.

Após o treino da rede, utilizou-se a opção de estatística existente no MatLab para verificar a porcentagem de acerto da classificação feita pela rede neural.

\subsubsection{Treinamento de redes neurais para identificação de terpenóides através de RMN ${ }^{13} \mathrm{C}$}

Um conjunto de 5308 espectros de $\mathrm{RMN}{ }^{13} \mathrm{C}$ foram extraído os bancos do sistema especialista SISTEMAT (Emerenciano et al., 1994; Nuzillard e Emerenciano, 2006). Essa extração foi feita utilizando-se um programa escrito especificamente para este fim. O 
programa escrito na linguagem Java, lê os dados presentes nos bancos do SISTEMAT e monta uma planilha com todos os deslocamentos químicos de RMN ${ }^{13} \mathrm{C}$. Esta planilha foi posteriormente analisada analisada através de um script escrito em PERL (Wall et al., 2000) para detectar possíveis inconsistências nos dados. Desse modo, os dados de RMN inconsistentes com a estrutura da respectiva substância foram eliminados da planilha. As moléculas que pertenciam a esqueletos raros ou cujos esqueletos contiam menos que 30 substâncias no banco foram descartadas, permanecendo na planilha, apenas substâncias que pertenciam a esqueletos com mais de 30 ocorrências no banco. $O$ vetor de entrada da RNA foi codificado de maneira que os deslocamentos químicos de cada substância fossem agrupados de acordo com o tipo de carbono: 1-4 para carbonos alifáticos $\left(\mathrm{CH}_{3}, \mathrm{CH}_{2}, \mathrm{CH}\right.$ e C); 5-7 para carbonos olefínicos $\left(=\mathrm{CH}_{2},=\mathrm{CH},=\mathrm{C}\right)$. Carbonos aromáticos e acetilênicos, embora possam ser codificados (8-11) não foram considerados, pois possuem ocorrência muito restrita em esqueletos terpênicos. Foi treinado utilizando-se o algoritmo de BP, um conjunto de RNAs para prever o tipo de esqueleto terpênico com base nos dados de RMN ${ }^{13} \mathrm{C}$. O número ideal de neurônios na camada de entrada para cada tipo de esqueleto foi determinado de maneira heurística através de um script em PERL.

Usando-se triterpenos como exemplo, o script em PERL conseguiu determinar que o número máximo de carbonos do tipo 1 (metilas) presentes em um triterpeno é 7 . Isso significa que no vetor de entrada para triterpenos, as posições de 1 até 7 deste vetor são reservadas para a entrada de deslocamento químico de metilas. Existem sete grupo de entrada nas redes que foram treinadas: grupo $1(\mathrm{CH} 3, \mathrm{sp} 3)$, grupo $2(\mathrm{CH} 2, \mathrm{sp} 3)$, grupo 3 $(\mathrm{CH}, \mathrm{sp} 3)$, grupo $4(\mathrm{C}, \mathrm{sp} 3)$, grupo $5(\mathrm{CH} 2, \mathrm{sp} 2)$, grupo $6(\mathrm{CH}, \mathrm{sp} 2)$, grupo $7(\mathrm{C}, \mathrm{sp} 2) . \mathrm{O}$ número de neurônios na camada de entrada pode variar dependendo da classe de cada esqueleto, assim foi treinada uma rede diferente para cada classe, conforme a tabela abaixo. 
Tabela 11 - Estrutura da camada de entrada e tamanho dos dados utilizado no treino da RNA para preever tipos de esqueltos terpênicos

\begin{tabular}{llllll}
\hline Classe & $\begin{array}{l}\text { distribuição do } \\
\text { vetor de entrada }\end{array}$ & \# de redes & \#espectros conj. treino & $\begin{array}{l}\text { conj. } \\
\text { teste }\end{array}$ \\
\hline Monoterpeno & $4,7,9,3,2,5,6$ & 4 & 487 & 260 & 51 \\
Sesquiterpeno & $8,8,8,5,5,6,8$ & 5 & 1076 & 333 & 54 \\
LST & $4,6,9,4,3,4,7$ & 3 & 926 & 550 & 90 \\
Diterpeno & $6,11,126,3,6,9$ & 7 & 1744 & 869 & 125 \\
Triterpeno & $8,13,9,7,2,3,9$ & 4 & 363 & 261 & 53 \\
Esteroide & $5,10,6,3,1,2,2$ & 5 & 711 & 461 & 90 \\
\hline
\end{tabular}

Na tabela acima, a segunda coluna indica quantos neurônios do vetor de entrada são reservados para os grupos (tipos de C) 1 a 7.

A saída da rede consiste de um vetor de variáveis, onde cada variável respresenta um esqueleto que assume valor 1 , indicando a presença daquelete esqueleto ou 0 , indicando a ausência daquele tipo de esqueleto.

A arquitetura de RNA escolhida para realizar a previsão de esqueletos foi uma rede multicamadas contendo três camadas, sendo a camada de entrada, cujo tamanho para cada tipo de esqueleto poder vista na tabela acima, coluna 3. O número de neurônios na camada escondida varia para cada tipo de esqueleto e varia de 3 a 12 neurônios. Na camada de saída, o número de neurônios é de 28 , cada um representando um tipo de esqueleto e apenas um neurônio, o que representa o esqueleto possível, assume valor 1 . O algoritmo utilizado para treinar a rede é do tipo BP, utilizando-se o MATLAB e 500 ciclos para treinamento, sendo o paramêtro $\xi$ (momento) ajustado para 0,9 e o parâmetro $\alpha$ (freqüência de aprendizado) ajustado para 0,1. A rede foi também otimizada com o algoritm LevenbergMarquardt. 


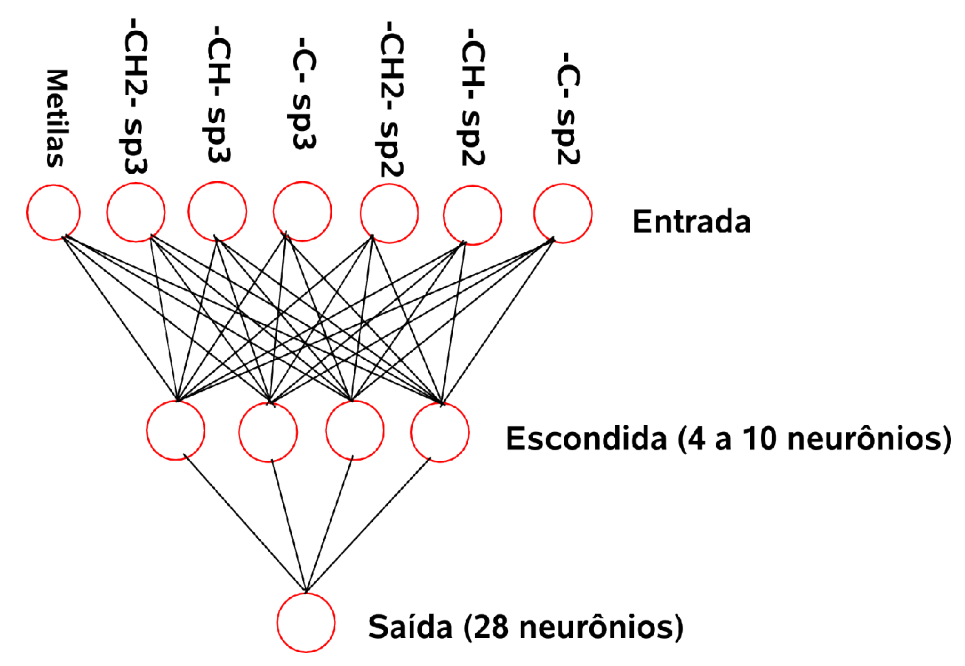

Figura 8 - Arquitetura da RNA de previsão de esqueletos.

Para testar a eficiência da rede, $20 \%$ dos dados foram reservados para testes. 0 objetivo de treinar esta rede foi ter uma metodologia que pudesse diferenciar diversos tipos de esqueletos terpênicos, incluindo esteróides. Os ddos para testes mesclaram dados deveriam ser reconhecidos como positivos, isto é, a rede devedria reconhecer como o esqueleto de determinado tipo e dados que deveriam ser reconhecidos como negativos, ou seja, a rede deveria reconhecer os dado como NÃO pertencente a determinado tipo. Pegando-se por exemplo o teste para Clerodanos, haviam 20 casos positivos (Clerodanos) no conjunto e que deveriam ser identificados como sendo do esqueleto Clerodano, neste mesmo conjunto de dados, haviam 85 ocorrências de esqueletos de outros tipos e que não deveriam ser reconhecidos como clerodanos. Este estilo de teste não só permite testar se a rede conmsegue reconhecer se uma substância pertende a determinado esqueleto, mas também permite testar a habilidade da rede em reconhecer quando uma substância não pertence ao esqueleto esperado. 


\subsubsection{Classificação de tipos de Diterpenos baseado em redes Kohonen}

Uma RNA do tipo Kohonen foi desenvolvida para classificar e separar diversos tipos de esqueletos de Diterpenos. Todas as estruturas e dados de RMN foram extraídos dos bancos do SISTEMAT da mesma forma descrita anteriormente. No total, foram extraídos dados de 2600 diterpenos dos quais os 927 melhores foram selecionados para o treino da rede. Os esqueletos selecionados estão na Tabela 12, sendo selecionados apenas os doze esqueletos de ocorrência mais ampla no reino vegetal.

Tabela 12 - Esqueletos selecionados para treino

\begin{tabular}{llll}
\hline Esqueleto \# & Nome & Esqueleto \# & Nome \\
\hline 1 & 12,13-sec-13-nor-totorano & 7 & clerodano \\
2 & 13-epi-rosano & 8 & ent-atisano \\
3 & abietano & 9 & ent-labdano \\
4 & andromedano & 10 & fitano \\
5 & cembrano & 11 & isopimarano \\
6 & ciatano & 12 & labdano \\
\hline
\end{tabular}

Uma planilha contendo 957 linhas e 25 colunas foi utilizada para codificar os diterpenos e seus respectivos deslocamentos químicos de $\mathrm{RMN}{ }^{13} \mathrm{C}$. Uma última coluna foi utilizada para colocar o ID do esqueleto $(1-12)$ a qual a substância pertencia. Este ID foi utilizado como um guia para a rede poder classificar cada tipo de esqueleto.

A RNA foi treinada utilizando-se o software MatLab e a biblioteca SOM Toolbox (Vesanto, 1999). Um mapa com a dimensão de $31 \times 20$ foi treinado utilizando-se a técnica de treinamento em lote (Batch training). Neste algoritmo, todos os dados são apresentados à rede de uma só vez e em cada ciclo os dados são particionados de acordo com cada região do mapa, sendo que os pesos são atualizados para refletir a classificação feita. $O$ número de ciclos necessários para a rede convergir é determinado automaticamente, isto é, 
a rede é treinada até o momento que haja o menor erro possível.

\subsubsection{Estudos de QSRR da biblioteca de padrões de LSTs}

A biblioteca de padrões do Laboratório de Farmacognosia possui 51 LSTs de diversas classes. Com o intuito de se ter um modelo que pode ser utilizado para prever o tempo de retenção relativo de LSTs que não estão presentes na biblioteca um modelo de QSRR foi criado para as LSTs presentes no banco. Esse modelo foi baseado em Redes neurais do tipo MLP (Multi Layer Perceptrons). Foram selecionados dois modelos finais uma para prever o tempo de retenção relativo das LSTs em $\mathrm{MeOH} / \mathrm{H}_{2} \mathrm{O}$ 55: 45 (trr1) e outro para prever o tempo de retenção relativo das LSTs em $\mathrm{MeCN} / \mathrm{H}_{2} \mathrm{O} 35: 55$ (trr2).

\subsubsection{Cálculo dos descritores}

Para se criar qualquer modelo de previsão envolvendo tanto QSRR como QSAR é fundamental a escolha e seleção de um conjunto de descritores moleculares que reflitam na teoria o comportamento observado em condições experimentais. Para o cálculo dos descritores, primeiro calculou-se as coordenadas 3D de cada LST presente no banco com o software CORINA (Sadowski et al., 1993), após esse cálculo, um conjunto de descritores, tanto físico-químicos tanto topológicos, foi calculado utilizando-se os softwares Adriana.Code e Petra 4. Os descritores calculados refletem características do analito que influem em seu tempo de retenção, tais como: volume, área acessível ao solvente, coeficiente de partição, peso molecular, número de doadores e aceptores de hidrogênio, 
polarizabilidade e momento de dipolo. Os descritores calculados foram colocados em uma tabela juntamente com os tempos de retenção relativos (variáveis dependentes) das LSTs.

\subsubsection{Seleção das LSTs para a criação do modelo}

Para selecionar as LSTs do banco que seriam utilizadas para criar o modelo de previsão de tempos de retenção utilizou-se uma RNA do tipo Kohonen. Essa rede foi treinada através do software SONNIA. Para tanto, uma RNA com a dimensão de $6 \times 6$ neurônios, utilizando 500 ciclos de treino, taxa de aprendizagem de 0,2 e topologia retangular (Figura 9) foi treinada e após o treino, foram selecionadas 29 LSTs que foram posteriormente utilizadas para a criação do modelo de QSRR. A seleção das LSTs se baseou nas substâncias chamadas de centroides, ou seja a substância melhor classificada em cada neurônio, isso permite que seja utilizado um conjunto de dados representativo durante o desenvolvimento do modelo e evita que um conjunto de dados pouco diverso com substâncias muito semelhantes entre si seja utilizado no desenvolvimento do modelo. Embora o mapa gerado tenha apresentado apenas 19 centróides, substâncias adicionais foram selecionadas através de uma análise criteriosa do mapa.

$\overline{\text { Quimitaxonomia e fitoquímica de espécies da tribo Heliantheae (Asteraceae) e uso de Quimioinformática em elucidação estrutural }}$ 


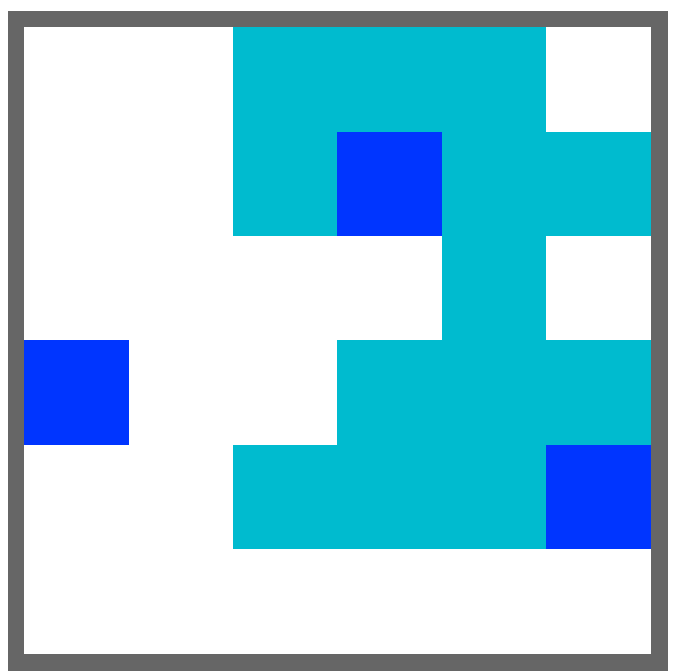

Figura 9 - Mapa Kohonen gerado para seleção do conjunto de LSTs utilizadas para QSRR.

\subsubsection{Criação do modelo de MLP para QSRR}

Para a criação do modelo MLP para a previsão do tempo de retenção relativo das LSTs foi utilizado o software Weka (Witten e Frank, 2005). Esse software permite a criação de diversos tipos de modelos estatísticos e de aprendizagem por inteligência artificial. Eliminou-se da tabela dos descritores calculados aquelas estruturas que não foram selecionadas na fase anterior e o modelo foi criado utilizando-se as 29 substâncias selecionadas (Figura 10).

Para desenvolver o modelo, após abrir a tabela de dados no WekaExplorer, utilizouse o módulo chamado WekaExplorer no modo interativo. Dentro do WekaExplorer o modo de Classificação foi selecionado e dentro desse modo, foi selecionado a opção de Multiple Layers Perceptrons. Vários modelos foram experimentados utilizando-se todos os descritores ou apenas alguns descritores selecionados. Como existiam apenas 10 
descritores, os melhores descritores foram selecionados através da análise de cada modelo criado. O Modelo final foi validado através da separação de $70 \%$ dos dados para treinamento e $30 \%$ para teste (test-split), o que é feito automaticamente pelo WEKA. Para a criação dos modelos finais, os seguintes dos seguintes descritores foram utilizados: XlogP, LogS, área acessível ao solvente, TPSA, momento de dipolo, volume molecular, índice de conectividade, polarizabilidade e ClogP. Os parâmetros para treinamento foi ajustado como se segue: momento de 0,3 , taxa de aprendizagem de 0,2 e foram utilizados 1000 ciclos de treinamento. 


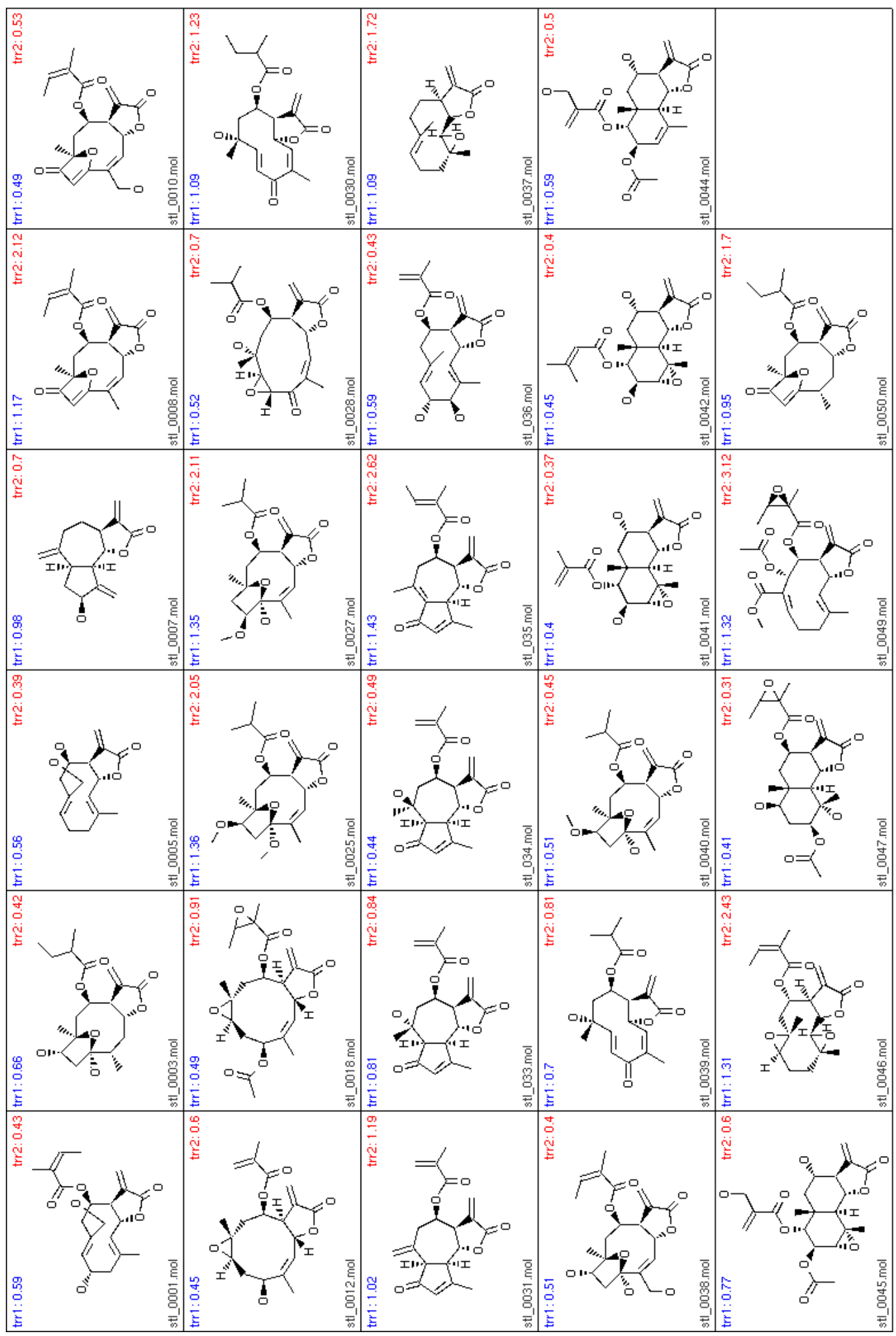

Figura 10 - LSTs utilizadas para o desenvolvimento do modelo de QSRR 


\subsection{Microamostragem dos tricomas glandulares}

Foi feita a microamostragem dos tricomas glandulares das espécies selecionadas e coletadas, cuja microamostragem ainda não tinha sido feita, com o intuito de identificar indiretamente as LSTs presentes nesses tricomas.

\subsubsection{Microamostragem dos tricomas glandulares de Calea hispida}

Os cromatrogramas da microamostragem dos tricomas glandulares de C. hispida podem ser vistos nas Figuras 10 e 11 respectivamente.

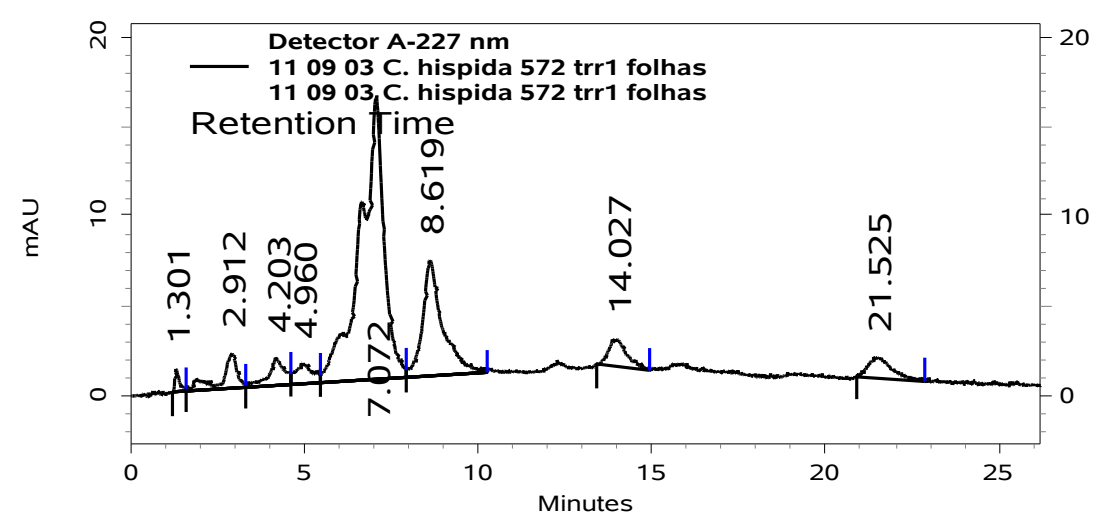

Figura 10 - Microamostragem dos tricomas glandulares de C. hispida trr1 


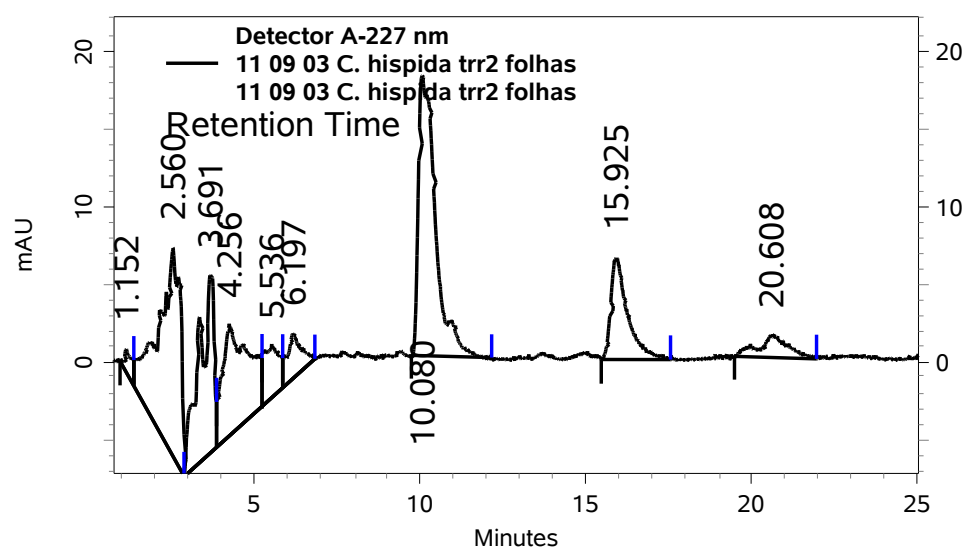

Figura 11 - Microamostragem dos tricomas glandulares de C. hispida trr2

A tabela a seguir mostra os picos e os trr1, trr2, $A_{225 / 265}$ e $\lambda_{\max }$ dos picos do cromatograma. Sendo que estes parâmetros permitem a identificação indireta dos compostos presentes nos tricomas glandulares.

Tabela 13 - Microamostragem de C. hispida

\begin{tabular}{lllllll}
\hline Pico \# & trr1 & trr2 & $\mathrm{A}_{225 / 265}$ & $\lambda_{\max }$ & Tipo & \#banco \\
\hline 1 & 0,068 & 0,057 & 0,397 & 201 & $\mathrm{~m}$ & - \\
2 & 0,187 & 0,17 & 3,464 & 243 & $\mathrm{~m}$ & - \\
3 & 0,28 & 0,187 & 0,634 & 201 & $\mathrm{~m}$ & - \\
4 & 0,445 & 0,509 & 1,62 & 205 & $*$ & - \\
5 & 0,471 & 0,554 & 1,59 & 214 & $*$ & 10 \\
6 & 0,576 & 0,806 & 1,597 & 205 & + & - \\
7 & 0,934 & 1,045 & - & 211 & $\mathrm{~m}$ & \\
\hline
\end{tabular}

(*) majoritário, (+) alta concentração, $(\mathrm{m})$ baixa concentração

Pela comparação dos dados da tabela 13 com os dados do nosso banco de padrões de LSTs, chegou-se a conclusão que o pico 5 do cromatograma dps tricomas glandulares de C. hispida é uma LST do tipo furanoeliangolido, denominada Budleína A, o que é corroborado por dados disponíveis em literatura (Bohlmann et al., 1982a). Os outros picos do cromatograma não puderam ser identificados, pois não possuímos os dados 
correspondentes no nosso branco de padrões.

\subsubsection{Microamostragem dos tricomas glandulares de Viguiera robusta.}

Os cromatogramas da microamostragem dos tricomas glandulares de $V$. robusta podem ser vistos nas figuras 12 e 13 respectivamente.

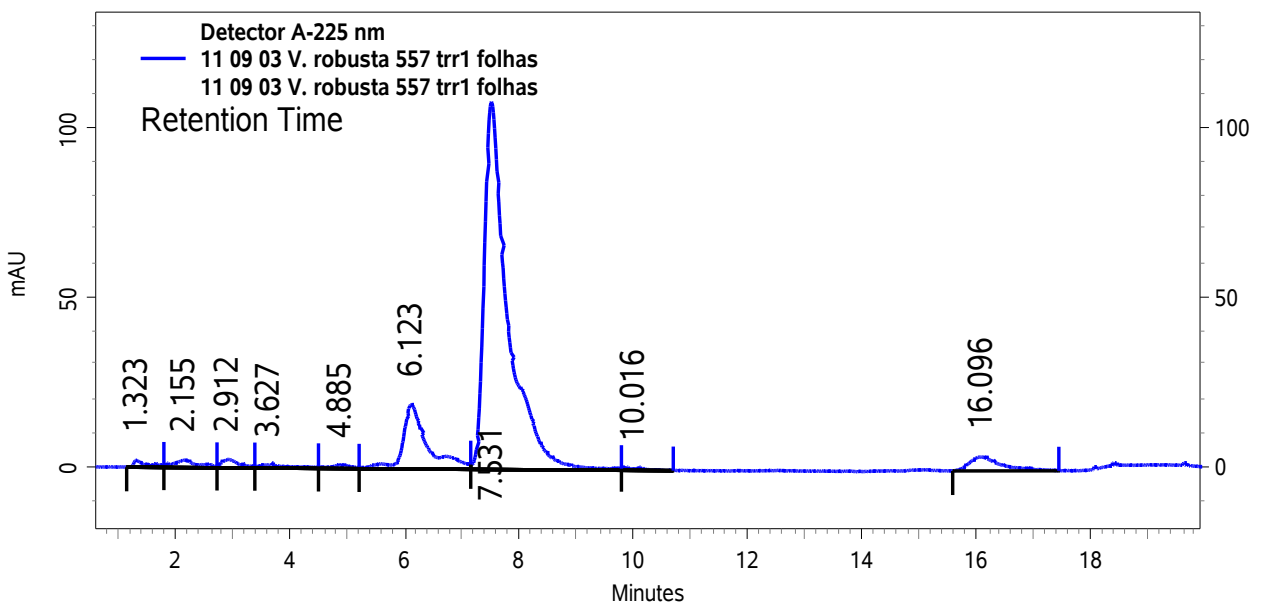

Figura 12 - Microamostragem dos tricomas glandulares de $V$. robusta trr1

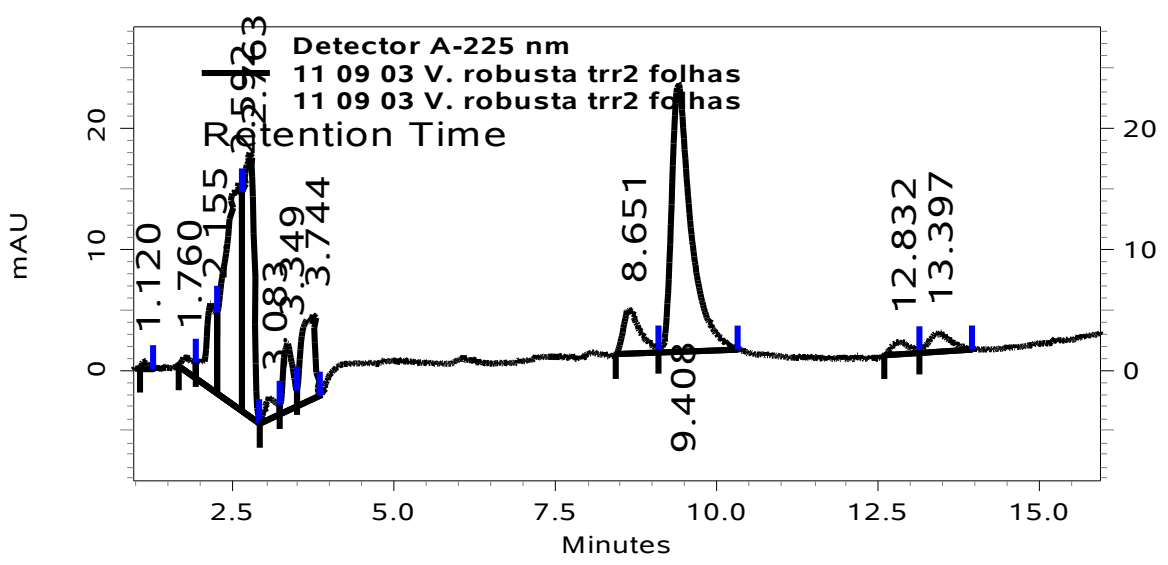

Figura 13 - Microamostragem dos tricomas glandulares de V. robusta trr2. 
Na tabela 14 temos os picos dos cromatogramas acima, acompanhados de trr1, trr2, $A_{225 / 265}$ e $\lambda_{\max }$, seguido também por sua identificação no banco de padrões.

Tabela 14 - Microamostragem de V. robusta

\begin{tabular}{lllllll}
\hline \#Pico & trr1 & trr2 & $\mathrm{A}_{225 / 265}$ & $\lambda_{\max }$ & Tipo & \#banco \\
\hline 1 & 0,088 & 0,009 & 3,06 & 216 & $\mathrm{~m}$ & - \\
2 & 0,144 & 0,138 & 2,81 & 203 & $\mathrm{~m}$ & - \\
3 & 0,164 & 0,139 & 0,83 & 270 & $\mathrm{~m}$ & - \\
4 & 0,196 & 0,157 & 5,04 & 242 & $\mathrm{~m}$ & - \\
5 & 0,41 & 0,46 & 1,65 & 206 & + & - \\
6 & 0,502 & 0,563 & 1,61 & 216 & $*$ & 10 \\
8 & 1,073 & 0,649 & 0,50 & 201 & + & - \\
\hline
\end{tabular}

(*) majoritário, (+) alta concentração, $(\mathrm{m})$ baixa concentração

Observando-se os dados acima, verifica-se que foi possível a identificação de apenas um composto através da microamostragem de tricomas glandulares. Esse composto é novamente a Budleína A. O que é corroborado novamente pelos dados presentes na literatura (ARAKAWA, 2003).

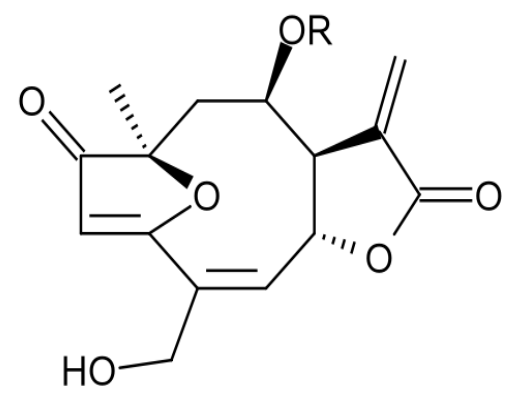<smiles>[R]C(=O)/C(C)=C/C</smiles>

Budleína A<smiles>[R]#CC(=O)/C(C)=C/C</smiles>

Budleína A Tiglato 


\subsubsection{Microamostragem dos tricomas glandulares de Dimerostemma} rontidifolium

Os cromatrogramas da microamostragem dos tricomas glandulares de $D$. rontudifolium podem ser vistos nas figuras 14 e 15 respectivamente.

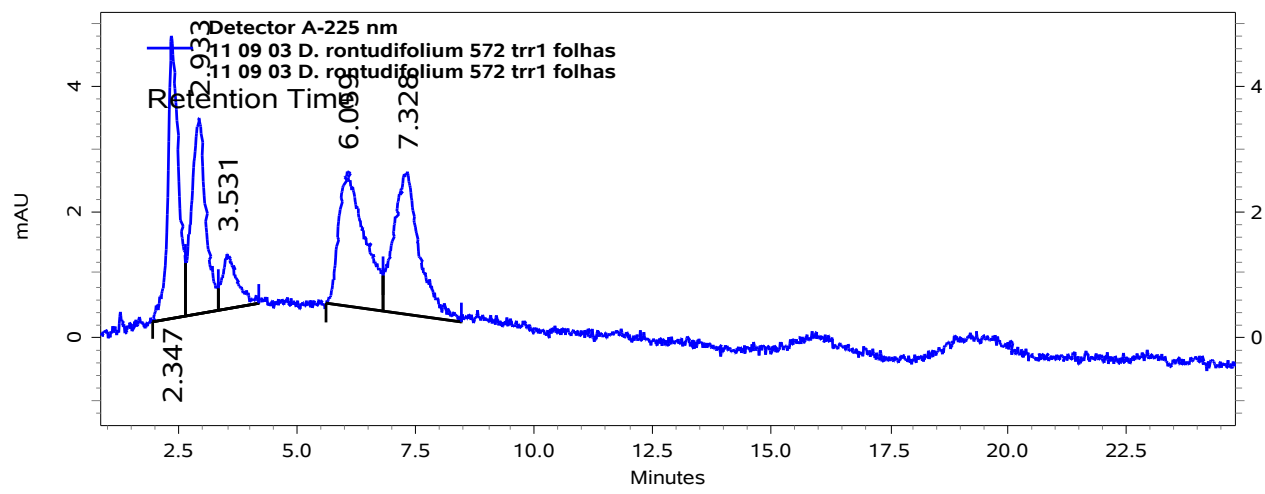

Figura 14 - Microamostragem de $D$. rontudifolium trr1

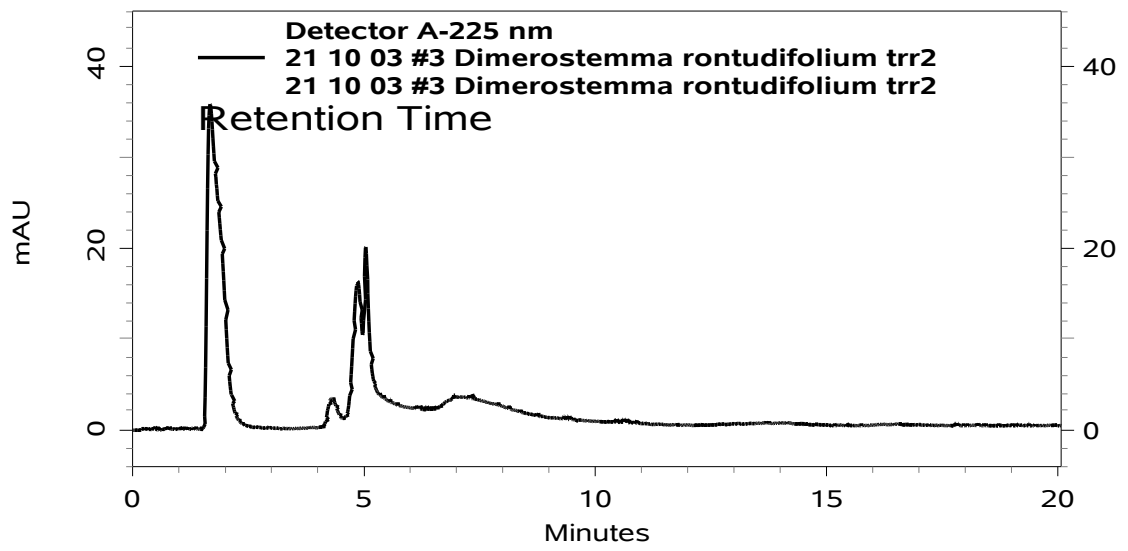

Figura 15 - Microamostragem de $D$. rontudifolium trr2

Na tabela 15, temos a comparação dos dados cromatográficos das duas análises em CLAE. 
Tabela 15 - Microamostragem de D. rontudifolium

\begin{tabular}{lllllll}
\hline \#Pico & Trr1 & Trr2 & $\mathrm{A}_{225 / 265}$ & $\lambda_{\max }$ & Tipo & \#banco \\
\hline 1 & 0,155 & 0,085 & 1,06 & 280 & $*$ & - \\
2 & 0,194 & 0,218 & 0,85 & 215 & + & - \\
3 & 0,233 & 0,246 & 2,36 & 220 & $\mathrm{~m}$ & - \\
4 & 0,402 & 0,256 & - & 227 & + & - \\
5 & 0,483 & 0,437 & - & 207 & + & - \\
\hline
\end{tabular}

$\left(^{*}\right)$ majoritário, $(+)$ alta concentração, $(\mathrm{m})$ baixa concentração

Pela análise da tabela acima, nota-se que não foi possível identificar nenhum dos componentes químico de $D$. rontudifolium através da microamostragem dos tricomas glandulares. Embora não fosse possível identificar os constituintes químicos desta espécie através da microamostragem, uma LST do tipo eudesmanolido foi isolada desta espécie através de métodos cromatográficos, o que corrobora dados disponíveis na literatura acerca deste gênero.

\subsubsection{Microamostragem dos tricomas glandulare de Tithonia diversifolia}

Foi feita a microamostragem dos tricomas glandulares da espécie $T$. diversifolia, cujos cromatogramas podem ser vistos nas figuras 16 e 17. 


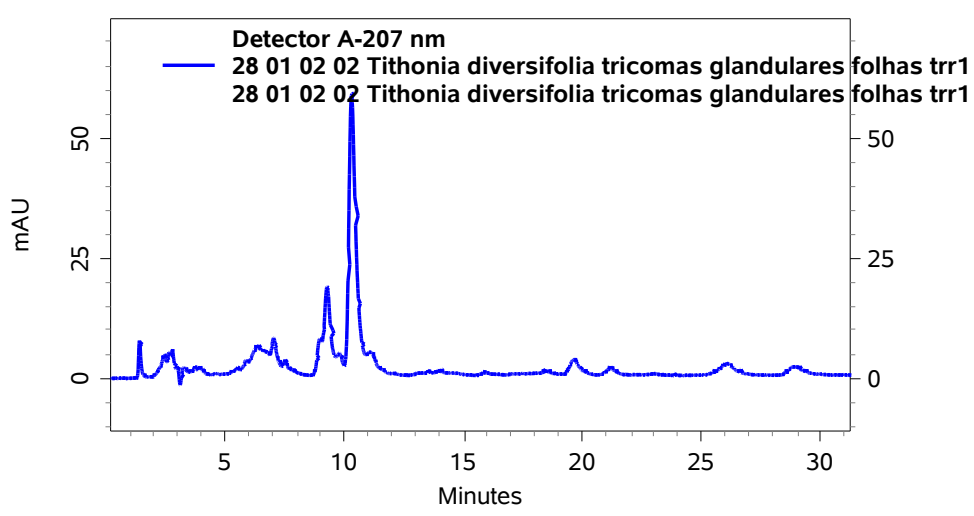

Figura 16 - Microamostragem de T. diversifolia trr1

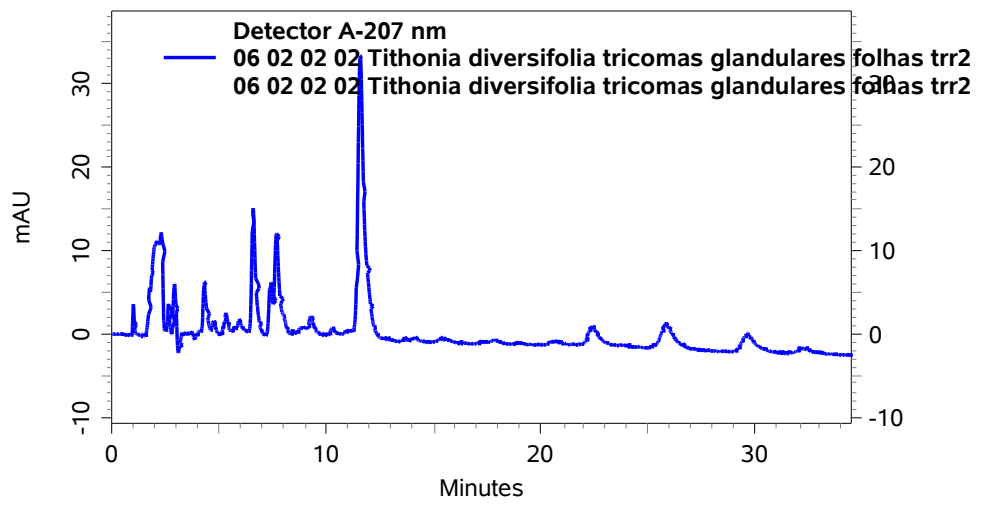

Figura 17 - Microamostragem de T. diversifolia trr2

A análise dos dados da microamostragem se encontra na tabela abaixo:

Tabela 16 - Microamostragem de T. diversifolia

\begin{tabular}{llllllll}
\hline \multicolumn{1}{c}{ Pico \# } & trr1 & \multicolumn{1}{c}{ trr2 } & $\mathrm{A}_{225 / 265}$ & $\lambda_{\max }$ & \multicolumn{2}{c}{ Tipo } & \#banco \\
\hline 1 & 0,094 & 0,053 & 3,63 & 202 & $\mathrm{~m}$ & - \\
2 & 0,164 & 0,10 & 0,53 & 202 & $\mathrm{~m}$ & - \\
3 & 0,177 & 0,107 & - & 202 & $\mathrm{~m}$ & - \\
4 & 0,186 & 0,121 & - & 203 & $\mathrm{~m}$ & - \\
5 & 0,204 & 0,138 & - & 226 & $\mathrm{~m}$ & - \\
6 & 0,469 & 0,346 & - & 203 & $\mathrm{~m}$ & - \\
7 & 0,619 & 0,403 & 18,20 & 210 & + & 3 \\
8 & 0,687 & 0,609 & 1,36 & 203 & $*$ & 39 \\
9 & 1,307 & 1,17 & - & 217 & $\mathrm{~m}$ & - \\
\hline
\end{tabular}

(*) majoritário, (+) alta concentração, $(\mathrm{m})$ baixa concentração 
De acordo com a análise dos dados da tabela 16, foi possível identificar a LST denominada tagitinina A e tagitinina $\mathrm{C}$, o que está de acordo com dados presentes na literatura (Pereira et al., 1997). Esta espécie também está sendo reinvestigada por outros alunos em nossa laboratório e os dados obtidos possibilitarão uma análise mais detalhada dos resultados mostrados acima.<smiles>[R]C(=O)C(C)C</smiles>

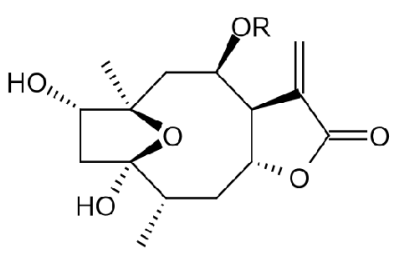

Tagitinina A<smiles>[2H]C1CC(C)(O)/C=C\C(=O)/C=C\OC(=O)C(=C)C1CO</smiles>

Tagitinina C

\subsection{Estudo Fitoquímico}

No decorrer deste trabalho, quatro espécies vegetais foram investigas quimicamente, sendo que três espécies pertencem ao gênero Dimerostemma (tribo Heliantheae, subtribo Verbesininae) e uma espécie pertence ao gênero Ichtyothere (tribo Heliantheae, subtribo Melampodinae). No total oito LSTs foram isoladas. Da espécie Dimerostemma brasilianum foram isoladas dois germacrolidos ( 1 e 2); da espécie Dimerostemma episcopale foi isolado um germacrolido (3) e um eudesmanolido (4); da espécie Dimerostemma rotundifolium foram isolados dois eudesmanolidos (5 e 6), finalmente, da espécie Ichthyothere terminalis 
foram isolados dois melampolidos (7 e 8).

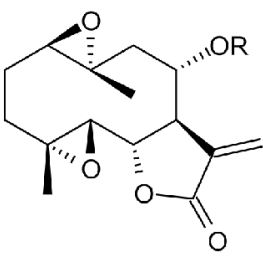<smiles>[R2][C@H]1CCC(=C)[C@]2(C)C[C@H](O)[C@H]3C(=C)C(=O)O[C@@H]3[C@@H]12</smiles>

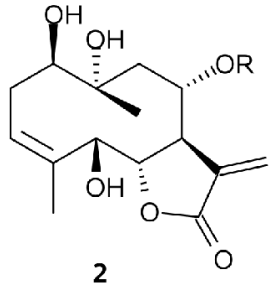

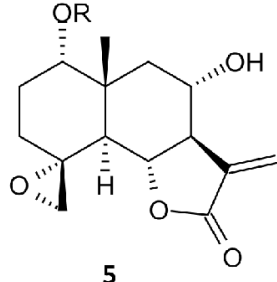<smiles>[R]O[C@H]1C/C(C)=C/CC/C(CO)=C\[C@@H]1OC(C)C</smiles>

3<smiles>[R2][C@H]1CC[C@]2(CO2)[C@@H]2[C@@H]3OC(=O)C(=C)[C@H]3[C@@H](O)C[C@]12C</smiles><smiles>[R]OC1[C@@H]2C(=C)C(=O)O[C@H]2[C@@H](OC(C)=O)/C(C(=O)OC)=C/[C@H](O)C[C@]2(C)O[C@H]12</smiles><smiles>[R]OC1[C@@H]2O[C@]2(C)CC/C=C(/C(=O)OC)[C@H](OC(C)=O)[C@@H]2OC(=O)C(=C)[C@H]12</smiles>

1,2 e $7 R=$<smiles>C=C(CO)C(=O)C(C)=O</smiles>

5 e $8 \quad R=$<smiles>CC(=O)C1(C)OC1C</smiles>

$6 \mathrm{R}=$ 年<smiles>C=C(C)C(=O)OC(=O)C1(C)OC1C</smiles> 


\subsubsection{Estudo fitoquímico de espécies do gênero Dimerostemma}

O gênero Dimerostemma Cass. (Asteraceae) é um pequeno gênero com 12 espécies nativas do Brasil, Bolívia e Paraguai (Karis e Ryding, 1994). Este gênero se caracteriza pela biossíntese de sesquiterpenóides (Bohlmann et al., 1981a, b, 1982), diterpenóides ( Bohlmann et al., 1981a, 1984), poliacetilenos (Bohlmann et al., 1981a, b) e lactonas sesquiterpênicas (Bohlmann et al., 1981a, 1981b, 1982, 1984; Stefani et al., 2003). Dentre as LSTs, os eudesmanolidos são o tipo característico deste gênero, possuindo um padrão de substituição peculiar, que não é encontrado em nenhum outro gênero.

O padrão de substituição deste eudesmanolidos se caracteriza por possuir sistemas epóxidos nas posições 3,4 (Stefani et al., 2003) ou 4,15 (Bohlmann et al., 1981a, b, 1982) além de grupos com orientação $\alpha$ nas posições 1 ou 8 do esqueleto. Essas características podem ser consideradas como marcadores quimiotaxonômicos do gênero. Neste trabalho, duas espécies do gênero Dimerostemma foram investigadas quanto à química. LSTs do tipo germacrolido e eudesmanolido foram isoladas do extrato das espécies investigadas, o que está de acordo com o esperado para o gênero.

\subsubsection{Estudo fitoquímico de Dimerostemma brasilianum}

Dois germacrolidos foram isolados do extrato bruto das folhas de Dimerostemma brasilianum Blake. Após o fracionamento do extrato, foram isolados $40 \mathrm{mg}$ (Fração 8.1) do germacranolido $1 \beta, 10 \alpha, 4 \alpha, 5 \beta$-diepóxido-8 $\alpha$-angeloiloxi-custonolido (1) (Miski et al., 1987), também foram isolados $8 \mathrm{mg}$ (Fração 8.2) do germacranolido $1 \beta, 5 \beta, 10 \alpha$-triidróxido-8 $\alpha$ angeloiloxi-germacra-3,11(13)-dien-6 $\alpha, 12$-olido (2), sendo que este último ainda não foi 
descrito na literatura. As estruturas das substâncias foram elucidadas através de RMN ${ }^{1} \mathrm{H}$ e

${ }^{13} \mathrm{C}$, além de técnicas bidimensionais.

\subsection{Elucidação estrutural da substância $1 \beta, 10 \alpha, 4 \alpha, 5 \beta$-diepóxido-8 $\alpha$-angeloiloxi- custonolido}

A estrutura da substância $1 \beta, 10 \alpha, 4 \alpha, 5 \beta$-diepóxido-8 $\alpha$-angeloiloxi-custonolido foi elucidada através da análise dos espectros de $\mathrm{RMN}{ }^{1} \mathrm{H}$ e ${ }^{13} \mathrm{C}$ (Tabela 17), além de HMBC e HMQC. A comparação dos dados de RMN da amostra com dados presentes na literatura (Gershenzon et al., 1984; Miski et al., 1987) também auxiliou no processo de elucidação estrutural desta substância.

A presença de dois $d$, um observado em $\delta 6,30(J=3,5 \mathrm{~Hz})$ e outro em $\delta 5,62(J=$ 3,0 Hz) são atribuídos a sinais típicos de hidrogênios olefínicos chamados $\mathrm{H}-13$, presentes em duplas exocíclicas em $\gamma$-trans-lactonas, o que nos permite determinar a estereoquímica do anel lactônico. A estereoquímica foi determinada ainda pela constante de acoplamento de 9,6 Hz entre um $d d$ em $\delta 4,61(J=9,6 \mathrm{~Hz})$, atribuído ao $\mathrm{H}-6$, e um $d d d d$ em $\delta 3,19(J=$ 3,0; 3,5; 9,6), atribuído ao H-7. A constante de acoplamento de 9,6 Hz é típica de acoplamentos trans, o que corrobora o fato do anel lactônico possuir estereoquimica trans, o que é também reforçado pelas constantes de acoplamento entre os $\mathrm{H}-13$ e o $\mathrm{H}-7$, pois constantes de acoplamentos maior ou igual a $3 \mathrm{~Hz}$ são típicos de aneis lactônicos com fusão trans (Samek, 1970). As atribuições de H-6 e H-7 são ainda evidenciadas pela correlação que o $\mathrm{H}-6$ apresenta no espectro de HMQC com um sinal em $\delta 80,3$, que foi atribuído ao C6, e cujo deslocamento químico é típico de carbonos carbinólicos. Além disso, ainda existe as corelações apresentadas pelo $\mathrm{H}-7$ no espectro HMBC com os sinal em $\delta 125,7$, típico de carbonos $\mathrm{sp}^{2}$ e que atribuído ao C-13, e com o sinal em $\delta 169,1$ que é típico de carbonilas 
de ésteres e que foi atribuído ao C-12.

A presença do éster angelato foi determinada através da observação de seus sinais típicos, que estavam presentes no espectro de $\operatorname{RMN}^{1} \mathrm{H}(6,14 d q[J=1,8 ; 3,5] ; 1,93 d[3 \mathrm{H} ; J$ $=1,8] ; 1,85 d[3 \mathrm{H} ; \quad J=1,8])$ e também no espectro de $\operatorname{RMN}{ }^{13} \mathrm{C}(167,4 ; 141,3 ; 126,8 ; 20,6$; 16,2). A posição do éster angelato em C-8 foi determinada através do deslocamento químico de um $d d$ em $\delta 4,70(J=2,5 ; 10,1 \mathrm{~Hz})$ no espectro de $\mathrm{RMN}{ }^{1} \mathrm{H}$, que foi atribuído ao $\mathrm{H}-8$, pois apresenta uma correlação com C-7 no espectro HMBC e também apresenta no espectro de HMQC uma correlação com um sinal em $\delta 69,8$, atribuído ao C-8. Os sinais tanto de H-8 como de C-8 são típicos de hidrogênios e carbonos de sistemas -COR-, desse modo, chegou-se à conclusão que o éster angelato estava ligado ao C-8. A orientação do éster em $\alpha$ foi determinada através do deslocamento químico de $\mathrm{H}-8$, além de experimentos NOE-diff. A irradiação do sinal atribuído ao $\mathrm{H}-8$ em um experimento NOE-diff resultou em pouco aumento do sinal atribuído ao $\mathrm{H}-7$ e aumentou muito um sinal em $\delta 1,77 d d(J=10,1 ; 13$, 8), o que permitiu atribuir este sinal ao $\mathrm{H}-9 \alpha$ e chegar à concluir que o $\mathrm{H}-8$ tinha orientação $\beta$. Dessa maneira, chegamos à seguinte estrutura parcial para esta substância:

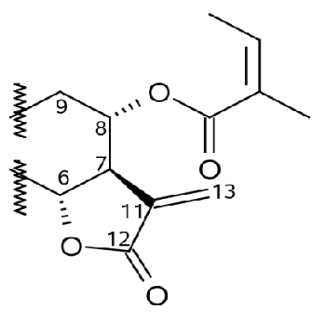

todavia, LSTs possuem uma variedade enorme de esqueletos e era preciso determinar o tipo de esqueleto que esta substância possuía.

O H-6 acopla com um $d$ em 2,86 $(J=9,6 \mathrm{~Hz})$, que foi atribuído ao $\mathrm{H}-5$. O H-5 por sua vez se correlaciona com um sinal em $\delta 66,3$ (C-5), que é típico de carbonos pertencentes a sistemas epóxidos. Uma correlação adicional no espectro HMBC de H-5 com um sinal em $\delta$ 59,8 (C-4); também típica de carbonos em sistemas epóxidos, evidencia a presença de um sistema epóxido entre C-4 e C-5. A ausência de correlações adicionais nos espectros HMBC 
e HMQC nos permite concluir que trata-se de um trans, trans germacranolido. A esteroquímica do epóxido em trans foi evidenciada pela constante de acoplamento entre $\mathrm{H}-5$ e H-6 $(9,6 \mathrm{~Hz})$, que é típica de sistemas com orientação trans. Através da interpretação dos dados de RMN que foi feita até este ponto, temos a seguinte estrutura parcial para esta substância:

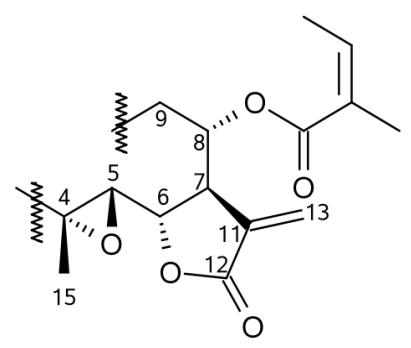

No espectro de $\operatorname{RMN}{ }^{1} \mathrm{H}$ havia um $d d$ em $\delta 3,00(J=1,0 ; 10,6)$ que não tinha sido atribuído a nenhum hidrogênio. Este $d d$ também possui deslocamento químico típico de hidrogênios pertencentes a sistemas epóxidos e também exibe uma correlação no espectro HMBC com um sinal em $\delta 58,9$, também típico de carbonos ligados a sistemas epóxido, e que sua vez se correlaciona com sinais em $\delta 1,77$ e em $\delta 2,53$, ambos atribuídos aos H-9. Estas informações nos permitiu atribuir o $d d$ em $\delta 3,00$ ao H-1, $\delta$ 58,9 ao C-10 e a existência da correlação de $\mathrm{H}-1$ com um sinal em $\delta 61,1$ no espectro HMQC, permitiu atribuir este sinal ao C-1. Sendo o sinal de C-1 também típico de carbonos pertencente a sistemas epóxido, a presença de um sistema epóxido entre C-1 e C-10 foi confirmada. A configuração em trans do sistema epóxido foi confirmada através da constante de acoplamento que $\mathrm{H}-1$ possui com ambos $\mathrm{H}-2(10,1 \mathrm{~Hz})$, que está de acordo com o descrito na literatura para tais sistemas epóxidos (Miski et al., 1987; Gershenzon et al., 1984). Os sinais de H-2 (1,55 m; $2,17 m)$ e de $\mathrm{H}-3(1,40 m ; 2,28 m)$, assim como os sinais de C-2 $(23,5)$ e de C-3 $(35,5)$ foram atribuídos através da análise dos espectros HMQC e HMBC. Assim, a estrutura final para o germacrolido $1 \beta, 10 \alpha, 4 \alpha, 5 \beta$-diepóxido-8 $\alpha$-angeloiloxi-custonolido é a seguinte: 


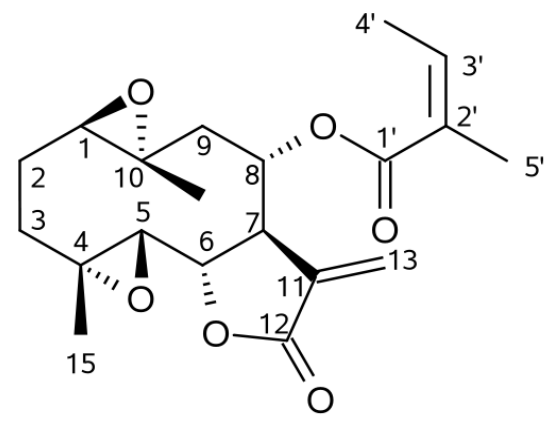

Tabela 17 - Dados de RMN ${ }^{1} \mathrm{H}(400 \mathrm{MHz})$ e ${ }^{13} \mathrm{C}(100 \mathrm{MHz})$ para a substância $1 \beta, 10 \alpha, 4 \alpha, 5 \beta$-diepóxido-8 $\alpha$-angeloiloxi-custonolido $\left(\mathrm{CDCl}_{3}\right)$

\begin{tabular}{|c|c|c|c|c|}
\hline Pos. & $\delta \mathrm{H}$ & $\delta C$ & HMBC & HMQC \\
\hline 1 & $3,00 d d(1,0 ; 10,6)$ & 61,1 & 23,5 (C-2); 58,9 (C-10); 18,6 (C-14) & 61,1 \\
\hline 2 & $1,55 m ; 2,17 m$ & 23,5 & $61,1(C-1) ; 35,5(C-3)$ & 23,5 \\
\hline 3 & $1,40 m ; 2,28 m$ & 35,5 & $59,8(C-4) ; 17,4(C-15)$ & 35,5 \\
\hline 4 & - & 59,8 & - & 59,8 \\
\hline 5 & $2,83 d(9,6)$ & 66,6 & 59,8 (C-4); 80,3 (C-6); 17,4 (C-15) & 66,6 \\
\hline 6 & $4,61 d d(9,6)$ & 80,3 & $51,0(C-7)$ & 80,3 \\
\hline 7 & $3,19 d d d d(2,5 ; 3,0 ; 3,5 ; 9,6)$ & 51,0 & $\begin{array}{c}69,8(\mathrm{C}-8) ; 133,0(\mathrm{C}-11) ; 169,1(\mathrm{C}-12) ; 125,4 \\
(\mathrm{C}-13)\end{array}$ & 51,0 \\
\hline 8 & $4,70 d d(2,5 ; 10,1)$ & 69,8 & $48,1(C-9)$ & 69,8 \\
\hline $9 \alpha$ & $1,77 d d(10,1 ; 13,8)$ & 48,1 & 58,9 (C-10); 18,6 (C-14) & 48,1 \\
\hline $9 \beta$ & $2,53 d d l(13,8)$ & - & - & - \\
\hline 10 & - & 58,9 & - & 58,9 \\
\hline 11 & - & 133,0 & - & 133,0 \\
\hline 12 & - & 169,1 & - & 169,1 \\
\hline $13 a$ & $5,62 d(3,0)$ & 125,4 & 133,0 (C-11); 169,1 (C-12) & 125,4 \\
\hline $13 b$ & $6,30 d(3,5)$ & - & - & - \\
\hline 14 & $1,46 s(3 \mathrm{H})$ & 18,6 & - & 18,6 \\
\hline 15 & $1,44 s(3 \mathrm{H})$ & 17,4 & - & 17,4 \\
\hline $1^{\prime}$ & - & 167,4 & - & 167,4 \\
\hline $2^{\prime}$ & - & 126,8 & - & 126,8 \\
\hline $3^{\prime}$ & $6,14 d q(1,8 ; 3,5)$ & 141,3 & $\begin{array}{c}\left.167,4\left(\mathrm{C}-1^{\prime}\right) ; 126,8 \mathrm{C}-2^{\prime}\right) ; 16,2\left(\mathrm{C}-4^{\prime}\right) ; 20,6 \text { (C- } \\
\left.5^{\prime}\right)\end{array}$ & 141,3 \\
\hline $4^{\prime}$ & $1,85 d(3 \mathrm{H} ; 1,8)$ & 16,2 & - & 16,2 \\
\hline $5^{\prime}$ & $1,93 d(3 \mathrm{H} ; 1,8)$ & 20,6 & - & 20,6 \\
\hline
\end{tabular}

Quimitaxonomia e fitoquímica de espécies da tribo Heliantheae (Asteraceae) e uso de Quimioinformática em elucidação estrutural 


\subsection{Elucidação estrutural da substância $1 \beta, 5 \beta, 10 \alpha$-triidróxido-8 $\alpha$-angeloiloxi- germacra-3,11(13)-dien-6 $\alpha, 12$-olido}

A estrutura da substância $1 \beta, 5 \beta, 10 \alpha$-triidróxido-8 $\alpha$-angeloiloxi-germacra-3,11(13)dien-6 $\alpha, 12$-olido foi elucidada através da análise dos espectros de $\mathrm{RMN}{ }^{1} \mathrm{H}$ e ${ }^{13} \mathrm{C}$ (Tabela 18), além de ${ }^{1} \mathrm{H}-{ }^{1} \mathrm{H}$ COSY, HMBC e HMQC e Espectrometria de Massas (EM) de média (ESIMS) e alta resoluções (HRMS). A estrutura desta substância não tinha sido ainda relatada na literatura.

Os dados de ESIMS mostraram um ion $[\mathrm{M}+\mathrm{H}]^{+}$com massa de 381,34 e os dados de HRMS mostraram um íon $\left[\mathrm{M}+\mathrm{H}^{+}\right.$com massa de 381,19078 , massa correspondente à fórmula molecular da estrutura proposta $\left(\mathrm{C}_{20} \mathrm{H}_{28} \mathrm{O}_{7}\right)$. A partir da comparação dos dados de RMN mono e bidimensionais desta substâncias com os da substância discutida anteriormente, concluiu-se que trata-se também de uma LSTs ambas são idênticas no anel lactônico, nas posições do esqueleto que vão de seis a nove e que também possuem o mesmo éster. Dessa maneira, esta LST possui a estrutura parcial a seguir:

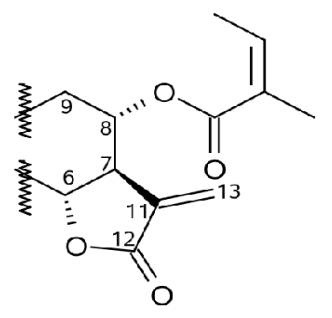

O acoplamento observado entre um $d d$ em $\delta 4,43(J=3,4 ; 10,6 \mathrm{~Hz})$, que foi atribuído ao $\mathrm{H}-6$, e um $d l$ em $\delta 4,95(J=3,4 \mathrm{~Hz})$, permitiu a atribuição deste último sinal ao $\mathrm{H}-5$. Observando-se o espectro de RMN ${ }^{1} \mathrm{H}-{ }^{1} \mathrm{H}$ COSY nota-se que o $\mathrm{H}-5$ acopla com $\mathrm{H}-6(\mathrm{~J}=3,4$ $\mathrm{HZ}$ ) e com um sl em $\delta 1,67(3 \mathrm{H})$, que foi atribuído ao H-15. Osinal atribuído ao H-5 também 
acopla com um sinal em $\delta 78,8$ no espectro HMQC, sinal que foi atribuído ao C-5. este sinal é típico de carbonos ligados a oxigênios $\mathrm{sp}^{3}$, o que infere a presença de um grupo -OH ligado ao C-5. A presença de uma correlação no espectro HMBC de $\mathrm{H}-5$ com um sinal em $\delta$ 134,2, que por sua correlaciona-se com o sinal atribuído ao $\mathrm{H}-15$, permite atribuir o sinal em $\delta 134,2$ ao C-4 confirma a presença de uma dupla ligação em C-4. Notou-se também a presença no espectro de $\mathrm{RMN}{ }^{13} \mathrm{C}$ de mais dois sinais, sendo um em $\delta 125,4$ e outro em $\delta$ 134,2, sinais típicos de carbono sp². Osinal atribuído ao C-4 acopla ainda com um $d d$ em $\delta$ $5,40(J=3,8 ; 5,0)$, tipíco de hidrogênios ligados a carbono $\mathrm{sp}^{2}$. Este sinal foi atribuído ao $\mathrm{H}$ 3, sendo que o espectro HMBC mostra o acoplamento de $\mathrm{H}-3$ um sinal em $\delta 125,4$, que foi imediatamente atribuído ao C-3. Dessa forma, conclui-se que esta substância possui uma hidroxila em C-5, cuja estereoquímica foi determinada através da constante de acoplamento entre H-5 e H-6; e uma dupla ligação entre C-3 e C-5, de modo que temos a seguinte estrutura parcial:

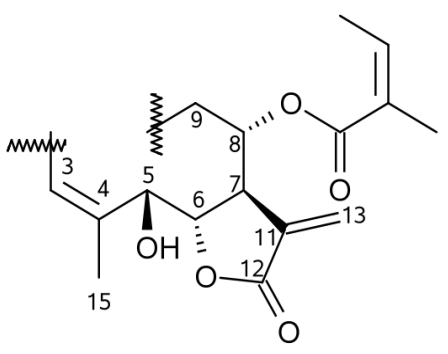

O espectro ${ }^{1} \mathrm{H}-{ }^{1} \mathrm{H}$ COSY mostrou a correlação do sinal de $\mathrm{H}-3$ com dois $d d d$, um em $\delta 2,72(J=2,3 ; 3,8 ; 11,4)$ e outro em $\delta 2,72(J=5,0 ; 9,8 ; 11,4)$, esses sinais se correlacionam com um sinal em $\delta 31,4$ no espectro HMQC. Esses sinais são de um grupo $-\mathrm{CH}_{2}$ - e foram atribuídos aos $\mathrm{H}-2$ e ao $\mathrm{C}-2$. Os sinais atribuídos aos $\mathrm{H}-2$, por sua vez acoplam com um $d d l$ em $\delta 4,26(J=2,3 ; 9,8)$, que foi atribuído ao H-1. O espectro HMQC mostra que o sinal de $\mathrm{H}-1$ um sinal em $\delta 73,6$, o qual é típico de carbonos pertencentes a sistemas - $\mathrm{COH}-$, o que permite concluir que há a presença de um hidroxila ligada ao C-1. Observa-se no espectro de HMBC uma correlação de $\mathrm{H}-1$ com um sinal em $\delta 74,0$, que 
também pertence a sistemas - $\mathrm{COH}-$, e que por sua vez, mostra um acoplamento com um $s$ em $\delta 1,26(3 \mathrm{H})$ atribuído aos $\mathrm{H}$-14. Essa informação permitiu atribuir o sinal em $\delta 74,0$ ao C-10 e o sinal em $\delta 24,1$ ao C-14, uma vez que este sinal acopla com o sinal de $\mathrm{H}-14$ (HMQC). Baseando-se em todas as informações apresentadas, foi possível chegar à estrutura final desta LST:

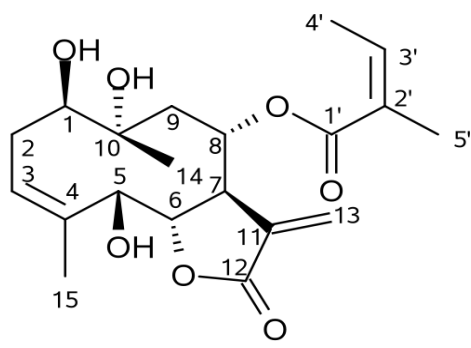

Tabela 18 - Dados de RMN ${ }^{1} \mathrm{H}(400 \mathrm{MHz})$ e ${ }^{13} \mathrm{C}(100 \mathrm{MHz})$ para a substância $1 \beta, 5 \beta, 10 \alpha-$ triidróxido-8 $\alpha$-angeloiloxi-germacra-3,11(13)-dien-6 $\alpha, 12$-olido $\left(\mathrm{CDCl}_{3}\right)$

\begin{tabular}{|c|c|c|c|c|c|}
\hline Pos, & $\delta \mathrm{H}$ & $\delta C$ & COSY & HMBC & HMQC \\
\hline 1 & $4,26(2,3 ; 9,8) \mathrm{br} d d$ & 73,6 & $\begin{array}{c}2,72(\mathrm{H}-2 \mathrm{a}) ; 2,76(\mathrm{H}- \\
2 \mathrm{~b})\end{array}$ & 73,6 & $\begin{array}{c}74,0 \text { (C-10); } 31,4 \text { (C- } \\
2)\end{array}$ \\
\hline $2 a$ & $\begin{array}{c}2,72(2,3 ; 3,8 ; 11,4) \mathrm{br} \\
\text { ddd }\end{array}$ & 31,4 & $\begin{array}{c}2,76(\mathrm{H}-2 \mathrm{~b}) ; 4,26(\mathrm{H}- \\
\text { 1); 5,70 (H-3); }\end{array}$ & 31,4 & $\begin{array}{c}125,4 \text { (C-3); } 134,2 \\
\text { (C-4) }\end{array}$ \\
\hline $2 b$ & $\begin{array}{c}2,76(9,8 ; 5,0 ; 11,4) \mathrm{br} \\
\text { ddd }\end{array}$ & - & $\begin{array}{c}2,72(\mathrm{H}-2 \mathrm{a}) ; 4,26(\mathrm{H}- \\
1) ; 5,70(\mathrm{H}-3)\end{array}$ & 31,4 & $\begin{array}{c}125,4(\mathrm{C}-3) ; 134,2 \\
\text { (C-4) }\end{array}$ \\
\hline 3 & $5,70(3,8 ; 5,0) d d$ & 125,4 & $\begin{array}{c}2,72(\mathrm{H}-2 \mathrm{a}) ; 2,76(\mathrm{H}- \\
2 \mathrm{~b})\end{array}$ & 125,4 & - \\
\hline 4 & - & 134,2 & - & - & - \\
\hline 5 & $4,95(3,4) b r d$ & 78,8 & 1,67 (H-15); 4,43 (H-6) & 78,8 & $\begin{array}{l}22,7(\mathrm{C}-15) ; 81,6(\mathrm{C}- \\
\text { 6); } 134,2(\mathrm{C}-4)\end{array}$ \\
\hline 6 & $4,43(3,4 ; 10,6) d d$ & 81,6 & 3,60 (H-7); 4,95 (H-5) & 81,6 & - \\
\hline 7 & $\begin{array}{c}3,60(3,3 ; 3,5 ; 5,6 ; \\
10,6) \text { dddd }\end{array}$ & 45,6 & $\begin{array}{c}\text { 4,43 (H-6); 5,38 (H-8); } \\
5,62(\mathrm{H}-13 a) ; 6,25(\mathrm{H}- \\
13 \mathrm{~b})\end{array}$ & 45,6 & $\begin{array}{l}\text { 43,5 (C-9); 71,6 (C- } \\
\text { 8); 122,2 (C-13) }\end{array}$ \\
\hline 8 & $5,38(5,6 ; 8,6 ; 9,0) d d d$ & 71,6 & $\begin{array}{c}2,17(\mathrm{H}-9 \mathrm{a}) ; 2,37(\mathrm{H}- \\
9 b) ; 3,60(\mathrm{H}-7)\end{array}$ & 71,6 & - \\
\hline $9 a$ & $2,17(8,6 ; 16,4) \mathrm{dd}$ & 43,5 & 2,37 (H-9b); 5,38 (H-8) & 43,5 & - \\
\hline $9 b$ & $2,37(9,0 ; 16,4) \mathrm{dd}$ & - & 2,17 (H-9a); 5,38 (H-8) & 43,5 & - \\
\hline 10 & - & 74,0 & - & - & - \\
\hline
\end{tabular}


Tabela 18 - Dados de RMN ${ }^{1} \mathrm{H}(400 \mathrm{MHz})$ e ${ }^{13} \mathrm{C}(100 \mathrm{MHz})$ para a substância $1 \beta, 5 \beta, 10 \alpha-$ triidróxido-8 $\alpha$-angeloiloxi-germacra-3,11(13)-dien-6 $\alpha$,12-olido $\left(\mathrm{CDCl}_{3}\right)$ (continuação)

\begin{tabular}{|c|c|c|c|c|c|}
\hline Pos, & $\delta \mathrm{H}$ & $\delta C$ & COSY & HMBC & HMQC \\
\hline 11 & - & $\mathrm{n}, \mathrm{o}$ & - & - & - \\
\hline 12 & - & $\mathrm{n}, \mathrm{o}$ & - & - & - \\
\hline $13 a$ & $5,62(3,3) d$ & 122,2 & 3,60 (H-7) & 122,2 & 45,6 (C-7) \\
\hline $13 b$ & $6,25(3,5) d$ & & 3,60 (H-7) & 122,2 & 45,6 (C-7) \\
\hline 14 & $1,26(3 \mathrm{H}) \mathrm{s}$ & 24,1 & - & 24,1 & $\begin{array}{c}73,6(\mathrm{C}-1) \\
74,0 \text { (C-10); } \\
43,5(\mathrm{C}-9)\end{array}$ \\
\hline 15 & $1,67(3 \mathrm{H}) \mathrm{s}$ & 22,7 & 4,95 (H-5) & 22,7 & $\begin{array}{l}125,4(C-3) \\
134,2(C-4)\end{array}$ \\
\hline $1^{\prime}$ & - & $\mathrm{n}, \mathrm{o}$, & - & - & - \\
\hline $2^{\prime}$ & - & 139,2 & - & - & - \\
\hline $3^{\prime}$ & $\begin{array}{c}6,18(1,3 ; 3,3) \\
d q\end{array}$ & 125,8 & $\begin{array}{l}\text { 1,93 (H-4'); } \\
\text { 2,03 (H-5') }\end{array}$ & 125,8 & 139,2 (C-2’) \\
\hline $4^{\prime}$ & $\begin{array}{c}1,93(3 \mathrm{H} ; 1,3) \\
\mathrm{d}\end{array}$ & 15,8 & 6,18 (H-3’) & 15,8 & - \\
\hline 5 & $\frac{2,03(3 \mathrm{H} ; 1,3)}{\mathrm{d}}$ & 20,4 & 6,18 (H-3’) & 20,4 & - \\
\hline
\end{tabular}

\subsubsection{Estudo fitoquímico de Dimerostemma rotundifolium}

Dois eudesmanolidos foram isolados do extrato bruto das folhas de Dimerostemma rotundifolium Blake. Após o fracionamento do extrato, foram isolados 15 mg (Fração 3.4) do eudesmanolido $1 \alpha$-epoxiangeloilóxi-8 $\alpha$-hidróxi-4,15 $\alpha$-epóxi-eudesm-11,13-en-6 $\alpha, 12$-olido (5) (BOHLMANNI et al., 1981a), também foram isolados 4 mg (Fração 4.2.4) do eudesmaolido

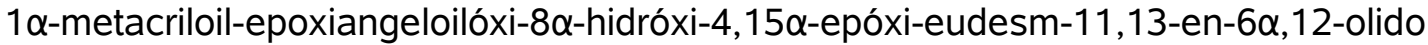
sendo que este último ainda não foi descrito na literatura. As estruturas das substâncias foram elucidadas através de $\mathrm{RMN}{ }^{1} \mathrm{H}$ e ${ }^{13} \mathrm{C}$, além de técnicas bidimensionais. 


\subsection{Elucidação estrutural da substância $1 \alpha$-epoxiangeloilóxi-8 $\alpha$-hidróxi-4,15 $\alpha$ - epóxi-eudesm-11,13-en-6 $\alpha, 12$-olido}

A estrutura da substância $1 \alpha$-epoxiangeloilóxi-8 $\alpha$-hidróxi-4,15 $\alpha$-epóxi-eudesm-11,13en-6 $\alpha, 12$-olido foi elucidada através da análise dos espectros de $\mathrm{RMN}{ }^{1} \mathrm{H}$ e ${ }^{13} \mathrm{C}$ (Tabela 19), além de HMBC e HMQC. A comparação dos dados de RMN da amostra com dados presentes na literatura (BOHLMANN et al., 1981b) também auxiliou no processo de elucidação estrutural desta substância, pois esta substância foi isolada anteriormente de Dimerostemma asperatum.

A presença de dois $d d$, um observado em $\delta 5,98(J=0,3 ; 3,03 \mathrm{~Hz})$ e outro em $\delta 6,13$ $(J=0,3 ; 3,03)$ são atribuídos a sinais típicos de hidrogênios olefínicos chamados $H-13$, presentes em duplas exocíclicas em $\gamma$-trans-lactonas. $\mathrm{O}$ acoplamento geminal observado entre os dois $\mathrm{H}-13$ ocorre apenas em 6,12 -lactonas- $\alpha, \beta$ insaturadas com a presença de um grupamento $-\mathrm{OH}$ na posição 8. A estereoquímica do grupamento hidroxila é determinada, ainda, pela própria constante de acoplamento geminal $(0,3 \mathrm{~Hz})$ que ocorre entre os $\mathrm{H}-13$, pois o efeito de aproximação de Van der Waals que ocorre entre a hidroxila em alfa e os $\mathrm{H}-13$ provoca tal acoplamento geminal. Se a hidroxila tivesse configuração relativa beta, tal acoplamento não seria observado (Yoshioka et al., 1971). A presença da hidroxila em C-8 é ainda evidenciada pelo deslocamento químico de um $d d d$ em $\delta 3,99(\mathrm{~J}=$ 4,85; 6,06; $11,11 \mathrm{~Hz}$ ) atribuído ao $\mathrm{H}-8$, que é típico de hidrogênios ligados a átomos carbinólicos. A estereoquímica do anel lactônico foi determinada da mesma maneira que as anteriores. A correlação que foi observada no espectro HMQC entre o sinal atribuído ao H-8 e um sinal em $\delta 75,8$, permitiu atribuir este sinal ao C-8. O espectro de HMBC, por sua vez, mostrou uma correlação entre o C-8 e um dddd em $\delta$ 2,52 (3,03; 3,03; 6,06; 10,35 Hz); este sinal foi atribuído ao $\mathrm{H}-7$, devido às constantes de acoplamento apresentadas, acoplando tanto com H-8 $(J=6,06 \mathrm{~Hz})$ e com ambos $\mathrm{H}-13(\mathrm{~J}=3,03 \mathrm{~Hz})$. A análise do espectro ${ }^{1} \mathrm{H}-{ }^{1} \mathrm{H}$ COSY permitiu observar um acoplamento adicional do H-7 com um $d d$ em $\delta$ 3,86 $(J=9,6$;

$\overline{\text { Quimitaxonomia e fitoquímica de espécies da tribo Heliantheae (Asteraceae) e uso de Quimioinformática em elucidação estrutural }}$ 
10,3), que foi atribuído ao H-6. O acoplamento adicional de $\mathrm{H}-6$ com um $d$ em 2,41 $(J=9,6)$, permitiu atribuir em $d$ ao $\mathrm{H}-5$.

Estas informações permitiram propor a seguinte estrutura parcial para esta substância:

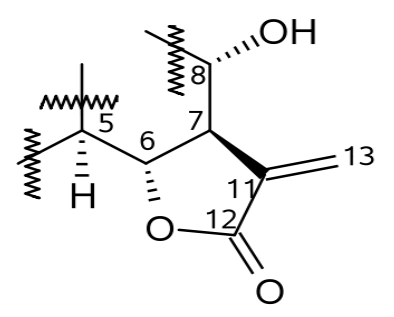

A comparação dos dados de $\mathrm{RMN}{ }^{1} \mathrm{H}$ desta substância com os dados presentes na literatura permitiu atribuir os dois $d d$ existentes em $\delta 1,85(J=11,11 ; 15,25 \mathrm{~Hz})$ e em $\delta 1,92$ $(J=4,85 ; 15,25 \mathrm{~Hz})$ aos $\mathrm{H}-9$.

A observação de uma correlação existente no espectro HMBC entre o H-5 e um sinal em $\delta 41,3$, que por sua vez se correlaciona com os $\mathrm{H}-9$, permitiu atribuir o sinal em $\delta 41,3$ ao C-10. Esses dados também corroboram a existência de uma ligação sp ${ }^{3}$ entre C-5 e C-10 e permitem concluir que esta substância é uma LST do tipo eudesmanolido. A partir dos dados da literatura, o s em $\delta 1,10(3 \mathrm{H})$ foi atribuído ao $\mathrm{H}-14$.

Duas correlações do sinal atribuído ao H-5 que foram mostradas no espectro HMBC, sendo uma com um um sinal em $\delta 60,5$ e outra com um sinal em $\delta 54,3$, ambos sinais típicos de sistemas epóxidos, despertou a suspeita da existência de um epóxido na molécula. Uma comparação com os dados na literatura confirmou a presença deste sistema. No caso específico desta molécula, existe um $d$ em $\delta 2,89(J=3,28 \mathrm{~Hz})$, que foi atribuído ao $\mathrm{H}-15 \mathrm{a}$, acoplando com um $d d$ em $\delta 3,22(\mathrm{~J}=2,02 ; 3,28 \mathrm{~Hz})$ que foi atribuído ao $\mathrm{H}-15 \mathrm{~b}$. A menor constante de acoplamento deste sinal $(2,02 \mathrm{~Hz})$ é atribuída ao acoplamento com um $m$ presente em $\delta 1,98$ que foi atribuído aos dois $\mathrm{H}-3$. A estereoquímica relativa do epóxido em beta foi determinada através do deslocamento químico do sinal atribuído ao $\mathrm{H}-5$ ( $\delta 2,42$ $d J=9,8 \mathrm{~Hz}$ ) pois comparando-se com dados presentes na literatura, nota-se que quando 
epóxido tem configuração relativa alfa, o sinal de H-5 é observado entre $\delta$ 2,52 e 2,65.

Esta substância é um eudesmanolido de um tipo peculiar, encontrado apenas no gênero Dimerostemma e é conhecido como dimerostemmolido. Esse esqueleto se caracteriza por no lugar da presença de um grupo metila no C-15, haver um grupamento epóxido, ora com configuração alfa, ora com configuração beta entre o C-4 e o C-15. O C-15 é um grupo metileno e os sinais de $\mathrm{H}-15$ apareçam em uma região de maior desblindagem, devido à presença deste grupamento epóxido. Os dois H-15 deste sistema se caracterizam como um $d$ em torno de $\delta 2,8$ a 3,0 correspondente ao H15b, e como um $d d$ entre $\delta 3,0$ e 3,2 que por sua vez corresponde ao H-15a. Desse modo, a partir dos dados de RMN da amostra e comparações com a literatura, chegamos à seguinte estrutura parcial para este substância:

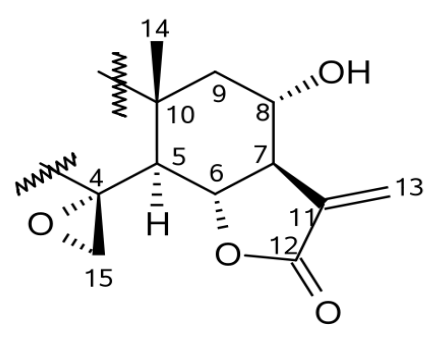

A existência de uma correlação de C-10 com um dd em $\delta 4,81(J=2,78 ; 2,53 \mathrm{~Hz})$, que foi atribuído ao H-1 e cujo deslocamento químico é típico de hidrogênios ligados a grupo -COR-, sugere a presença em C-1 de um grupo oxigenado maior que uma simples hidroxila, provavelmente um éster, devido ao deslocamento químico observado para $\mathrm{H}-1$, bem maior do que o observado para H-8. Além disso, a correlação observada no espectro HMQC entre o $\mathrm{H}-1$ e um sinal em $\delta 76,1$, permitiu atribuir este sinal ao C-1.

Foi verificada a presença de um $q$ em $\delta 3,11(J=5,3 \mathrm{~Hz})$ que acopla com um $d$ integrado para $3 \mathrm{H}$ em $\delta 1,35(J=5,3 \mathrm{~Hz})$, sendo que o deslocamento químico desse $q$ é típico de hidrogênios ligados a carbonos de epóxidos, o que sugere a presença de um grupamento epóxido diferente daquele observado anteriormente na molécula entre C4 e C15. Existe ainda um s integrado para $3 \mathrm{H}$ em $\delta 1,65$, sendo que este sinal é típico de grupos 
metilas ligados a carbonos carbinólicos. Esses sinais observados são típicos de epoxiangelato, um grupamento que ocorre tipicamente em LSTs, o que permitir confirmar a presença deste éster na molécula. Devido ao deslocamentos químicos de $\mathrm{C}-1$ e $\mathrm{H}-1$, conclui-se que o éster estava ligado em C-1.

A orientação do éster em C-1 foi determinada através de experimento NOE-diff. A irradiação do sinal atribuído ao $\mathrm{H}-1$ provocou um aumento da intensidade do sinal que foi atribuído aos H-14. Como essa metila tem orientação relativa beta, chega-se à conclusão que o éster tem configuração relativa alfa, pois do contrário, não haveria aumento na intensidade do sinal. Os sinais de $\mathrm{H}-2, \mathrm{H}-3, \mathrm{C}-2$ e $\mathrm{C}-4$ foram atribuídos através da comparação com os dados presentes na literatura, dessa forma, a estrutura proposta para esta substância é:

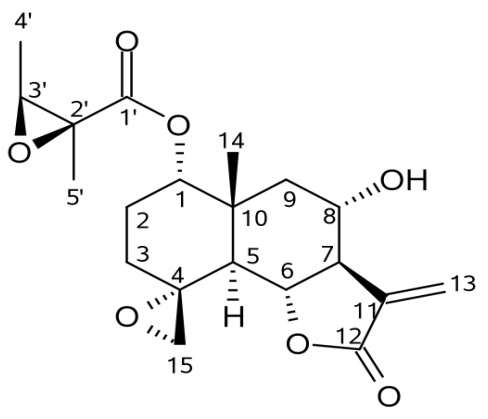

Tabela 19 - Dados de RMN ${ }^{1} \mathrm{H}(400 \mathrm{MHz})$ e ${ }^{13} \mathrm{C}(100 \mathrm{MHz})$ para a substância $1 \alpha-$ epoxiangeloilóxi-8 $\alpha$-hidróxi-4,15 $\alpha$-epóxi-eudesm-11,13-en-6 $\alpha, 12$-olido $\left(\mathrm{CDCl}_{3}\right)$

\begin{tabular}{|c|c|c|c|c|c|}
\hline Pos. & $\delta \mathrm{H}$ & $\delta C$ & $\cos Y$ & HMBC & $H M Q C$ \\
\hline 1 & $4.81 d d(2,53 ; 2,78)$ & 76,1 & $1,97(\mathrm{H}-2)$ & $\begin{array}{l}41,3(\mathrm{C}-10) \\
1,1(\mathrm{C}-14) \\
45,3(\mathrm{C}-2)\end{array}$ & 76,1 \\
\hline 2 & $1,97 m$ & 45,3 & 4,81 (H-1); 1,98 (H-3) & $\begin{array}{l}76,1(\mathrm{C}-1) \\
25,2(\mathrm{C}-3) \\
60,12(\mathrm{C}-4)\end{array}$ & 45,3 \\
\hline 3 & $1,98 m$ & 25,2 & $\begin{array}{l}1,97(\mathrm{H}-2) ; 3,22(\mathrm{H}- \\
15 a)\end{array}$ & $\begin{array}{l}60,12(C-4) \\
54,3(C-15)\end{array}$ & 25,2 \\
\hline
\end{tabular}


Tabela 19 - Dados de RMN ${ }^{1} \mathrm{H}(400 \mathrm{MHz})$ e ${ }^{13} \mathrm{C}(100 \mathrm{MHz})$ para a substância $1 \alpha-$ epoxiangeloilóxi-8 $\alpha$-hidróxi-4,15 $\alpha$-epóxi-eudesm-11,13-en-6 $\alpha, 12$-olido $\left(\mathrm{CDCl}_{3}\right)$ (continuação)

\begin{tabular}{|c|c|c|c|c|c|}
\hline Pos. & $\delta \mathrm{H}$ & $\delta C$ & COSY & HMBC & HMQC \\
\hline 4 & - & 60,1 & - & - & - \\
\hline 5 & $2,41 d(9,6)$ & 47,5 & 3,86 (H-6) & $\begin{array}{l}42,3 \text { (C-10); } \\
54,3 \text { (C-15); } \\
\text { 58,9 (C-6) }\end{array}$ & 47,5 \\
\hline 6 & $3,86 d(9,6)$ & 68,9 & $\begin{array}{l}\text { 2,41 (H-5); } \\
\text { 2,52(H-7) }\end{array}$ & $\begin{array}{l}47,5 \text { (C-5); } \\
53,1 \text { (C-7); } \\
75,1 \text { (C-8); } \\
147,0 \text { (C-11) }\end{array}$ & 68,9 \\
\hline 7 & $\begin{array}{l}2,52 d d d d \\
(3,03 ; 3,03 \\
6,06 ; 10,35)\end{array}$ & 53,1 & $\begin{array}{l}3,86(\mathrm{H}-6) ; \\
3,99(\mathrm{H}-8) ; \\
5,98(\mathrm{H}-13 \mathrm{a}) ; \\
6,13(\mathrm{H}-13 \mathrm{~b})\end{array}$ & $\begin{array}{l}68,9 \text { (C-6); } \\
75,1 \text { (C-8); } \\
\text { 147, } 0 \text { (C-11); } \\
125,1 \text { (C-13) }\end{array}$ & 53,1 \\
\hline 8 & $\begin{array}{l}3,99 \text { ddd } \\
(4,85 ; 6,06 \\
11,11)\end{array}$ & 75,1 & $\begin{array}{l}2,52(\mathrm{H}-7) ; \\
1,92(\mathrm{H}-9 \mathrm{a}) \\
1,85(\mathrm{H}-9 \mathrm{~b})\end{array}$ & $\begin{array}{l}30,8 \text { (C-9); } \\
47,1(C-7)\end{array}$ & 75,1 \\
\hline $9 a$ & $\begin{array}{l}1,92 \text { dd }(4,86 \\
15,25)\end{array}$ & 30,8 & $\begin{array}{l}3,99(\mathrm{H}-8) \\
\text { 1,85 (H-9b) }\end{array}$ & $\begin{array}{l}41,3 \text { (C-10); } \\
20,1 \text { (C-14); } \\
75,1 \text { (C-8) }\end{array}$ & 30,8 \\
\hline $9 b$ & $\begin{array}{l}1,85 \mathrm{dd} \\
(11,11, \\
15,25)\end{array}$ & - & $\begin{array}{l}\text { 3,99 (H-8); } \\
\text { 1,92 (H-9a) }\end{array}$ & - & - \\
\hline 10 & - & 41,3 & - & - & - \\
\hline 11 & - & 147,0 & - & - & - \\
\hline 12 & - & 170,5 & - & - & - \\
\hline $13 a$ & $\begin{array}{l}6,13 \text { dd }(0,3 \\
3,03)\end{array}$ & 125,1 & $\begin{array}{l}5,98(\mathrm{H}-13 \mathrm{~b}) ; \\
2,52(\mathrm{H}-7)\end{array}$ & $\begin{array}{l}170,1(\mathrm{C}- \\
123) ; 147,0 \\
(\mathrm{C}-11) ; 53,1 \\
(\mathrm{C}-7)\end{array}$ & 125,1 \\
\hline $13 b$ & $\begin{array}{l}5,98 \text { dd }(0,3 \\
3,3)\end{array}$ & - & $\begin{array}{l}\text { 6,13 (H-13a); } \\
2,52(\mathrm{H}-7)\end{array}$ & - & - \\
\hline 14 & $1,1 \mathrm{~s}$ & 20,1 & - & $\begin{array}{l}30,8 \text { (C-9); } \\
41,3(\mathrm{C}-10) \\
76,1 \text { (C-1) }\end{array}$ & 20,1 \\
\hline $15 a$ & $\begin{array}{l}3,22 \text { dd }(2,02 \\
3,28)\end{array}$ & 54,3 & $\begin{array}{l}2,89(\mathrm{H}-15 b) ; \\
1,98(\mathrm{H}-3)\end{array}$ & $\begin{array}{l}60,1(\mathrm{C}-4) ; \\
25,2(\mathrm{C}-3)\end{array}$ & 54,3 \\
\hline
\end{tabular}


Tabela 19 - Dados de RMN ${ }^{1} \mathrm{H}(400 \mathrm{MHz})$ e ${ }^{13} \mathrm{C}(100 \mathrm{MHz})$ para a substância $1 \alpha-$ epoxiangeloilóxi-8 $\alpha$-hidróxi-4,15 $\alpha$-epóxi-eudesm-11,13-en-6 $\alpha, 12$-olido $\left(\mathrm{CDCl}_{3}\right)$ (continuação)

\begin{tabular}{llllll}
\hline Pos. & SH & SC & COSY & HMBC & HMQC \\
\hline $15 b$ & $2,89 d(3,28)$ & - & $3,22(\mathrm{H}-15 a)$ & - & - \\
$1^{\prime}$ & - & 166,8 & - & - & - \\
$2^{\prime}$ & - & 61,2 & - & - & - \\
$3^{\prime}$ & $1,65 \mathrm{~s}$ & 59,7 & - & $61,2\left(\mathrm{C}-2^{\prime}\right)$ & 59,7 \\
$4^{\prime}$ & $1,35 \mathrm{~d}(5,3)$ & 16,5 & $3,12\left(\mathrm{H}-5^{\prime}\right)$ & - & 16,5 \\
$5^{\prime}$ & $3,12 \mathrm{q} \mathrm{(5,3)}$ & 18,3 & $1,35\left(\mathrm{H}-4^{\prime}\right)$ & - & 18,3 \\
\hline
\end{tabular}

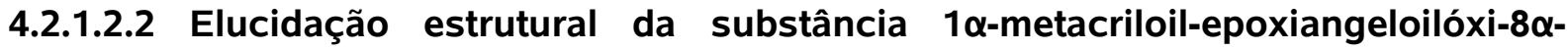 hidróxi-4,15 $\alpha$-epóxi-eudesm-11,13-en-6 $\alpha, 12$-olido}

A estrutura da substância $1 \alpha$-metacriloil-epoxiangeloilóxi-8 $\alpha$-hidróxi-4,15 $\alpha$-epóxieudesm-11,13-en-6 $\alpha, 12$-olido foi elucidada através da análise dos espectros de RMN ${ }^{1} \mathrm{H}$ e ${ }^{13} \mathrm{C}$ (Tabela 20), além de ${ }^{1} \mathrm{H}-{ }^{1} \mathrm{H}$ COSY, HMBC e HMQC e Espectrometria de Massas (EM) de média (ESIMS) e alta resoluções (HRMS). A estrutura desta substância não tinha sido ainda relatada na literatura.

Os dados de ESIMS mostraram um ion $[\mathrm{M}+\mathrm{H}]^{+}$com massa de 449,12 e os dados de HRMS mostraram um íon [M + H $]^{+}$com massa de 449,1546 massa correspondente à fórmula molecular da estrutura proposta $\left(\mathrm{C}_{23} \mathrm{H}_{30} \mathrm{O}_{9}\right)$.

A comparação dos dados de $\mathrm{RMN}{ }^{1} \mathrm{H}$ de bidimensionais esta substância com os da substância anterior e com os dados da literatura (BOHLMANN et al., 1981a, b) permitiu concluir que esta substância e as substância anterior são muito semelhantes e possuem um esqueleto básico idêntico, tendo a estrutura parcial abaixo:

$\overline{\text { Quimitaxonomia e fitoquímica de espécies da tribo Heliantheae (Asteraceae) e uso de Quimioinformática em elucidação estrutural }}$ 


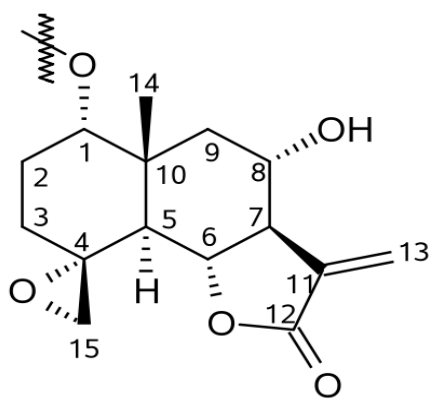

Observando-se o espectro de RMN ${ }^{1} \mathrm{H}$, notou-se que este possuía os sinais típicos do epóxiangelato ( $3,02 q ; 1,65 s 3 \mathrm{H} ; 1,38 d 3 \mathrm{H}$ ). Porém, observa-se no mesmo espectro dois sinais típicos de hidrogênios metilênicos que aparecem no espectro como dois $s l$, sendo um em $\delta 5,8$ e outro em $\delta .6,4$. A existência de correlações no espectro de HMQC destes dois sinais com o mesmo átomo carbono $(\delta 123,5)$ confirma que estes hidrogênios estão ligados ao mesmo carbono. Há a presença ainda, de uma correlação destes hidrogênios com um sinal de carbono $\mathrm{sp}^{2}$ quartenário em $\delta$ 137,1 e com uma carbonila em $\delta$ 168,1, o que levantou a hipótese da existência de um outro éster além do epoxiangelato.

A partir da presença de apenas cinco sinais de carbonos carbinolicos no espectro de $\mathrm{RMN}{ }^{13} \mathrm{C}$, que devem ser atribuídos ao C-8 $(\mathrm{C}-\mathrm{OH}), \mathrm{C}-6$ (anel lactônico), C-4 e C-15 (epóxido) e ao carbono onde estaria ligado ao éster, conclui-se que a molécula possui um sistema de ésteres condensados entre si.

A posição do éster em C-1 foi determinada através da correlação observada no espectro de $\mathrm{HMBC}$ para o sinal atribuído ao $\mathrm{H}-1$ com o sinal atribuído ao C-14 e ao C-10, que por sua vez, se correlaciona com o sinal atribuído ao H-5. Para determinar-se a orientação do éster, levou-se em conta o deslocamento químico de H-5 para esse tipo de esqueleto, pois quando o éster em C-1 possui orientação beta, o deslocamento químico de H-5 fica na faixa entre $\delta 2,25$ e 2,40. Todavia, quando o éster possui orientação alfa, essa faixa passa a ser de $\delta 2,40$ a 2,70. Como o deslocamento químico de H-5 é $\delta$ 2,44, suspeitou-se que a orientação do éster em C-1 era alfa. Esta hipótese foi confirmada pelo acoplamento em $\mathrm{W}$ de $\mathrm{H}-1$ com um $d d d d$ em $\delta 2,21(\mathrm{~J}=1,3 \mathrm{~Hz})$ que foi atribuído ao $\mathrm{H}-3$ alfa 
após inspeção dos espectros HMBC e HMQC. Assim, chegou-se à seguinte proposta de estrutura para esta substância:

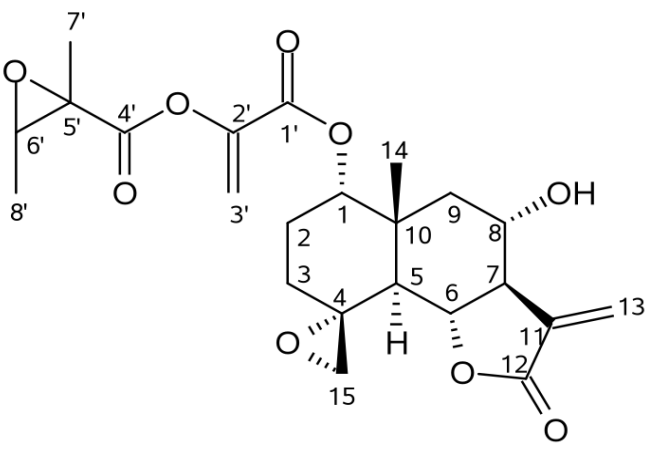

Tabela 20 - Dados de $\mathrm{RMN}{ }^{1} \mathrm{H}(400 \mathrm{MHz})$ e ${ }^{13} \mathrm{C}(100 \mathrm{MHz})$ para a substância $1 \alpha-$ metacriloil-epoxiangeloilóxi-8 $\alpha$-hidróxi-4,15 $\alpha$-epóxi-eudesm-11,13-en-6 $\alpha, 12$-olido $\left(\mathrm{CDCl}_{3}\right)$

\begin{tabular}{|c|c|c|c|c|c|}
\hline Pos. & $\delta \mathrm{H}$ & $\delta C$ & COSY & HMBC & HMQC \\
\hline 1 & $4,8 d d d d(1,3 ; 3,0 ; 5,6 ; 9,0)$ & 75,8 & $2,13(\mathrm{H}-2)$ & $\begin{array}{l}41,3(\mathrm{C}-10) \\
1,1(\mathrm{C}-14) \\
45,1(\mathrm{C}-2)\end{array}$ & 75,8 \\
\hline 2 & $2,13 m$ & 45,1 & 4,8 (H-1); 2,08 (H-3) & $\begin{array}{l}75,8(C-1) \\
25,6(C-3) \\
60,1(C-4)\end{array}$ & 45,1 \\
\hline 3 & $2,08 m$ & 25,6 & $\begin{array}{l}2,13(\mathrm{H}-2) ; 3,22(\mathrm{H}- \\
15 \mathrm{a})\end{array}$ & $\begin{array}{l}60,1(\mathrm{C}-4) \\
54,3(\mathrm{C}-15)\end{array}$ & 25,6 \\
\hline 4 & - & 60,1 & - & - & - \\
\hline 5 & $2,44 d(9,8)$ & 47,5 & 3,98 (H-6) & $\begin{array}{l}41,3(\mathrm{C}-10) \\
53,8(\mathrm{C}-15) \\
68,3(\mathrm{C}-6)\end{array}$ & 47,5 \\
\hline 6 & $3,98 d d(9,8)$ & 68,3 & 2,44 (H-5); 2,54 (H-7) & $\begin{array}{l}\text { 47,5 (C-5); } \\
54,8 \text { (C-7); } \\
\text { 75,3 (C-8); } \\
\text { 147,0 (C-11) }\end{array}$ & 68,3 \\
\hline 7 & $2,54 d d d d(3,03 ; 3,03 ; 6,6 ; 9,8)$ & 54,8 & $\begin{array}{l}3,98(\mathrm{H}-6) ; 4,05(\mathrm{H}-8) \\
5,98(\mathrm{H}-13 \mathrm{a}) ; 6,13(\mathrm{H}- \\
13 \mathrm{~b})\end{array}$ & $\begin{array}{l}68,9(\mathrm{C}-6) ; \\
75,1(\mathrm{C}-8) ; \\
\text { 147, } 0 \text { (C-11); } \\
\text { 124,5 (C-13) }\end{array}$ & 54,8 \\
\hline
\end{tabular}


Tabela 20 - Dados de $\mathrm{RMN}{ }^{1} \mathrm{H}(400 \mathrm{MHz})$ e ${ }^{13} \mathrm{C}(100 \mathrm{MHz})$ para a substância $1 \alpha-$ metacriloil-epoxiangeloilóxi-8 $\alpha$-hidróxi-4,15 $\alpha$-epóxi-eudesm-11,13-en-6 $\alpha, 12$-olido (continuação)

\begin{tabular}{|c|c|c|c|c|c|}
\hline \multicolumn{2}{|c|}{ Pos. $\delta \mathrm{H}$} & $\delta C$ & COSY & HMBC & HMQC \\
\hline 8 & $\begin{array}{l}4,05 d d d(5,5 \\
\quad 6,6 ; 8,8)\end{array}$ & 75,3 & $\begin{array}{l}2,52(\mathrm{H}-7) ; 1,92(\mathrm{H}-9 \mathrm{a}) \\
1,85(\mathrm{H}-9 \mathrm{~b})\end{array}$ & $\begin{array}{l}30,8 \text { (C-9); } \\
54,8 \text { (C-7) }\end{array}$ & 75,3 \\
\hline $9 a$ & $\begin{array}{c}1,88 d d(5,5 \\
10,5)\end{array}$ & 30,8 & 4,05 (H-8); 1,96 (H-9b) & $\begin{array}{l}41,3 \text { (C-10); 20,1 (C-14); } \\
75,3 \text { (C-8) }\end{array}$ & 30,8 \\
\hline $9 b$ & $\begin{array}{c}1,96 d d(6,6 \\
10,5)\end{array}$ & - & 4,05 (H-8); 1,88 (H-9a) & - & - \\
\hline 10 & - & 41,3 & - & - & - \\
\hline 11 & - & 147,0 & - & - & - \\
\hline 12 & - & 170,5 & - & - & - \\
\hline $13 a$ & $\begin{array}{c}6,13 d d(0,3 \\
3,03)\end{array}$ & 124,5 & $5,98(\mathrm{H}-13 \mathrm{~b}) ; 2,52(\mathrm{H}-7)$ & $\begin{array}{l}170,5(\mathrm{C}-12) ; 147,0 \text { (C- } \\
11) ; 54,8(\mathrm{C}-7)\end{array}$ & 124,5 \\
\hline $13 b$ & $\begin{array}{c}5,98 d d(0,3 \\
3,03)\end{array}$ & - & 6,13 (H-13a); 2,54 (H-7) & - & - \\
\hline $4^{\prime}$ & - & 166,8 & - & - & - \\
\hline $5^{\prime}$ & - & 61,2 & - & - & - \\
\hline $6^{\prime}$ & $3,02 q(5,0)$ & 59,7 & $1,18\left(\mathrm{H}-8^{\prime}\right)$ & - & 59,7 \\
\hline $7^{\prime}$ & $1,65 s(3 \mathrm{H})$ & 16,5 & - & - & 16,5 \\
\hline $8^{\prime}$ & $1,18 d(5,0 ; 3 \mathrm{H})$ & 18,3 & $3,02\left(H-6^{\prime}\right)$ & - & 18,3 \\
\hline
\end{tabular}

\subsubsection{Estudo fitoquímico de espécies do gênero Ichthyothere}

O gênero Ichthyothere Spreng. (Asteraceae, Melampodinae) é um gênero formado por 25 espécies nativas da América do Sul e Central (Rauscher, 2002). Este gênero se caracteriza pela biossíntese de diterpenóides (Bohlmann et al., 1982), poliacetilenos 
(Cascon et al., 1965), flavonóides (Bohm e Stuessy, 1982) e lactonas sesquiterpênicas ( BOHLMANN et al., 1982). Dentre as LSTs, os melampolidos são o tipo característico deste gênero.

\subsubsection{Estudo fitoquímico da espécie Ichthyothere terminalis}

Dois melampolidos foram isolados do extrato de lavagem foliar de Ichthyothere terminalis Spreng. Após o fracionamento do extrato, foram isolados 8 mg (Fração 4.3) do melampolido enidrina (8) (Inoue et al., 1995; Krishnaswamy e Ramji, 1995), também foram isolados $10 \mathrm{mg}$ (Fração 4.7) do melampolido 2 $\alpha$-hidroxi-longipilina (7) (Bohlmann et al., 1982). Por tratar-se de substâncias amplam ente descritas na literatura, as estruturas das substâncias foram elucidadas através de $\mathrm{RMN}{ }^{1} \mathrm{H}$ e comparação com dados da literatatura.

\subsection{Elucidação estrutura da substância enidrina}

A estrutura da substância enidrina foi elucidada através da análise dos espectros de RMN ${ }^{1} \mathrm{H}$ (Tabela 21). A comparação dos dados de RMN da amostra com dados presentes na literatura (Inoue et al., 1995; Krishnaswamy e Ramji, 1995) também auxiliou no processo de elucidação estrutural desta substância, pois esta substância foi isolada anteriormente de diversos membros da subtribo Melampodinae (Asteraceae, Heliantheae).

Dois $d$, um observado em $\delta 6,34(J=3,5 \mathrm{~Hz})$ e outro em $\delta 5,85(J=3,0 \mathrm{~Hz})$, sinais típicos de hidrogênios ligados a carbono $\mathrm{sp}^{2}$, foram atribuídos aos $\mathrm{H}-13$, presentes em duplas exocíclicas em $\alpha$-metileno- $\gamma$-lactonas. $\mathrm{O}$ acoplamento dos $\mathrm{H}-13$ com um $d d d d$ em $\delta$ 
2,98 $(\mathrm{J}=1,8 ; 3,5 ; 3,5 ; 9,5 \mathrm{~Hz})$, permitiu atribuir este sinal ao $\mathrm{H}-7 . \mathrm{O} \mathrm{H}-7$ por sua vez, acopla com um $d d$ em $\delta 2,98(J=9,5 ; 9,5 \mathrm{~Hz})$ que foi atribuído ao $\mathrm{H}-6$.

A presença do éster epoxiangelato foi determinada através da observação de seus sinais típicos, que estavam presentes no espectro de RMN ${ }^{1} \mathrm{H}(3,02 d[\mathrm{~J}=5,0 \mathrm{~Hz}]$; $1,35 \mathrm{~s}[3 \mathrm{H}] ; 1,18 d[\mathrm{~J}=5,0 \mathrm{~Hz}, 3 \mathrm{H}])$. A posição do éster angelato em $\mathrm{C}-8$ foi determinada através do deslocamento químico de um $d d$ em $\delta 6,72(J=1,8 ; 8,5 \mathrm{~Hz})$ no espectro de RMN ${ }^{1} \mathrm{H}$, que foi atribuído ao $\mathrm{H}-8$, pois apresenta um acoplamento com o sinal que foi atribuído ao $\mathrm{H}-7(\mathrm{~J}=1,8 \mathrm{~Hz})$. Dessa maneira, chegamos à seguinte estrutura parcial para esta substância:

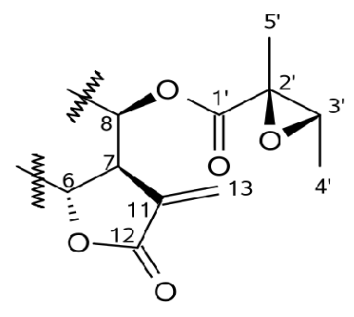

O H-8 apresenta além do acoplamento com H-7, um acoplamento adicional com um $d$ em $\delta 5,86(J=8,5 \mathrm{~Hz})$, que foi atribuído ao H-9. Devido ao deslocamento químico de $H-9$, que encontra-se muito deslindado, suspeito-se que este hidrogênio sofria a influência de um grupo sacador de eletrons. A comparação dos dados de RMN experimental com os dados presentes na literatura, confirma a presença de um grupo acetato ligado ao C-9. A presença do acetato ligado ao C-9 somada à influência do éster ligado ao C-8 justifica o deslocamento químico encontrado para $\mathrm{H}-9$. A presença de um $s$ em $\delta 3,80(3 \mathrm{H})$, típico de metoxilas; aliado à presença de apenas três sinais de outras metilas no espectro de RMN ${ }^{1} \mathrm{H}$, das quais duas pertenciam ao epóxiangelato, permitiu deduzir que umas das metilas do esqueleto terpênico estava funcionalizada. Assim, pela comparação dos dados de RMN da amostra com os dados da literatura, concluiu-se que o C-15 estava funcionalizado como uma carbonila, o que é típico do esqueleto melampolidos. Esses dados tornou possível concluir que havia presença de um grupo $-\mathrm{COOCH}_{3}$ nesta substância, grupo também típico 
de melampolidos e que ajudou a confirmar que esta substância é um melampolido.

O acoplamento adicional de $\mathrm{H}-6$ com um $d$ em $\delta 2,67(J=9,5 \mathrm{~Hz})$, permitiu atribuir este sinal ao $\mathrm{H}-5$. $\mathrm{O} \mathrm{H}-5$ possui um deslocamento químico quie evidencia hidrogênios ligados a carbonos pertencentes a epóxidos, o que infere na presença de um sistema epóxido entre C-4 e C-5. A estereoquímica deste sistema epóxido foi determinada através da comparação com os dados já presentes em literatura.

A partir da informções reunidas até aqui, foi proposta a seguinte estrutura parcial para esta substância:

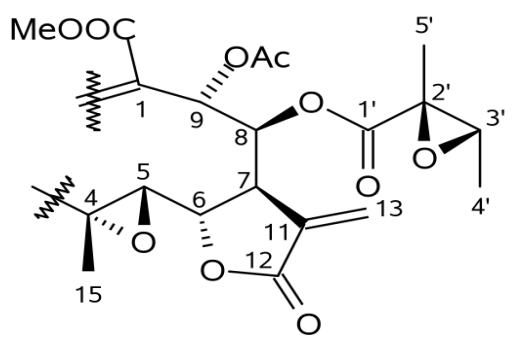

As outras posições 1,2 e 3 desta substância foram atribuídas de uma forma simples, apenas pela comparação dos dados experimentais com os dados presentes na literatura, chegando-se finalmente, à estrutura desta substância:

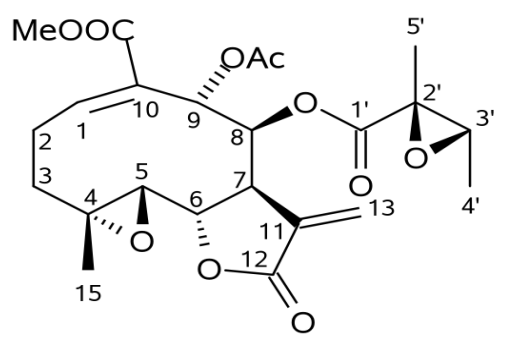


Tabela 21 - Dados de RMN ${ }^{1} \mathrm{H}(400 \mathrm{MHz})$ para a substância enidrina $\left(\mathrm{CDCl}_{3}\right)$

\begin{tabular}{|c|c|}
\hline 1 & 7,15 dd $(6,3 ; 9,7)$ \\
\hline 2 & $2,34 \mathrm{~m} ; 2,45 \mathrm{~m}$ \\
\hline 3 & $2,0 \mathrm{~m}$ \\
\hline 5 & $2,67 d(9,5)$ \\
\hline 6 & $4,27 \mathrm{~d}(9,5)$ \\
\hline 7 & 2,98 dddd $(1,8 ; 3,5 ; 3,5 ; 9,5)$ \\
\hline 8 & 6,72 dd $(1,8 ; 8,5)$ \\
\hline 9 & $5,86 \mathrm{dd}(8,5)$ \\
\hline $13 a$ & $6,34 \mathrm{~d}(3,5)$ \\
\hline $13 b$ & $5,84 \mathrm{~d}(3,5)$ \\
\hline 15 & $1,72 \mathrm{~s}$ \\
\hline OAC & $2,05 \mathrm{~s}$ \\
\hline OMe & $3,80 \mathrm{~s}$ \\
\hline $3^{\prime}$ & $3,02 \mathrm{~d}(5,0)$ \\
\hline $4^{\prime}$ & $1,18 \mathrm{~d}(5,0)$ \\
\hline $5^{\prime}$ & $1,35 \mathrm{~s}$ \\
\hline
\end{tabular}

\subsection{Elucidação estrutura da substância $2 \alpha$-hidróxi-longipilina}

A estrutura da substância $2 \alpha$-hidróxi-longipilina foi elucidada através da análise dos espectros de RMN ${ }^{1} \mathrm{H}$ (Tabela 22). A comparação dos dados de RMN da amostra com dados presentes na literatura (Bohlmann et al., 1982) também auxiliou no processo de elucidação estrutural desta substância, pois esta substância foi isolada anteriormente de $I$. terminalis.

Esta substância e muito semelhante à substância anterior e com parando-se os 
espectros de RMN de ambas, nota-se que possuem o mesmo tipo de esqueleto. Tdavia, uma observação atenta dos dados de RMN mostra ausência dos sinais típicos do epóxidoangelato e a presença de sinais que podem ser atribuídos ao angelato $(6,15 d q$ [ $J=$ 1,8; 3,5]; $1,94 d[3 \mathrm{H} ; J=1,8] ; 1,77 d[3 \mathrm{H} ; J=1,8]$ ). Dessa modo, a estrtura parcial desta substância é seguinte:

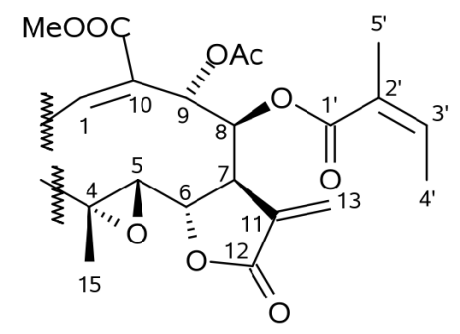

O sinal atribuído ao $\mathrm{H}-1(\delta 6,95 d[\mathrm{~J}=7,9 \mathrm{~Hz}])$ tem uma multiplicidade do $\mathrm{H}-1$ presente na enidrina e acopla com um $d d d$ em $\delta 5,20(J=3,2 ; 7,9 ; 11,3 \mathrm{~Hz})$, sendo que este sinal só pode ser atribuído ao H-2. Devido ao deslocamento químico deste sinal, conclui-se que deve haver um grupo sacador de eletrons ligado ao C-2, neste caso uma hidroxila. A orientação da hidroxila em $\alpha$ foi determinada através da constante de acoplamento entre $\mathrm{H}-1$ e $\mathrm{H}-2$, pois se a hidroxila estive orientada em em beta, a constante seria maior. A comparação dos dados de RMN $1 \mathrm{H}$ da amostra com os dados da literatura também confirmaram a orientação em $\alpha$. Assim, a estrtura desta substância é:

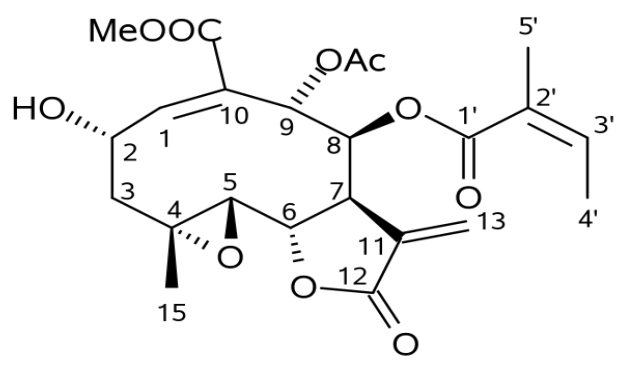


Tabela 22 - Dados de $\mathrm{RMN}^{1} \mathrm{H}(400 \mathrm{MHz})$ para a substância $2 \alpha$-hidróxi-longipilina $\left(\mathrm{CDCl}_{3}\right)$

\begin{tabular}{ll}
\hline Pos. & oH \\
\hline $\mathrm{H}-1$ & $6.95 d(7,9)$ \\
$\mathrm{H}-2$ & $5,20 d d d(3,2 ; 7,9 ; 11,3)$ \\
$\mathrm{H}-3 \mathrm{a}$ & $2.53 d d(3,2 ; 11,3)$ \\
$\mathrm{H}-3 \mathrm{~b}$ & $1,49 d d(11,3 ; 17,9)$ \\
$\mathrm{H}-5$ & $2,71 d(9,5)$ \\
$\mathrm{H}-6$ & $4,28 d d(9,5)$ \\
$\mathrm{H}-7$ & $3,0 d d d d(1,7 ; 3 ; 3,2 ; 9,5)$ \\
$\mathrm{H}-8$ & $6,75 d d(1,2 ; 8,5)$ \\
$\mathrm{H}-9$ & $5,58 d(8,5)$ \\
$\mathrm{H}-13 a$ & $6,36 d(3,2)$ \\
$\mathrm{H}-13 \mathrm{~b}$ & $5,98 d(3,0)$ \\
$\mathrm{H}-15$ & $1,7 \mathrm{~s}$ \\
$\mathrm{OMe}$ & $3,89 \mathrm{~s}$ \\
$\mathrm{OAc}$ & $2,03 \mathrm{~s}$ \\
$\mathrm{OAng}$ & $6,15 q q$ \\
& $1,94 d q$ \\
& $1,77 d q$ \\
\hline
\end{tabular}

\subsection{Resultados obtidos com o programa NAPROSYS}

Faz-se vários testes para testar a eficiência do programa NAPROSYS para identificar substâncias baseado no espectro de $\mathrm{RMN}{ }^{13} \mathrm{C}$ e também nos dados cromatográficos. 


\subsubsection{Identificação de LSTs presentes no extrato bruto de Tithonia diversifolia e Viguiera robusta}

Os espectros de RMN ${ }^{13} \mathrm{C}$ e DEPT 90 e 135 obtidos dos extratos brutos de $V$. robusta e $T$. diversifolia foram submetidos à análise através do programa NAPROSYS, cujos resultados estão na tabela 24.

Os dados do espectro obtido (tabela 23) foram informados ao NAPROSYS e este então efetuou a busca por substâncias baseando-se nestes dados. Levando-se em conta que várias substâncias estão em mistura no extrato bruto, foi possível através do NAPROSYS identificar 20 sinais pertencentes à budleína A, o que corrobora a análise feita através de CLAE. Além disso, foi possível também identificar 17 sinais pertencentes à substância denominada tiglato de budleína A. Pelo fato do programa conseguir identificar em um extrato bruto dois compostos com estruturas muito semelhantes, que diferem uma da outra apenas pelo éster ligado ao C-8, pode-se dizer que esta é uma ferramenta eficiente na identificação de compostos presentes em misturas.

Tabela 23 - Dados de RMN ${ }^{13} \mathrm{C}$ do extrato bruto de $V$. robusta

\begin{tabular}{ccccc}
\hline $\mathbf{q}$ & $\mathbf{t}$ & $\mathbf{d}$ & $\mathbf{d}$ & $\mathbf{s}$ \\
\hline 15,0 & 30,1 & 45,3 & 105,0 & 88,3 \\
16,3 & 38,3 & 48,6 & 105,3 & 88,4 \\
18,8 & 42,6 & 48,7 & 105,4 & 126,6 \\
19,6 & 43,0 & 75,2 & 129,2 & 138,9 \\
20,4 & 62,8 & 74,5 & 131,4 & 146,6 \\
21,7 & 72,3 & 75,6 & 136,2 & 166,1 \\
28,1 & 124,3 & 73,9 & 140,2 & 169,3 \\
& 123,8 & 75,7 & 142,1 & 182,9 \\
& & 77,7 & 138,8 & 205,7 \\
\hline
\end{tabular}

Quimitaxonomia e fitoquímica de espécies da tribo Heliantheae (Asteraceae) e uso de Quimioinformática em elucidação estrutural 
Tabela 24 - Dados de RMN ${ }^{13} \mathrm{C}$ dos compostos identificados no extrato bruto de $V$. robusta através do NAPROSYS

\begin{tabular}{lllll}
\hline & \multicolumn{2}{c}{$\begin{array}{c}\text { Viguiera robusta } \\
\text { Budleína A }\end{array}$} & \multicolumn{2}{c}{$\begin{array}{c}\text { Viguiera robusta } \\
\text { Budleína A tiglato }\end{array}$} \\
\hline Carbono & Exp. & Lit. & Exp. & Lit. \\
\hline C-1 & 205,7 & 205,3 & 205,7 & 205,2 \\
C-2 & 105,0 & 105,0 & - & 104,9 \\
C-3 & 182,9 & 182,5 & 182,9 & 183 \\
C-4 & 138,9 & 138,8 & 138,1 & 138,4 \\
C-5 & 136,2 & 134,3 & 134,5 & 134,2 \\
C-6 & 74,5 & 74,7 & - & 74,2 \\
C-7 & 48,7 & 48,2 & 47,4 & 48,6 \\
C-8 & 75,2 & 75,1 & 74,5 & 75,5 \\
C-9 & 42,6 & 42,5 & - & 42,1 \\
C-10 & 88,3 & 88,0 & 88,3 & 87,9 \\
C-11 & 138,9 & 135,6 & 138,9 & 136,2 \\
C-12 & 169,3 & 168,8 & 170,0 & 168,9 \\
C-13 & 123,8 & 123,4 & 123,8 & 123,8 \\
C-14 & 21,7 & 21,4 & 21,5 & 21,2 \\
C-15 & 62,8 & 62,5 & 62,8 & 62,4 \\
C-1' & 166,1 & 166,4 & 166,9 & 166,8 \\
C-2' & 126,6 & 127,3 & 127,5 & 127,9 \\
C-3' & 140,2 & 139,7 & 138,4 & 138,5 \\
C-4' & 16,3 & 14,6 & 14,1 & 14,5 \\
C-5' & 15,0 & 13,8 & 12,8 & 12,1 \\
\hline
\end{tabular}

No caso de $T$. diversifolia, os sinais obtidos no espectro de RMN ${ }^{13} \mathrm{C}$ (Tabela 25) foram analisados com o NAPROSYS e os sinais pertencentes à tagitinina $F$ foram identificados e estão de acordo com os dados presentes na literatura (Pereira et al., 1997). Também foi possível identificar através do NAPROSYS os sinais pertencente à tagitinina A (todos sinais) e também os sinais pertencentes à tagitinina C (17 sinais). Assim, o programa conseguiu entender que as três substâncias, tagitininas $A, C$ e $F$ estavam presentes no extrato (Tabela 26). O isolamento prévio destas substâncias em nosso laboratório confirmou as propostas do NAPROSYS.

Em conjunto com a identificação feita, o NAPROSYS também mostra a quantidade e os sinais que foram identificados. Isso é necessário porque o NAPROSYS não possui um gerador automático de estruturas, isto é, o programa pode apenas fazer um busca comparativa entre os sinais existentes na amostra e os sinais das substâncias existentes no 
banco. Em outras palavras, o programa falha ao se confrontar os dados de uma substância nova com os dados existentes no banco do NAPROSYS, contudo se a substância for semelhante a alguma substância já existente no banco, os sinais semelhantes podem ser identificados e é possível obter uma estrutura parcial, o que pode dar ao químico uma idéia da estrutura da substância desconhecida e a elucidação estrutural pode ser finalizada por meios usuais.

A metodologia utilizada pelo NAPROSYS faz de maneira automatizada o mesmo trabalho feito por um químico, quando este inicia a elucidação estrutural de uma substância desconhecida. O químico faz este trabalho comparando os dados do espectro desconhecido com os dados presentes na literatura, em handbooks ou de substâncias previamente isoladas em seu laboratório e muitas vezes, é possível identificar a estrutura de uma substância, ou pelo menos a maior parte dela, apenas nesta etapa. Esse tipo de metodologia, conhecida em inglês como dereplication é utilizada em sistemas CASE como um filtro preliminar (Elyashberg et al., 2004), todavia existem sistemas que se limitam a esta etapa e são confiáveis para a identificação de substâncias conhecidas (Schütz et al., 1997; Strokov e Lebedev, 1999; Bobzin et al., 2000; Steinbeck et al., 2003), sendo que estas ferramentas também podem auxiliar em parte a elucidação estrutural de uma substância desconhecida (Steinbeck et al., 2004).

Tabela 25 - Dados de RMN ${ }^{13} \mathrm{C}$ do extrato bruto de $T$. diversifolia

\begin{tabular}{ccccc}
\hline $\mathbf{q}$ & $\mathbf{t}$ & $\mathbf{d}$ & $\mathbf{d}$ & $\mathbf{s}$ \\
\hline 31,7 & 44,8 & 19,0 & 82,1 & 72,3 \\
25,3 & 50,1 & 19,1 & 128,0 & 87,4 \\
21,1 & 70,1 & 30,1 & 129,9 & 108,7 \\
20,1 & 122,1 & 34,4 & 142,1 & 136,4 \\
19,6 & 122,6 & 34,6 & 131,2 & 139,1 \\
& 124,8 & 47,3 & 137,6 & 139,3 \\
& 125,0 & 8,2 & 139,8 & 140,0 \\
& 123,8 & 70,2 & 161,0 & 148,4 \\
& & 70,6 & & 169,9 \\
& & 74,5 & & 170,3 \\
& & 75,1 & & 176,3 \\
& & 77,8 & & 176,7 \\
& & 78,8 & & 197,3 \\
\hline
\end{tabular}

$\overline{\text { Quimitaxonomia e fitoquímica de espécies da tribo Hefiantheae (Asteraceae) e uso de Quimioinformática em elucidação estrutural }}$ 
Tabela 26 - Dados de RMN ${ }^{13} \mathrm{C}$ dos compostos identificados no extrato bruto de $T$. diversifolia através do NAPROSYS

\begin{tabular}{lllll}
\hline & \multicolumn{2}{c}{$\begin{array}{c}\text { Tithonia diversifolia } \\
\text { Tagitinina F }\end{array}$} & \multicolumn{2}{c}{$\begin{array}{c}\text { T, diversifolia } \\
\text { Tagitinina C }\end{array}$} \\
\hline Carbono & Exp, & Lit, & \multicolumn{1}{c}{ Exp, } & Lit, \\
\hline C-1 & 161,0 & 160,4 & 131,2 & 130,8 \\
C-2 & 129,9 & 129,6 & 139,2 & 139,2 \\
C-3 & 197,3 & 196,8 & 108,8 & 108,3 \\
C-4 & 139,2 & 138,9 & 139,8 & 139,5 \\
C-5 & 137,6 & 137,2 & 128,0 & 127,5 \\
C-6 & 76,4 & 76,0 & 75,1 & 74,6 \\
C-7 & 47,4 & 47,0 & 47,4 & 47,7 \\
C-8 & 74,5 & 74,1 & 76,4 & 76,4 \\
C-9 & 48,2 & 48,4 & - & 43,7 \\
C-10 & 72,3 & 71,9 & 87,5 & 86,9 \\
C-11 & 136, & 136,1 & 139,2 & 138,8 \\
C-12 & 170,0 & 169,7 & 170,2 & 169,7 \\
C-13 & 124,8 & 124,4 & - & 124,2 \\
C-14 & 29,3 & 28,9 & 32,3 & 31,3 \\
C-15 & 19,9 & 19,7 & 20,1 & 20,6 \\
C-1' & 176,2 & 176,2 & 176,2 & 175,7 \\
C-2' & 34,4 & 34,1 & 34,4 & 34,1 \\
C-3' & 19,2 & 18,9 & 19,2 & 18,8 \\
C-4' & 19,0 & 18,6 & 19,0 & 18,6 \\
\hline
\end{tabular}

\subsection{Resultados obtidos com redes neurais}

\subsubsection{Treinamento de redes neurais para identificação de terpenóides através de RMN ${ }^{13} \mathrm{C}$}

Os resultados obtidos para os 28 esqueletos terpênicos (Figura 18) considerados neste estudo estão apresentados na tabela 27. Analisando-se a tabela, verifica-se que os resultados obtidos são muito significantes, pois o conjunto de redes conseguiu distinguir tanto os casos positivos quanto os negativos para vários esqueletos, sendo que os casos de 
falso positos ou falso negativos não foram freqüentes. 


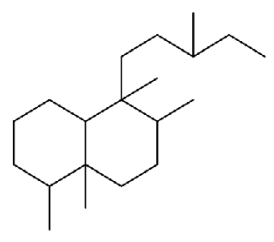

Clerodano<smiles>CCC(C)CCC1C(C)CCC2C(C)(C)CCC[C@]12C</smiles>

Labdano

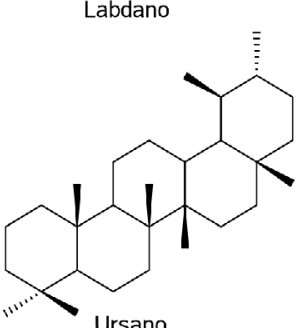<smiles></smiles>

Aromadendrano Carotano

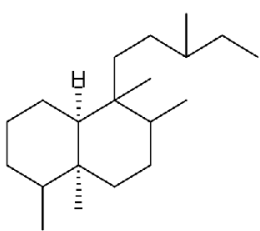

cis-Clerodano

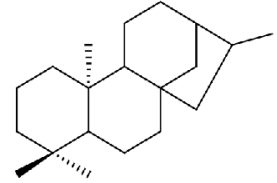

ent-Caurano<smiles>CC[C@]1(C)CCC2C(CCC3C(C)(C)CCC[C@@]23C)C1</smiles>

Isopimarano<smiles>CCC(C)(CC)CCC1C(C)CCC2C1CCC1C(C)(C)CCC[C@]21C</smiles><smiles>CC1CCCC2C3(C)CCC4C5CC(C)(C)CC[C@]5(C)CC[C@]4(C)[C@H]3CC[C@]12C(C)(F)F</smiles>
Cembrano Oleano<smiles>C=C1C(=O)OC2C1CCC(C)C1CCC(C)C12</smiles>

Guaianolido<smiles>C[C@]12CCCCC1CCC1C3CC[C@H](C4=CC(=O)OC4)C3CC[C@]12C</smiles>
Eudsesmanolido<smiles>C=C1C(=O)OC2C1CCC1(C)CCCC(C)C21</smiles>

Colestano

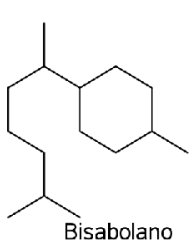
Bisabolano<smiles>CC(C)CCCC(C)[C@H]1CC[C@]2(C)C3CCC4C(C)(C)CCC[C@]4(C)C3CC[C@]12C</smiles>

Lanostano

Drimano<smiles>C=C1C(=O)OC(CC(C)CCCC(C)(C)CC2CCCCC2)C1CCC1(C)CCC(C)(C2(C)CCCC2C)CC1</smiles><smiles>CCC(C(C)CCCC(C)C)[C@@]1(C)CCC2C(C[C@H]3CCCCC23C)C1CC</smiles>

Androstano<smiles>CC1CCC2C3CCC4CCCC[C@]4(C)C3CC[C@]12C</smiles>

Pregnano<smiles>CC1CCC(C(C)C)CC1</smiles>

Mentano

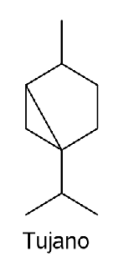<smiles>CCC(C)CCCC(C)C</smiles>

Mircano

Cardenolido

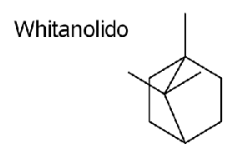

Bornano

Figura 18- Esqueletos utilizados para treino da RNA 
Tabela 27 - Resultados do treino e do teste da rede

\begin{tabular}{|c|c|c|c|c|c|c|c|c|}
\hline \multirow[t]{2}{*}{ Esqueleto } & \multicolumn{4}{|c|}{ treino } & \multicolumn{4}{|c|}{ teste } \\
\hline & \# pos. & $\%$ pos. & \%neg. & \%méd. & \#pos. & $\%$ pos. & \%neg. & $\% m$ \\
\hline Clerodano & 202 & 84,7 & 94,2 & 92,0 & 20 & 90 & 66,2 & 70,0 \\
\hline ent-Clerodano & 58 & 94,8 & 99,9 & 99,6 & 8 & 87,5 & 97,2 & 96,6 \\
\hline ent-Caurano & 185 & 88,8 & 88,7 & 88,7 & 22 & 90,9 & 68,8 & 72,7 \\
\hline Isopimarano & 94 & 86,2 & 100 & 99,6 & 10 & 90 & 97,2 & 96,6 \\
\hline Labdanos & 123 & 92,1 & 88,5 & 89,0 & 22 & 89,1 & 58,6 & 64,0 \\
\hline ent-Labdano & 38 & 100,0 & 100,0 & 100,0 & 7 & 71,4 & 80,5 & 80,0 \\
\hline Cembrano & 139 & 97,8 & 99,7 & 99,4 & 16 & 93,7 & 99,5 & 98,8 \\
\hline Oleano & 79 & 100,0 & 100,0 & 100,0 & 10 & 70 & 87,3 & 84,0 \\
\hline Ursano & 49 & 100,0 & 100,0 & 100,0 & 6 & 66,70 & 84,0 & 82,0 \\
\hline Friedelano & 41 & 100,0 & 100,0 & 100,0 & 8 & 100,0 & 90,1 & 91,6 \\
\hline Lanostano & 62 & 100,0 & 100,0 & 100,0 & 9 & 88,5 & 74,6 & 77,0 \\
\hline Drimano & 31 & 100,0 & 100,0 & 100,0 & 4 & 99,1 & 73,1 & 75,0 \\
\hline Aromadendrano & 44 & 100,0 & 100,0 & 100,0 & 6 & 100,0 & 100,0 & 100,0 \\
\hline Carotano & 83 & 96,5 & 95,8 & 96,0 & 10 & 100,0 & 87,7 & 90,0 \\
\hline Bisabolano & 100 & 81,2 & 80,9 & 81,0 & 8 & 87,5 & 72,8 & 75,0 \\
\hline Tricotecanos & 45 & 100,0 & 100,0 & 100,0 & 6 & 100,0 & 100,0 & 100,0 \\
\hline Germacranolido & 285 & 98,2 & 83,5 & 91,1 & 37 & 81,1 & 81,1 & 81,1 \\
\hline Guaianolido & 70 & 88,6 & 70,6 & 72,9 & 13 & 84,6 & 57,6 & 61,5 \\
\hline Eudesmanolido & 165 & 92,9 & 97,2 & 95,9 & 20 & 95,0 & 95,0 & 95,0 \\
\hline Colestano & 157 & 89,6 & 72,0 & 78,0 & 24 & 79,2 & 73,5 & 75,0 \\
\hline Androstano & 85 & 94,9 & 80,7 & 83,3 & 16 & 94,0 & 78,6 & 81,3 \\
\hline Pregnano & 84 & 98,9 & 93,4 & 94,4 & 11 & 81,3 & 71,5 & 72,7 \\
\hline Cardenolido & 79 & 100,0 & 100,0 & 100,0 & 13 & 92,3 & 83,3 & 84,6 \\
\hline Whitanolido & 26 & 100,0 & 100,0 & 100,0 & 6 & 100,0 & 83,1 & 82,1 \\
\hline
\end{tabular}


Tabela 27 - Resultados do treino e do teste da rede (continuação)

\begin{tabular}{lcccccccc}
\hline \multicolumn{1}{c}{ Esqueleto } & \multicolumn{4}{c}{ treino } & \multicolumn{5}{c}{ teste } \\
\hline & \# pos. & \% pos. & \%neg. & \%méd. & \#pos. $\%$ pos. & \%neg. & $\%$ méd. \\
\hline Mentano & 105 & 99,3 & 98,8 & 99,0 & 14 & 85,7 & 75,9 & 78,6 \\
Mircano & 60 & 97,2 & 87,8 & 90,0 & 8 & 88,5 & 87,3 & 87,5 \\
Borano & 23 & 100,0 & 100,0 & 100,0 & 6 & 100,0 & 100,0 & 100,0 \\
Tujano & 42 & 63,1 & 64,2 & 64,0 & 3 & 100,0 & 57,5 & 60,0 \\
\hline
\end{tabular}

Analisando a tabela acima, nota-se que os resultados globais estão ótimos, embora exista uma diferença de performace para diferentes tipos de esqueletos. Nota-se por exemplo, que a maior parte dos falso negativos e falso positvos, encontra-se nos esqueletos que possuem menor quantidade de dados disponíveis. Em outros palavras: para classificar bem substâncias pertencentes a diversos esqueletos, é necessário que a rede tenha um exemplo diverso de cada tipo de esqueleto. Uma prova de que a quantidade e a diversidade de exemplos que a rede toma durante o treino pode influenciar o desempenho da rede é que após o treino, a rede foi capaz de diferenciar com segurança esqueletos do tipo clerodano e cis-clerodano, cuja única diferença entre eles é geometria cis/trans na junção dos anéis $\mathrm{A}$ e B.

\subsubsection{Classificação de tipos de Diterpenos baseado em redes Kohonen}

A tabela 29 possui uma visão geral dos resultados obtidos, tanto em valores absolutos quanto em porcentagem. Já a Figura 19 mostra o mapa Kohonen que foi obtido após o treinamento da rede. Para testar a capacidade de generalização da rede, 113 casos de teste foram selecionados de forma aleatória e apresentados à rede como se fossem 
novos dados, tomando-se o cuidado para este conjunto possuir dados que representassem todos os esqueletos que foram treinados.

Após o treino, a rede foi capaz de classificar cada tipo de esqueleto com base nos dados de RMN ${ }^{13} \mathrm{C}$ das substâncias. Examinando-se o mapa kohonen que foi gerado, notase que a rede conseguiu agrupar esqueletos semelhantes próximos uns aos outros e esqueletos muitos diferentes ficaram distantes uns dos outros. Pegando-se por exemplo esqueletos muto semelhantes entre si, tais como os labdanos e ent-labdanos, verifica-se que a rede apresentou um bom desempenho mesmo nestes casos, principalmente se levarmos em conta que única diferença entre os dois esqueletos é apenas a orientação de metila. Isso também significa que a rede é bem sensível a pequenas mudanças no espectro, o que por sua vez é reflexo de características estruturais, neste caso, a orientação estereoquímica de um grupo.

Outra característica interessante do mapa é que esqueletos similares do ponto de vista biogenético formam clusters vicinais. Isso pode ser visto observando-se os clusters formados pelos esqueletos cembrano e fitano, ambos semelhantes do ponto de vista biogenético e que foram dois clusters vicinais. 


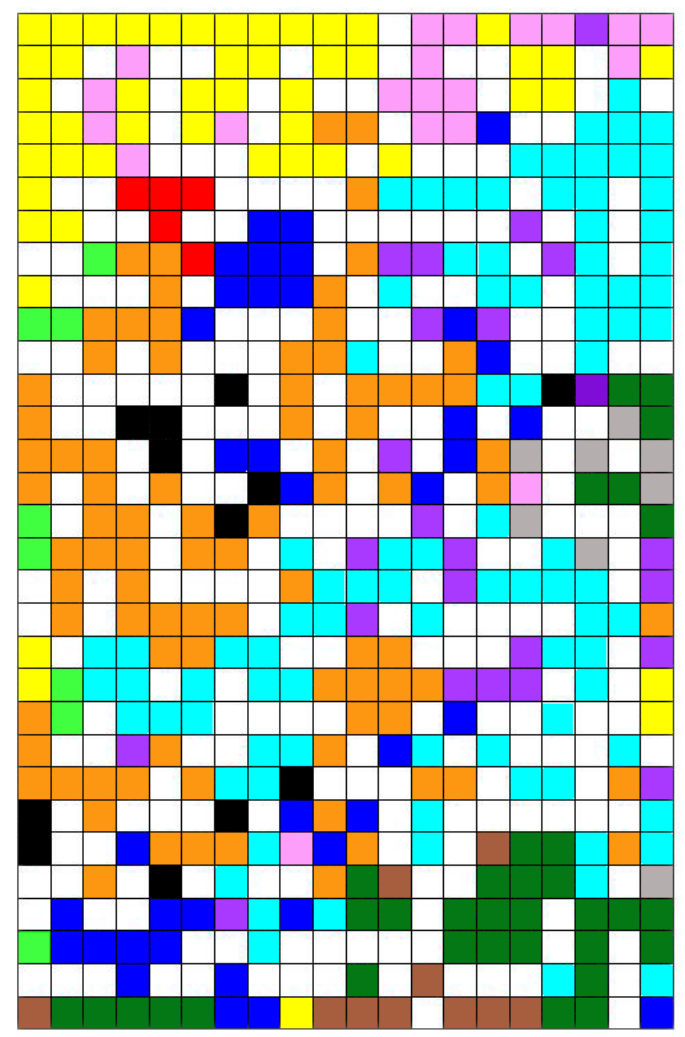

Figura 19 - Mapa Kohonen após o treinamento da rede.

Tabela 28 - Tipos de esqueletos e as respectivas cores no mapa Kohonen da figura 19.

\begin{tabular}{|c|c|}
\hline ID Esqueleto & Cor \\
\hline \multicolumn{2}{|c|}{1 12,13-SEC-13-NOR-TOTARANO preto } \\
\hline 2 13-EPI-ROSANO & cinza \\
\hline 3 ABIETANO & azul \\
\hline 4 ANDROMEDANO & verde \\
\hline 5 CEMBRANO & amarelo \\
\hline 6 CYATHANO & vermelho \\
\hline 7 CLERODANO & laranja \\
\hline 8 ENT-ATISANO & marrom \\
\hline 9 ENT-LABDANO & púrpura \\
\hline 10FITANO & rosa \\
\hline 11ISOPIMARANO & verde escuro \\
\hline 12 LABDANO & ciano \\
\hline
\end{tabular}


Tabela 28 - Visão geral dos resultados obtidos durante o treino e teste da rede neural.

\begin{tabular}{lllll}
\hline \multicolumn{4}{c}{ Treinamento } & Teste \\
\hline ID & Acertos & $\%$ & Acertos & $\%$ \\
\hline 1 & 30 & 78,95 & 4 & 100,00 \\
2 & 14 & 82,35 & 3 & 100,00 \\
3 & 89 & 94,68 & 8 & 88,89 \\
4 & 24 & 85,71 & 5 & 62,50 \\
5 & 142 & 94,67 & 10 & 83,33 \\
6 & 12 & 100,0 & 2 & 66,67 \\
7 & 169 & 90,86 & 15 & 71,43 \\
8 & 27 & 93,10 & 5 & 83,33 \\
9 & 36 & 76,60 & 3 & 75,00 \\
10 & 40 & 78,43 & 4 & 66,67 \\
11 & 94 & 96,91 & 6 & 60,00 \\
12 & 195 & 93,75 & 20 & 74,07 \\
Total & 872 & 91,12 & 85 & 75,22 \\
\hline
\end{tabular}<smiles>CCC1C(C(C)C(C)C)CCC2C(C)CCCC21C</smiles>

1) 12, 13-SEC-NOR-TOTARANE

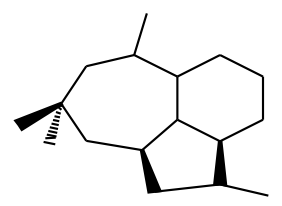

4) ANDROMEDANE

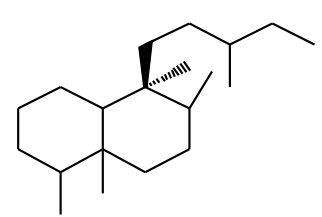

7) CLERODANE

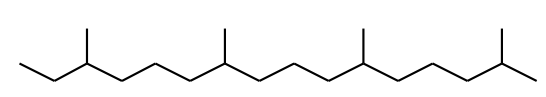

10) FITANE

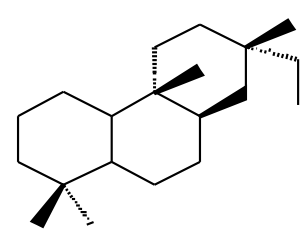

2) 13-EPI-ROSANE

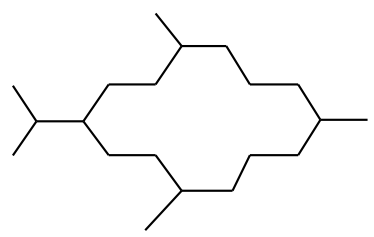

5) CEMBRANO

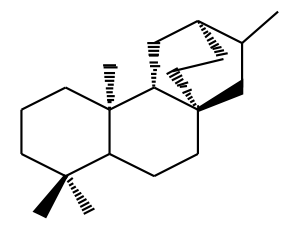

8) ENT-ATISANE

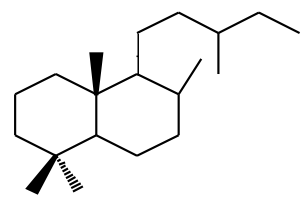

11) LABDANE

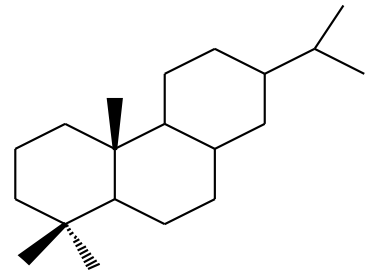

3) ABIETANE

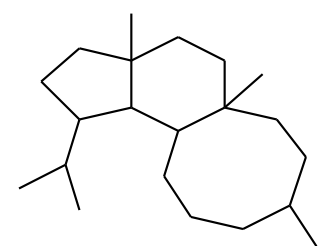

6) CIATANE<smiles>CCC(C)CCC1C(C)CCC2C(C)(C)CCC[C@]12C</smiles>

9) ENT-LABDANE

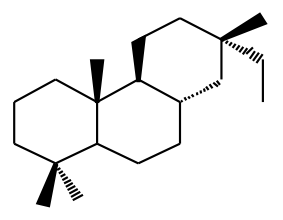

12) ISOPIMARANE

Figura 20 - Tipos de diterpenos utilizados no treinamento da Rede. 
Devido à capacidade que os mapas Kohonen têm para perceber pequenas diferenças mesmo em esqueletos muito semelhantes, os mapas Kohonen podem ser utilizados como critério para fazer uma pré-seleção de esqueletos em sistemas de elucidação estrutural automatizada.

\subsubsection{Análise quimiotaxonômica através de redes neurais}

Um mapa Kohonen de $6 \times 6$ conseguiu classificar diversos gêneros da tribo Heliantheae, agrupando os gêneros que possuiam LSTs semelhantes próximos uns dos outros (Figura 21).

Mapa SOM da classificação quimiotaxonômica dos gêneros de Heliantheae.

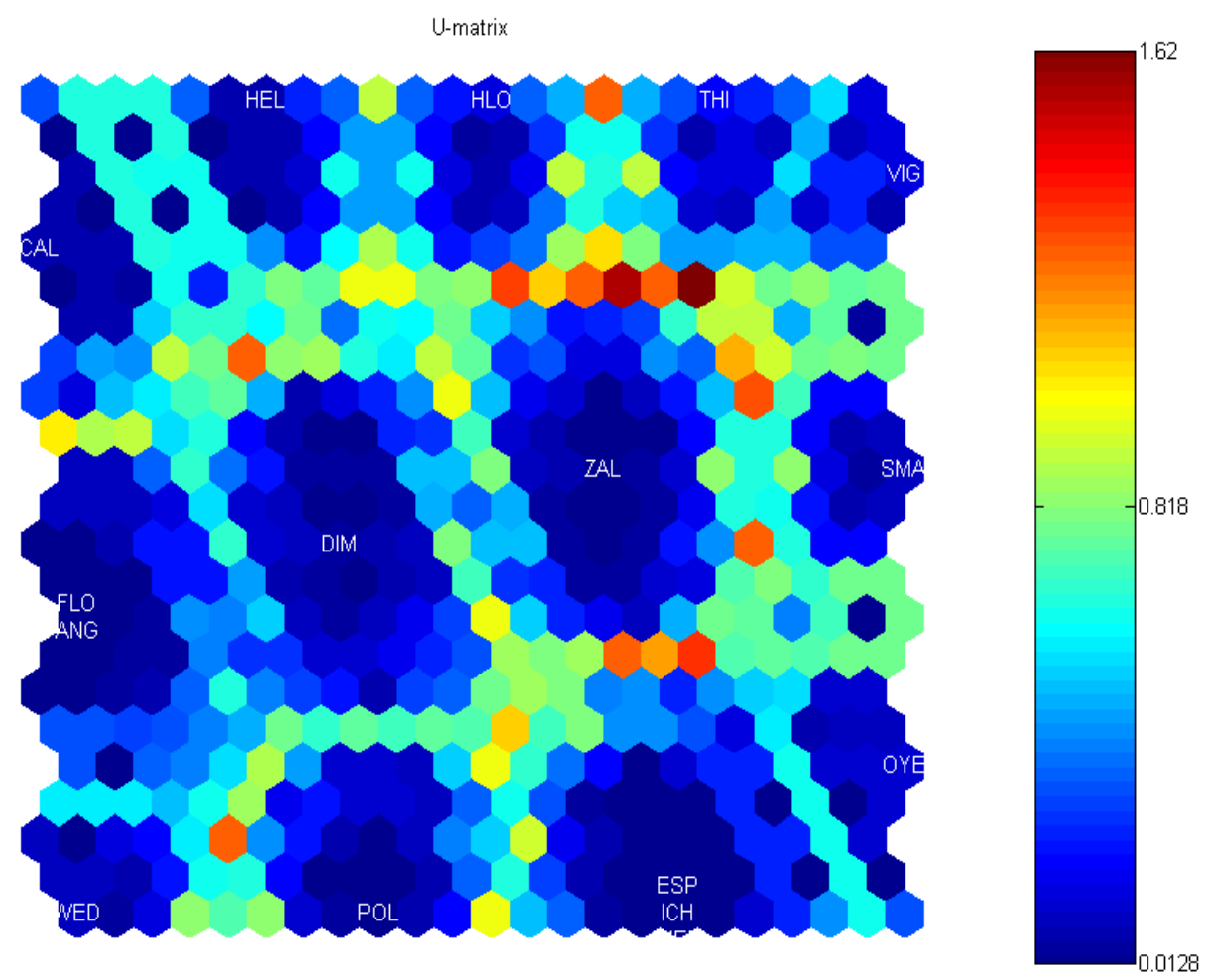

SOM 04-Aug-2005

$\overline{\text { Quimitaxonomia e fitoquímica de espécies da tribo Heliantheae (Asteraceae) e uso de Quimioinformática em elucidação estrutural }}$ 
Figura 21 - Mapa SOM. ANG = Angelphytum, CAL = Calea, DIM = Dimerostemma, ESP = Espeletia, $\mathrm{FLO}=$ Flourensia, $\mathrm{HEL}=$ Helianthus, $\mathrm{HLO}=$ Heliomeris, $\mathrm{ICH}=$ Ichthyothere OYE = Oyedaeae, $\mathrm{POL}=$ Polymnia, $\mathrm{SMA}=$ Smalanthus, $\mathrm{THI}=$ Tithonia, $\mathrm{WED}=$ Wedelia, $\mathrm{ZAL}=$ Zaluzania.

O mapa utiliza geometria quadrada e conseguiu classificar os gêneros com aproximadamente $75 \%$ de acerto. Analisando-se o mapa, conseguimos ver que a rede agrupou os gêneros Calea, Helianthus, Heliomeris, Thithonia, Zaluzania e Viguiera próximos uns dos outros. Estes gêneros pertencem à mesma subtribo (Helianthinae) e se caracterizam pela biossíntese de furanoheliangolidos. Os gêneros Espeletia, Ichthyothere e Melampodium, todos pertencentes à subtribo Melampodinae e que se caracterizam pela biossíntese de melampolidos, também foram agrupados próximos uns dos outros; os gêneros Angelphytum, Dimerostemma e Wedelia que se caracterizam pela biossíntese de eudesmanolidos e pertencem todos à subtribo Ecliptinae também foram agrupados próximos uns dos outros.

É interessante notar que todos os gêneros que estão correlacionados botanicamente ficaram próximos uns dos outros, assim concluimos que as redes neurais podem ser uma ferramenta muito útil em quimiotaxonomia.

Por outro lado, a classificação dos gêneros Smallanthus, Flourensia e Oyedaea não foi feita com sucesso, pois Smallanthus que se caracteriza pela biossíntese de melampolidos e pertence à tribo Melampodinae, foi classificado próximo aos membros da subtribo Helianthinae. O gênero Oyedaea, pertencente à subtribo Ecliptinae, foi classificado próximo aos membros da subtribo Melampodinae. Todavia, os gêneros mal classificados não possuem um perfil químico uniforme possuindo esqueletos de LSTs que podem ser característicos de mais de uma subtribo. Isso induz a classificações confusas, uma vez que pela própria arquitetura das redes Kohonen, para ter-se uma boa classificação, é necessário um grupo de dados que tenha uma certa uniformidade. 


\subsection{Resultados obtidos com o modelo QSRR}

Os resultados obtidos após a criação dos modelos tanto para trr1 como para trr2 podem ser vistos nas tabelas 29 e 30 . Os descritores foram escolhidos com base nas correlações existentes entre eles, sendo que dentre os descritores correlacionados, isto é, os descritores onde $R^{2}$ entre ambos é $>0,9$, tais como peso e volume, foi eliminado um deles. Tomou-se o cuidado para eliminar também os descritores que não traduzem propriedades importantes para cromatografia e deixar apenas os considerados indispensáveis.

Tabela 29 - Resultados das validações (test-split) dos modelos QSRR

\begin{tabular}{lllllllll}
\hline & \multicolumn{3}{c}{ trr1 } & \multicolumn{5}{c}{ trr2 } \\
\hline Instância & $t R$ & previsto & $\Delta$ & Instância & $t R$ & previsto & $\Delta$ \\
\hline 1 & 0,41 & 0,623 & $-0,213$ & 1 & 0,31 & 0,51 & 0,208 \\
2 & 0,95 & 0,907 & $-0,043$ & 2 & 1,7 & 2,11 & 0,416 \\
3 & 0,90 & 1,459 & $-0,559$ & 3 & 0,87 & 1,466 & 0,596 \\
4 & 1,09 & 1,443 & 0,353 & 4 & 1,72 & 3,11 & 1,39 \\
5 & 0,45 & 0,436 & $-0,014$ & 5 & 0,4 & 0,789 & 0,389 \\
6 & 0,56 & 0,503 & $-0,057$ & 6 & 0,39 & 0,961 & 0,571 \\
7 & 1,09 & 1,055 & $-0,035$ & 7 & 1,23 & 1,5 & 0,27 \\
8 & 1,35 & 1,181 & $-0,169$ & 8 & 2,11 & 0,638 & $-1,472$ \\
9 & 0,44 & 0,864 & 0,424 & 9 & 0,49 & 0,673 & 0,183 \\
10 & 0,45 & 0,490 & 0,040 & 10 & 0,47 & 0,6 & 0,13 \\
\hline
\end{tabular}

Quimitaxonomia e fitoquímica de espécies da tribo Heliantheae (Asteraceae) e uso de Quimioinformática em elucidação estrutural 
Tabela 30 - Estatísticas das validações dos modelos QSRR

\begin{tabular}{lll}
\hline Estatística & Trr1 & Trr2 \\
\hline R2 & 0,7488 & 0,6589 \\
MAE & 0,2133 & 0,5765 \\
RMSE & 0,2848 & 0,6755 \\
VIF & 3,98 & 2,93 \\
\hline
\end{tabular}

A análise dos dados acima nos permite tirar algumas conclusões, a primeira delas, a mais óbvia e menos interessante é que o modelo proposto possui mais erros para o sistema $\mathrm{MeCN} / \mathrm{H}_{2} \mathrm{O}$ do que para o sistema $\mathrm{MeOH} / \mathrm{H}_{2} \mathrm{O}$. Analisando-se a estatística VIF (Variance Inflation Factor) que expressa a forma como vários descritores se relacionam e que pode ser expressa pela Eq. 4, nota-se que o seu valor é menor para o modelo de previsão de trr2. Uma vez que a correlação entre os descritores é inversamente proporcional ao valor de VIF, conclui-se que os descritores selecionados para o modelo trr2 não são os ideais, uma vez que descritores muito correlacionados (VIF > 9) e nem pouco correlacionados (VIF $<3,5$ ) não são ideais (Moon et al, 2003).

$$
\mathrm{VIF}=\frac{1}{1-\mathrm{R}^{2}}
$$

Assim, novos descritores foram selecionados para criar um novo modelo de previsão para o trr2, uma vez que o analito interage com esse sistema de forma diferenciada da interação para o trr1. Desse modo, em adição aos descritores selecionados anteriormente, descritores que indicam a capacidade da molécula formar postes de hidrogênio (HbondAccCount, HbondDonCount, HighestHbondDonPot e HighestHbondAccPot) foram incluídos no modelo, sendo que os resultados obtidos estão na tabela 31. 
Tabela 31 - Resultados das validações (test-split) do modelo adicional QSRR para trr2.

\begin{tabular}{llll}
\hline & \multicolumn{3}{c}{ trr2 } \\
\hline Instância & $t R$ & previsto & $\Delta$ \\
\hline 1 & 0,31 & 0,443 & 0,133 \\
2 & 1,7 & 2,287 & 0,584 \\
3 & 0,87 & 1,225 & 0,355 \\
4 & 1,72 & 2,499 & 0,779 \\
5 & 0,4 & 0,572 & 0,172 \\
6 & 0,39 & 0,323 & $-0,064$ \\
7 & 1,23 & 1,603 & 0,373 \\
8 & 2,11 & 1,132 & $-0,978$ \\
9 & 0,49 & 0,573 & 0,083 \\
10 & 0,47 & 0,77 & 0,30 \\
\hline
\end{tabular}

Para o modelo acima foi obtido um $R^{2}$ de 0,7446 , um MAE de 0,4586, um RMSE de 0,5373 e um VIF de 3,92 que é ainda um pouco menor do que o apresentado pelo modelo utilizado para prever trr1. todavia os resultados globais melhoraram. Fez-se um teste para saber como um modelo criado para prever trr1 que incluísse os mesmos descritores utilizados para trr2 comportaria, contudo os resultados para trr1 pioraram. Desse modo, chega-se à conclusão que em QSRR sistemas diferentes requerem descritores diferentes. Além disso, quando se trata de trr2, a contribuição das pontes de hidrogênio entre o analito, a fase estacionária e a fase móvel é um pouco mais significativa do que quando se trata de trr1. Diferenças significativas entre diferentes modelos envolvendo metanol e acetonitrila também foram relatados na literatura (Kaliszan, 2003). Um outro fator bastante conhecido e relatado na literatura é que quando quando a fase móvel possui uma alta porcentagem de água, caso de nosso trr2, as longas cadeias alifáticas que ficam sobre a fase estacionária se colapsam, diminuindo a interação com o analito, ao mesmo tempo em que aumenta a interação entre os hidrogênios da fase móvel com os da amostra, o que resulta em um 
aumento do tempo de retenção (Baczek et al., 2000), o que pode explicar porque os descritores envolvendo os hidrogênios são mais importantes nos modelos de trr2 do que nos modelos de trr1.

Analisando-se os desvios obtidos nas previsões tanto de trr1 como de trr2, podemos ver que existem discrepâncias com alguns tempo de retenção bem previstos e muito próximos dos experimentais, enquanto outros estão muito distantes dos tempo de retenção experimentais, principalmente se considerarmos trr2. Um exame detalhado da tabela dos descritores que foram calculados mostra que existem descritores que são muito semelhantes para moléculas diferentes, como por exemplo o volume molecular, que é uma propriedade importante para a cromatografia. Embora esses descritores semelhantes sejam compensados pelos descritores com valores diferentes, eles ainda são importantes para os modelos e os influenciam, o que pode fazer o sistema de previsão falhar e apresentar um desempenho médio quando deveria apresentar um desempenho ótimo. A grande semelhança estrutural entre as diversas LSTs também contribui para esta queda no desempenho dos modelos e é a razão da classe dos melampolidos ter sido excluída do modelo, pois além de ser uma classe com pouca diversidade estrutural na biblioteca de padrões, existem muitos enantiômeros na biblioteca e o modelo foi desenvolvido tendo em vista colunas C-18 ODS aquirais.

Finalmente, embora os modelos apresentem desempenho um pouco abaixo do padrão esperado, ele pode dar uma noção do tempo de retenção relativo de novas LSTs e pode ser ser melhorado se forem incluídos descritores que sejam sensíveis o suficiente para diferenciar as LSTs do ponto de vista estereoquímico, isto é, se forem utilizados descritores $3 \mathrm{D}$, pois nestes modelos foram utilizados apenas descritores topológicos $2 \mathrm{D}$, mesmo com o cálculo das coordenadas 3D feitos.

Quimitaxonomia e fitoquímica de espécies da tribo Heliantheae (Asteraceae) e uso de Quimioinformática em elucidação estrutural 


\subsection{Estudos Quimiotaxonômicos}

\subsubsection{Quimiotaxonomia do gênero Ichthyothere}

O gênero Ichthyothere é representado por 25 espécies distribuidas nas américas central e do sul (Rauscher, 2002) e a sua classificação é ainda objeto de muita discussão. O gênero foi primeiramente incluído por Hoffmann (Hoffmann, 1890) na subtribo Melampodiinae, mas foi posteriormente movido para a subtribo Meliriinae (Stuessy, 1977). Estudos baseados em caracteres morfológicos do gênero sugeriu que o gênero deveria permanecer na subtribo Melampodiinae (Robinson, 1981), enquanto um estudo abrangente de cladística da tribo Heliantheae classificou este gênero com de classificação incerta em nível de subtribo (Karis e Ryding, 1994). Todavia, um estudo recente evolvendo filogenética micromolecular sugere que o gênero Ichthyothere está relacionado como grupo Espeletia (Rauscher, 2002). Embora a relação exata ainda seja desconhecida, está claro Espeletia é um membro de Melampodiine, o que reforça as evidências de que Ichthyothere deve permanecer nesta subtribo.

É certo que existem divergências sobre a classificação de Ichthyothere e a química do gênero pode auxiliar na sua classificação. Embora até o momento apenas duas espécies de Ichthyothere foram investigadas, os resultados obtidos corroboram que este gênero deve permanecer em Melampodiinae, pois LSTs do tipo encontrado no gênero (melampolidos) são muito encontrados na subtribo e são considerados marcadores quimiotaxonômicos de Melampodiinae. Isso inclui LSTs comuns a outros gêneros de Melampodiinae, como por exemplo a enidrina, que foi isolada também de Enhydra, Smallanthus e Polymnia 
(Krishnaswamy e Ramji, 1995; Inoue et al., 1995; Lin et al., 2003). Neste estudo, foram identificados dois melampolidos no extrato de lavagem foliar de I. terminalis, seguido por análise em CLAE. Esta técnica é uma técnica segura para a análise de LSTs de Heliantheae (Da Costa et al,, 2001; Schorr et al., 2002).

Além das LSTs, outras classes de metabólitos secundários podem auxiliar na classificação do gênero Ichthyothere. Um estudo envolvendo flavonóides (Bohm e Stuessy, 1992) não corroborou uma hipótese levantada sobre uma possível proximidade entre o gênero Clibadium, Desmanthodium e Ichthyothere (Cascon et al., 1965). Enquanto Clibadium e Desmanthodium possuem um preferência biossintética por flavonóides glicosilados derivados do caempeferol e outros tipos 7-O-glicosilados, Ichthyothere demonstra uma preferência pela biossíntese de diidroflavonóis e de flavonóis tricglicosilados e 3-O-metilados.

\subsubsection{Quimiotaxonomia do gênero Dimerostemma}

Este gênero foi colocado primeiramente na subtribo Verbesiniinae (Stuessy, 1977), sendo movido posteriormente para a subtribo Ecliptinae (Robinson, 1981). Ao contrário do gênero Ichthyothere, parece não haver muita divergência sobre a posição taxonômica que Dimerostemma deve ocupar em Heliantheae, pois estudos envolvendo filogenia micromolecular corroboram o posicionamento deste gênero na subtribo Ecliptinae (Panero et al., 1999) e além disso, moveu a maioria das espécies de Verbesiniinae para Ecliptinae, embora um estudo anterior feito com características morfológicas tenha corroborado o trabalho de Stuessy, ou seja, recomendava a permanência de Dimerostemma na subtribo Verbesiniinae (Karis e Ryding, 1993). Contudo, o trabalho de Karis e Ryding promoveu uma fusão entre as subtribos Ecliptinae e Verbesiniinae por considerar que o nome Ecliptinae 
não era um nome correto para a tribo, pois a análise filogenética do gênero Eclipta provou que o gênero é um gênero isolado, não mostrando correlação com a maioria dos gêneros de Ecliptinae, enquanto diversos gêneros de Ecliptinae e Verbesiniinae se mostram muito próximos. Assim, exceto por uma questão de nomenclatura de subtribos, os trabalhos de Panero e Karis mostram resultados idênticos.

Do ponto de vista químico, o gênero Dimerostemma é semelhante a outros gêneros pertencentes à subtribo Ecliptinae tais como Zinnia, Zexmenia, Balsamorhiza e Angelphytum. Todos esses gêneros também produzem 6,12 eudesmanolidos com padrão de substituição $\alpha$, que também é comum em Dimerostemma, além de outros tipos de metabólitos secundários comuns na subtribo tais como diterpenos e poliacetilenos. É interessante notar que Dimerostemma possui uma química peculiar, muito particular do gênero e que se caracteriza por produzir LSTs onde a presença de epóxidos é maçissa. É certo que outros gêneros da subtribo também possuem esta característica, mas no caso destes gêneros, as posições das substituições e orientação estereoquímica são totalmente diferentes.

O único gênero do qual foram isoladas LSTs com padrões de substituição idênticos aos apresentados em Dimerostemma é o gênero Angelphytum (Nascimento, 2005). Angelphytum e Dimerostemma estão morfologicamente relacionados e a única diferença morfológica existente entre os gêneros é que em Angelphytum as flores periféricas das inflorescências são férteis, enquanto que em Dimerostemma, essas mesmas flores são esteréis (Robinson, 1984). Os estudos fitoquímicos corroboram, até o momento, as observações feitas por Robinson. A química também corrobora a permanência de Dimerostemma na subtribo Ecliptinae, pois embora os padrões de substituição encontrados em Dimerostemma seja peculiares, o gênero produz substâncias que possuem o mesmo esqueleto básico de substâncias produzidas por outros gêneros da subtribo. 
A partir dos resultados obtidos, conclui-se que unindo-se a química e a informática podemos ter ferramentas valiosas que podem auxiliar o gerenciamento de bibliotecas de substâncias químicas, representação 2D/3D de estruturas químicas em um computador, planejamento de síntese, elucidação semi- ou totalmente automatizada de substâncias naturais, o estudo das relações estrutura/propriedades químicas (QSPR), busca de novos produtos bioativos (Virtual Screening) e com atividades biológicas específicas (QSAR). Além disso, a Quimioinformática pode ser utilizada como ferramenta de auxilio a outras áreas, como por exemplo a quimiotaxonomia e desenvolvimento de novos fármacos, dentre outras. Assim, as aplicações desta nova disciplina que se desenvolveu nos últimos 40 anos, saiu de simples métodos de representação de estruturas para em menos de 15 se tornar uma ferramenta presente em várias áreas da química. Se o desenvolvimento da Quimioinformática manter o ritmo atual, em pouco tempo será possível utilizar o computador para o planejamento de novas moléculas com as propriedades que desejamos, assim como engenheiros e arquitetos utilizam o computador para planejar novos carros e edifícios.

Os resultados dos estudos fitoquímicos obtidos corroboram e reforçam a classificação atual das espécies investigadas. O uso da microamostragem de tricomas glandulares em CLAE e de programas para a busca de dados de RMN podem agilizar a identificação de substâncias já conhecidas, permitindo que o pesquisador concentre seus estudos na busca de identificação de novas substâncias. 
BACZEK, T.; MARKUSZEWSKI M.; KALISZAN, R.;STRATEN, M. A.; CLAESSENS, H. A. Linear and Quadratic Relationships between Retention and Organic Modifier Content in Eluent in Reversed Phase High-Performance Liquid Chromatography: A Systematic Comparative Statistical Study. J. High Res. Chromatogr., 2000, vol. 23, p. 667-676.

BACZEK, T.; KALINSZAN, R. Predictive approachs to gradient retention based on analyte structural descriptors from calculation chemistry. J. Chrom. A, 2003, vol. 987, p. 29-37.

BOBZIN, S. C.; YANG, S.; KASTEN, T. P. LC-NMR: a new tool to expedite the dereplication and identification of natural products. J. Indust. Microlbiol. Biotechnol., 2000, vol.25, 342-345.

BOHLMANN, F. Chemistry of the Heliantheae (Compositae). Pl. Syst. Evol., 1990, Suppl. 4, p. 67-75.

BOHLMANN, F.; DHAR, A. K.; JAKUPOVIC, J.; KING, R. M.; ROBINSON, H. Eudesmanolides from Dimerostemma lippioides. Phytochemistry, 1981b, vol. 20, p. 838-839.

BOHLMANN, F.; GUPTA, R. K.; JAKUPOVIC, J.; KING, R. M.; ROBINSON, H. Furanoheliangolides and farnesol derivatives from Calea hispida. Phytochemistry, 1982a, vol. 21 , p. 2899-2903.

BOHLMANN, F.; JAKUPOVIC, J.; SCHUSTER, A.; KING, R. M.; ROBINSON, H. New melampolides, kaurene derivatives and other constituents from Ichthyothere species. Phytochemistry, 1982b, vol. 21, p. 2317-2327.

BOHLMANN, F.; MISRA, L. N.; JAKUPOVIC, J.; KING, R. M.; ROBINSON, H. Further Quimitaxonomia e fitoquímica de espécies da tribo Heliantheae (Asteraceae) e uso de Quimioinformática em elucidação estrutural 
eudesmanolides from Dimerostemma species. Phytochemistry, 1984, vol. 23, p. 1802-1804.

BOHLMANN, F.; SINGH, P.; JAKUPOVIC, J.; KING, R. M.; ROBINSON, H. Eudesmanolides from Dimerostemma brasilianum. Phytochemistry, 1982a, vol. 21, p. 1343-1347

BOHLMANN, F, ZDERO, C.; ROBINSON, H.; KING, R. M. 15 $\alpha$-Methylacryloyloxy-entkaurenic acid from Ichthyothere species. Phytochemistry, 1981a, vol. 20, p. 522-523.

BOHLMANN, F.; ZIESCHE, J.; KING, R. M.; ROBINSON, H. Eudesmanolides and other constituents from Dimerostemma asperatum. Phytochemistry, 1981c, vol. 20, p. 1335-1338.

BOHM, B. A.; STUESSY, T. F. Flavonol derivatives of Ichthyothere terminalis. Phytochemistry, 1982, vol. 21, p. 2761-2763.

BREMER, K. Major clades and grades of the Asteraceae. In Hind, D. J. N.; Beentje H. J. (eds.). Compositae: Systematics. Proceedings of the International Compositae. Kew: Royal botanic gardens, 1994, vol. 1, p. 1-7.

CASCON, S. C.; MORS, W. B.; TURSCH, B. M.; APLIN, R. T.; DURHAM, L. J. Ichthyothereol and Its Acetate, the Active Polyacetylene Constituents of Ichthyothere terminalis (Spreng.) Malme, a Fish Poison from the Lower Amazon. J. Am. Chem. Soc, 1965, vol. 87 , p. 5237-5241.

CASTRO, A. A. J. F.; MARTINS; F. R.; TAMASHIRO, J. Y.; SHEPHERD, G. J. How Rich is the Flora of Brazilian Cerrados ? Ann. Misouri Bot. Gard., 1999, vol. 86, p. 192-224. 
CERQUEIRA, E. O.; ANDRADE, J. C.; POPPI, R. J.; MELLO, C. Redes neurais e suas aplicações em calibração multivariada. Quím. Nova, 2001, vol. 24, p. 864-873.

DA COSTA, F. B.; SCHORR, K.; ARAKAWA, N. S.; SCHILLING, E. E.; SPRING, O. Infraspecific Variation in the Chemistry of Glandular Trichomes of two Brazilian Viguiera Species (Heliantheae; Asteraceae). J. Braz. Soc., 2001, vol. 12, p. 403-407.

DUBOIS, J. E.; SOBEL, Y. DARC System for Documentation and Artificial Intelligence in Chemistry. J. Chem. Inf. Comput. Sci., 1985, vol. 25, p. 326-333.

ELYASHBERG, M. E.; BLINOV, K. A.; WILLIAMS, A. J; MOLODTSOV, S. G.; MARTIN, G. E.; MARTIROSIAN, E. R. Structure Elucidator: A Versatile Expert System for Molecular Structure Elucidation from 1D and 2D NMR Data and Molecular Fragments. J. Chem. Inf. Comput. Sci., 2004, vol. 44, p. 771-792.

EMERENCIANO, V. D.; RODRIGUES G. D., MACARI, P. A. T.; VESTRI, S. A.; BORGES, J. H. G.; GASTMANS, J. P.; FROMANTEAU, D. L. G. Applications of Artificial-Intelligence in Organic-Chemistry .17. New Programs in the SISTEMAT Project. Spectroscopy, 1994, vol. 12, p. $91-98$.

FAULON, J. L. Stochastic Generation of Chemical Structures. 1. Applications to the Structure Elucidation of Large Molecules. J. Chem. Inf. Comput. Sci., 1994, vol. 34, p. 1204-1218.

FERREIRA, M. J. P.; RODRIGUES, G. V.; BRANT, A. J. C.; EMERENCIANO, V. P. REGRAS: An Auxiliary Program for Pattern Recognition and Substructure Elucidation of Monoterpenes. Spectroscopy, 2001, vol. 15, p. 65-98.

Quimitaxonomia e fitoquímica de espécies da tribo Heliantheae (Asteraceae) e uso de Quimioinformática em elucidação estrutural 
FROMANTEAU, D. L. G.; GASTMANS J. P.; VESTRI, S. A.; EMERENCIANO, V. D.; BORGES, J. H. G. A Constraints Generator in Structural Determination by Microcomputer. Computers Chem., 1993, vol. 17, p. 369-378.

GASTEIGER, J. The central role of Chemoinformatics. Chem. Intel. Lab. Syst., 2006, vol. 82, p. 200-209.

GASTEIGER, J.; ZUPAN, J. Neural Networks in Chemistry and Drug Design: An Introduction. Stuttgart, Willey VCH, 1999, vol. único,. 367p.

GERSHENZON, J.; PFEIL, R. M.; LIU, Y. L.; MABRY, T. J.; TURNER, B. L. Sesquiterpene lactones from two newly-described species of Vernonia: $V$. jonesii and $V$. pooleae. Phytochemistry, 1984, vol. 23, p. 777-780.

GRAY, N. A. B. Computer Assisted structure elucidation. New York, Jon Wiley \& Sons, 1986, vol. único, 593p.

GOSLING, J.; BRACHA, G.; JOY, B.; STEELE, G. J. The Java Language Specification. San Francisco, Addison-Wesley, 2000, 544p.

HAN, Y.; STEINBECK, C. Evolutionary-Algorithm-Based Strategy for Computer-Assisted Structure Elucidation. J. Chem. Inf. Comput. Sci., vol. 44, p. 489-498.

HARVEY, A. Strategies for discovering drugs from previously unexplored natural products. Drug Discovery Today, 2000, vol. 5, p. 294-300. 
HEGNAUER, R. Phytochemistry and plant taxonomy — an essay on the chemotaxonomy of higher plants. Phytochemistry, 1986, vol. 25, p. 1519-1535.

HEYWOOD, V. H.; MOORE, D. M.; DERRICK, L. N.; MITCHELL, K. A.; SCHEEPEN, J.; The European Taxonomic, Floristic and Biosystematic Documentation System - an introduction. In: Allkin, R.; Bisby, F. A. (eds.). Databases in systematics. London, Academic Press, 1984, vol. único, p. 79-89.

HOFFMANN, O. Compositae. In: Engler, A.; Prantl, K. (eds.). Die Natürlichen Pflanzenfamilien, Leipzig, Engelmann, 1890, vol. 4, p. 210-297.

INOUE, A.; TAMOGAMI, S.; KATO, H.; NAKAZATO, Y.; AKIYAMA, M;. KODAMA, O.; AKATSUKA T.; HASHIDOKO, Y. Antifungal melampolides from leaf extracts of Smallanthus sonchifolius. Phytochemistry, 1995, vol. 39, p. 845-848.

JASPARS, M. Computer Assisted Structure Elucidation of Natural Products Using TwoDimensional NMR Spectroscopy. Nat. Prod. Rep., 1999, vol. 16, p. 241-248.

KALCHHAUSER, H.; ROBIEN, W. CSEARCH: A Computer Program for Identification of Organic Compounds and Fully Automated Assignment of Carbon-13 Nuclear Magnetic Resonance. J. Chem. Inf. Comput. Sci., 1985, vol. 25, p. 103-108.

KALINSZAN, R. Quantitative structure-retention relationships applied to reversed-phase high-performance liquid chromatography. J. Chrom. A, 1993, vol. 656, p. 417-435. 
KALISZAN, R.; BACZEK, T.; BUSCINSKI, A.; BUSZEWSKI, B.; SZTUPECKA, M. Prediction of gradient retention from linear solvent strength (LSS) model, quantitative structurerelationships (QSRR) and artificial neural networks (ANN). J. Sep. Sci., 2003, vol. 26, p. 271282.

KARIS, P. O.; RYDING, O. Tribe Heliantheae. In: BREMER, K. (ed.). Asteraceae: cladistics and classification. Portland, Timber Press, 1994, vol. único, p. 559-624.

KRISHNASWAMY, N. R.; RAMJI, N. Sesquiterpene lactones from Enhydra fluctuans. Phytochemistry, 1995, vol. 39, p. 433-435.

KORYTKO, A.; SCHULZ, K. P.; MADISON, M. S.; MUNK, M. E. HOUDINI: A New Approach to Computer-Based Structure Generation. J. Chem. Inf. Comput. Sci., 2003, vol. 43, p. 14341446.

LINDSAY, R. K.; BUCHANAN, B. G.; FEIGENBAUM, E. A.; LEDERBERG, J. Application of artificial intelligence for Organic Chemistry: The DENDRAL Project. New York, McGrawHill, 1980, vol. único, 580p.

MISKI, M.; GAGE, D. A.; MABRY, T. J. Terpenoids of Piptothrix sinaloae. Phytochemistry, 1987, vol. 26, p. 2753-2757.

MOON, T.; CHI, M. W.; PARK, S. J.; YOON, C. N. Prediction of HPLC Retention Time using 
Multiple Linear Regression: Using one and tow descriptos. J. Chrom. Relat. Tecnol., 2003, vol. 26, p. 2987-3002.

MORGAN, H. L. The Generation of a Unique Machine Description for Chemical Structures-A Technique Developed at Chemical Abstracts Service. J. Chem. Doc., 1965, vol. 5, p. 107113.

MUNK, M. E.; CHRISTIE, B. D. The Characterization of Structure by Computer. Anal. Chim. Acta, 1989, vol. 216, p. 57-68.

NORD, L. I.; FRANSSON, D.; JACOBSSON, S. P. Prediction of liquid chromatographic retention times of stereoids by threee-dimensional structure descriptors and partial least squares modeling. Chem. Intell. Lab. Syst., 1998, vol. 44, p. 257-269.

NUZILLARD, J. M. Automatic Structure Determination of Organic Molecules: Principle and Implementation of the LSD Program. Chin. J. Chem., 2003, vol. 21, 1263-1267.

NUZILLARD, J. M.; EMERENCIANO, V. P. Automatic Structure Elucidation through database search and 2D NMR spectral analysis. Nat. Prod. Comm., 2006, vol. 1, p. 57-64.

PASSREITER, C. M.; ISMAN, M. B. SEAMAN, F.C. (1982). Antifeedant Bioactivity of Sesquiterpene Lactones from Neurolaena lobata and their Antagonism by gammaAminobutyric Acid. Biochem. Syst. Ecol., 1997, vol. 25, pp. 371-377. 
PEREIRA, P. S.; DIAS, D. A.; VICHNEWSKI, W.; NASI, A., N. T. T.; HERZ, W. Sesquiterpene lactones from brazilian Tithonia diversifolia. Phytochemistry, 1997, vol. 45, p. $1445-1448$.

PICMAN, A. K. Biological Activities of sesquiterpene lactones. Biochem. Syst. Ecol., 1986, vol. 14 , p. $255-281$.

RAUSCHER, J. T. Molecular phylogenetics of the Espeletia complex (Asteraceae): evidence from nrDNA ITS sequences on the closest relatives of an Andean adaptive radiation. Am. J. Bot., 2002, vol. 89, p. 1074-1084.

ROBINSON, H. A revision of the tribal and subtribal limits of the Heliantheae (Asteraceae). Smithson. Contrib. Bot., 1981, vol. 51, p. 1-102.

ROBINSON, H. Studies in the Heliantheae (Asteraceae). XXXIV. Redelimitation of the genus Angelphytum. Proc, Biol. Scoc. Wash., 1994, vol. 97, p. 961-969.

SAMEK, Z. Determination of stereochemistry of 5-membered alpha, beta-unsaturated lactones with an exomethylene double bond based on allylic long-range couplings of exomethylene protons. Tet. Lett., 1970, vol. 9, p. 671-676.

SCHEFZICK, S.; KIBBEY, C.; BRADLEY, M. P. Prediction of HPLC conditions using QSPR 
techniques: an effective tool to improve combinatorial library design. J. Comb. Chem., 2004, vol. 6, p. 916-927.

SCHILLING, E. E.; DA COSTA, F. B.; LOPES, N. P.; HEISE, P. J. Brazilian species of Viguiera (Asteraceae) exhibit low levels of ITS sequence variation. Edinburg. J. Bot., 2000, vol. 57 , p. 323-332.

SCHORR, K. GARCIA-PIÑERES, A. J.; SIEDLE, I.; MERFORT, I.; DA COSTA, F. B. Guaianolides from Viguiera gardneri inhibit the transcription factor NF-kappaB. Phytochemistry, 2002, vol. 60, p. 733-740.

SCHÜTZ, V.; PURTUC, V.; FELSINGER, S.; ROBIEN, W. CSEARCH-STEREO: A new generation of NMR database systems allowing three-dimensional spectrum. Fresen. J. Anal. Chem., 1997, vol. 349, p. 33-41.

SEAMAN, F.C. Sesquiterpenes lactones as taxonomic characters in Asteraceae. Bot. Rev., 1982, vol. 48, p. 123-551.

SHELLEY, C. A.; MUNK, M. E. Computer prediction of substructures from carbon-13 Nuclear magnetic ressonance spectra. Anal. Chem., 1982, vol. 54, p. 516-521.

SMITH, E. G. The Wiswesser line-formula chemical notation (WLN). New York, Chemical 
Information management, 1976, vol. único, 281 p.

SOEJARTO, D. D. Biodiversity prospecting and benefit-sharing: perspectives from the field. J. Ethnopharcol., 1996, vol. 51, p. 1-15.

SPRING, O. Microsampling: an alternative approach using sesquiterpenes lactones for systematics. Biochem. Syst. Ecol., 1989, vol. 17, p. 509-517.

SPRING, O. Trichome microsampling of sesquiterpenes lactones for use of systematics studies. In: Fisher, N. H.; Isman, M. B.; Stafford, H. A. (eds). Recents Advances in Phytochemistry, Plenum Press, 1991, vol. 25 - Modern phytochemical methods.

SPRING, O. Chemotaxonomy based on metabolites from glandular trichomes. Adv. Bot. Res., 2000, vol. 31, p. 153-174.

SPRING, O.; BUSCHMANN, H. A Chemotaxonomic survey of sesquiterpene lactones in Heliantheae (Compositae). In Hind, D. J. N.; Beentje H. J. (eds.). Compositae: Systematics. Proceedings of the International Compositae. Kew: Royal botanic gardens, 1994, vol. 1, p. 307-316.

STEFANI, R.; TOMAZELLA, D. M.; ERBELIN, M. N.; DA COSTA, F. B. Eudesmanolides from Dimerostemma vestitum. J. Nat. Prod., 2003, vol. 66, p. 401-403.

STEINBECK, C. SENECA: A Platform-Independent, Distributed, and Parallel System for Computer-Assisted Structure Elucidation of Organic Compounds. J. Chem. Inf. Comput. Sci., 
2001, vol. 41, p. 1500-1507.

STEINBECK, C.; HAN, Y.; KUHN, S.; HORLACHER, O.; LUTTMANN, E.; WILLIGHAGEN, E. The Chemistry Development Kit (CDK): An Open-Source Java Library for Chemo- and Bioinformatics. J. Chem. Inf. Comp. Sci., 2003, vol 43, p. 493-500.

STEINBECK, C. KRAUSE, S. KUHN, S. NMRShiftDB-Constructing a Free Chemical Information System with Open-Source Components. J. Chem. Inf. Comp. Sci., 2003, vol 43, p. 1733-1739.

STEINBECK, C.; KUHN, S. NMRShiftDB - compound identification and structure elucidation support through a free community-built web database. Phytochemistry, 2004, vol. 65, 27112717.

STROKOV, I. I.; LEBEDEV, K. S. Computer Aided Method for Chemical Structure Elucidation Using Spectral Databases and ${ }^{13} \mathrm{C}$ NMR Correlation Tables. J. Chem. Inf. Comput. Sci., 1999, vol. 39, p. 659-665.

STUESSY, T. F. Heliantheae - systematic review. In: HEYWOOD, V. H.; HARBORNE, J. B.; TURNER, B. L. (eds). The Biology and Chemistry of Compositae. New York, Academic Press, vol. único, p. 621-671.

The GNU C/C++ and Fortran Compiler. Por STALLMAN, R. M; 2003. Disponível em: <http://www.gnu.org/gcc>. Último acesso em: 02/10/2006. 
VERPOORTE, R. Exploration of nature's chemodiversity: the role of seconday metabolites as lead in drug development. Drug Discovery Today, 1998, vol.3, p. 232-238.

VESANTO, J. SOM based data visualization methods. Intel. Data Anal., 1999, vol. 3, p. 111128.

WALL, L.; ORWANT, J.; CHRISTIANERSEN, T. Programming Perl. New York, O'Reilly, 2000, vol. único, 1048p.

WEININGER, D.; WEININGER, A.; WEININGER, J. L. SMILES 2. Algorithm for generation unique SIMILES notation. J. Chem. Inf. Com put. Sci., 1989, 29, 97-101.

WITTEN, I. H.; FRANK E. Data Mining: Practical machine learning tools and techniques. San Francisco, Morgan Kaufmann, 2005, vol. único, 526p.

YOSHIOKA, H.; MABRY, T. J.; IRWIN, M. A.; GEISSMAN, T. A.; SAMEK, Z. (The geminal coupling and paramagnetic shift of exomethylene protons in the $\alpha, \beta$-unsaturated $\gamma$-lactone group of sesquiterpene lactones containing $C_{8}-\alpha$-hydroxyl groups. Tetrahedron, 1971, vol. 27, p. 3371-3322. 
Apêndice I - Espectro de $\mathrm{RMN}^{1} \mathrm{H}$ da substância $1 \beta, 10 \alpha, 4 \alpha, 5 \beta$ diepóxido-8 $\alpha$-angeloiloxi-custonolido $\left(400 \mathrm{MHz}, \mathrm{CDCl}_{3}\right)$

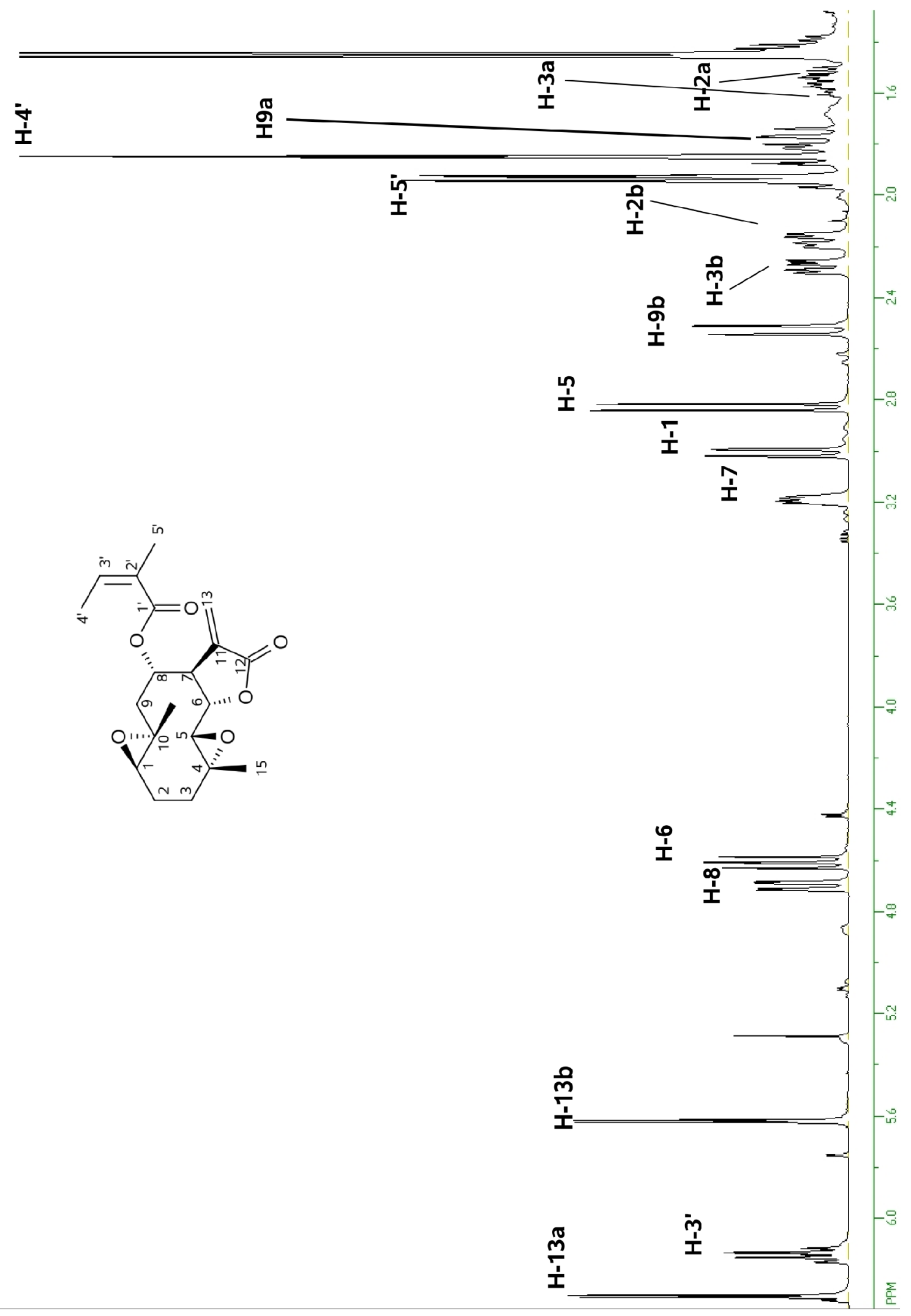




\section{Apêndice II - Espectro de RMN ${ }^{13} \mathrm{C}$ da substância $1 \beta, 10 \alpha, 4 \alpha, 5 \beta$ -} diepóxido-8 $\alpha$-angeloiloxi-custonolido (100 $\mathrm{MHz}, \mathrm{CDCl}_{3}$ ).

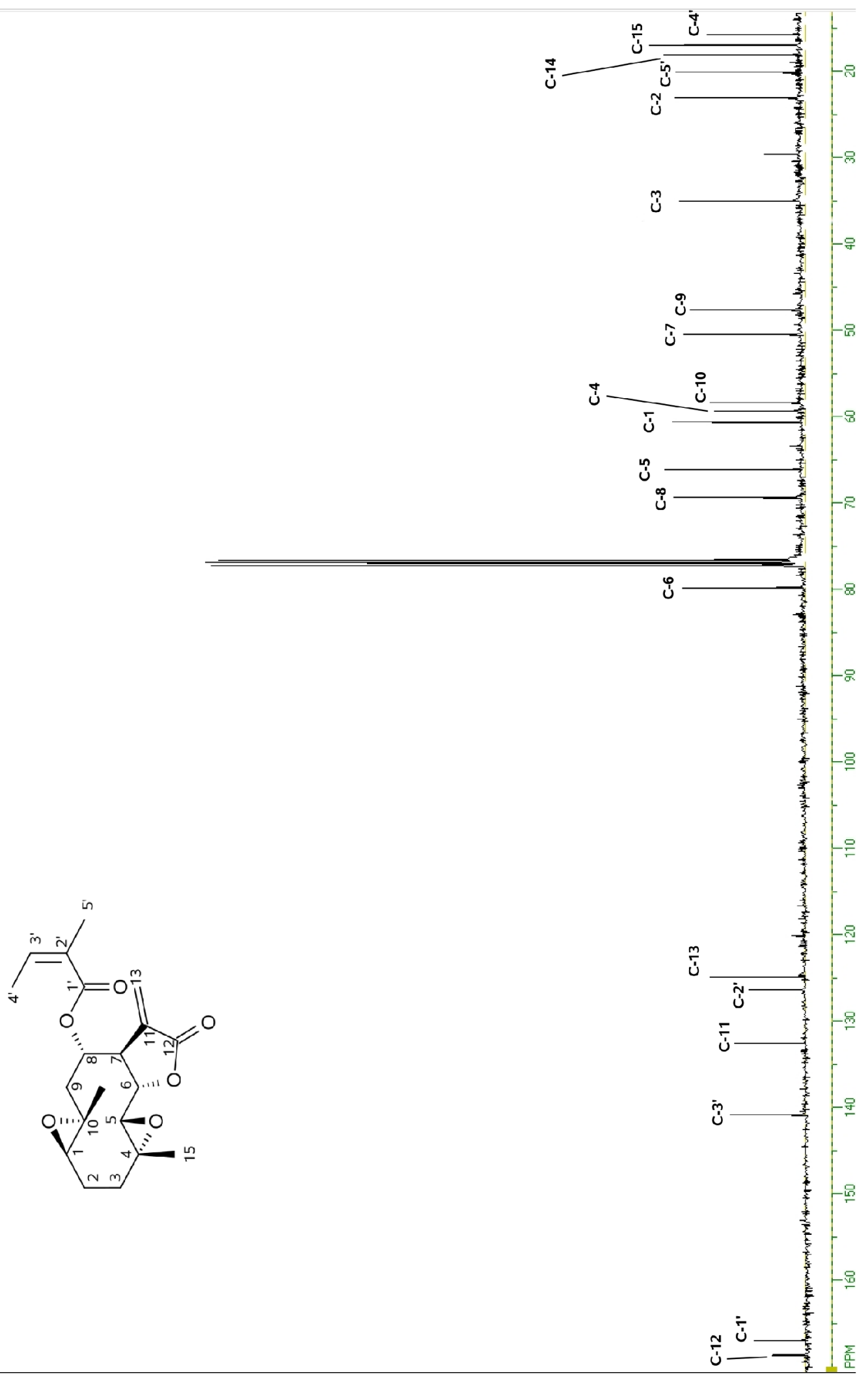


Apêndice III - Espectro de RMN ${ }^{1} \mathrm{H}$ da substância $1 \beta, 5 \beta, 10 \alpha$-triidróxido-8 $\alpha$ angeloiloxi-germacra-3,11(13)-dien-6 $\alpha, 12$-olido (400 $\mathrm{MHz}, \mathrm{CDCl}_{3}$ )

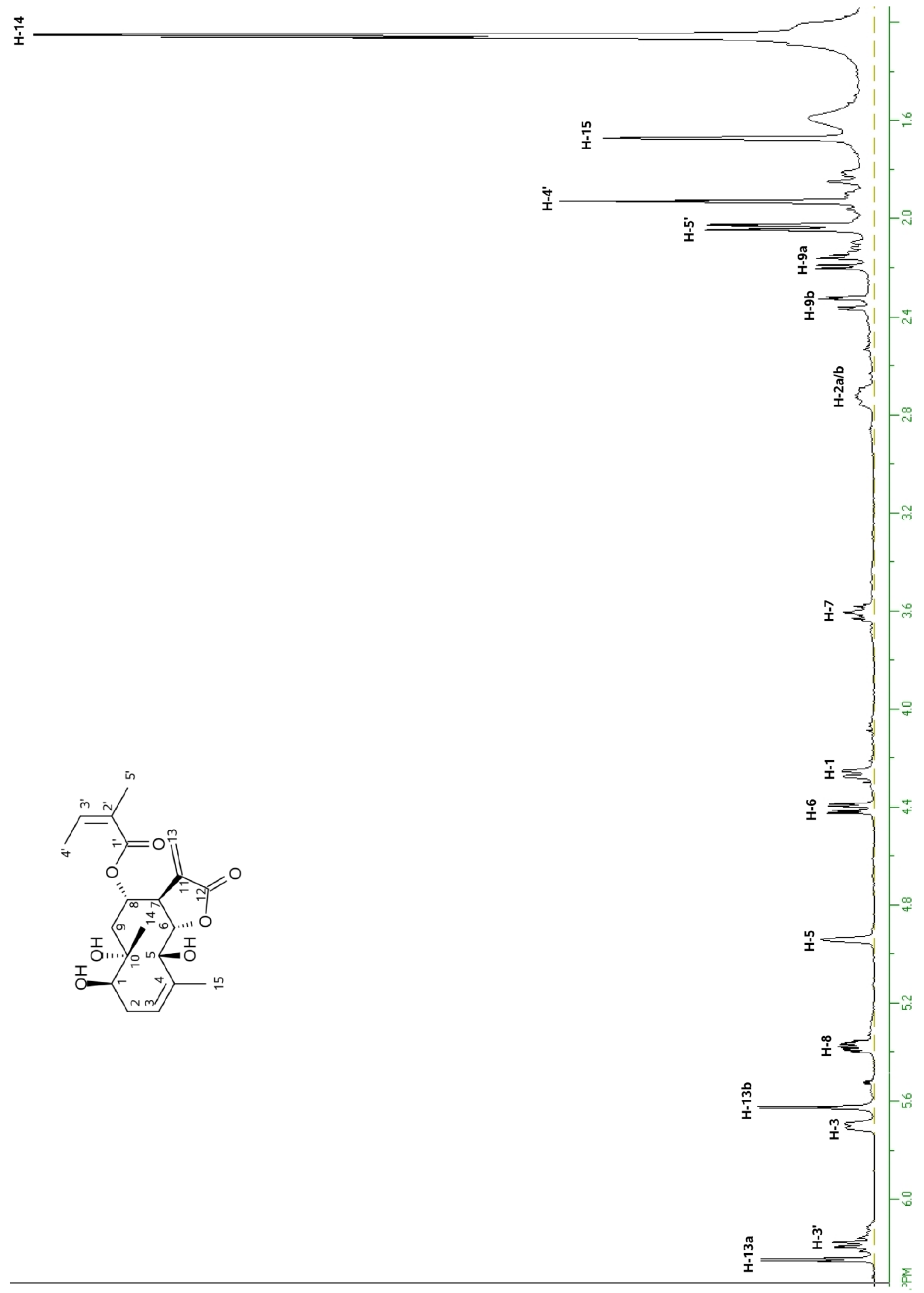


Apêndice VI - Espectro de RMN ${ }^{13} \mathrm{C}$ da substância $1 \beta, 5 \beta, 10 \alpha$-triidróxido-8 $\alpha$ angeloiloxi-germacra-3,11(13)-dien-6 $\alpha, 12$-olido (100 $\mathrm{MHz}, \mathrm{CDCl}_{3}$ )

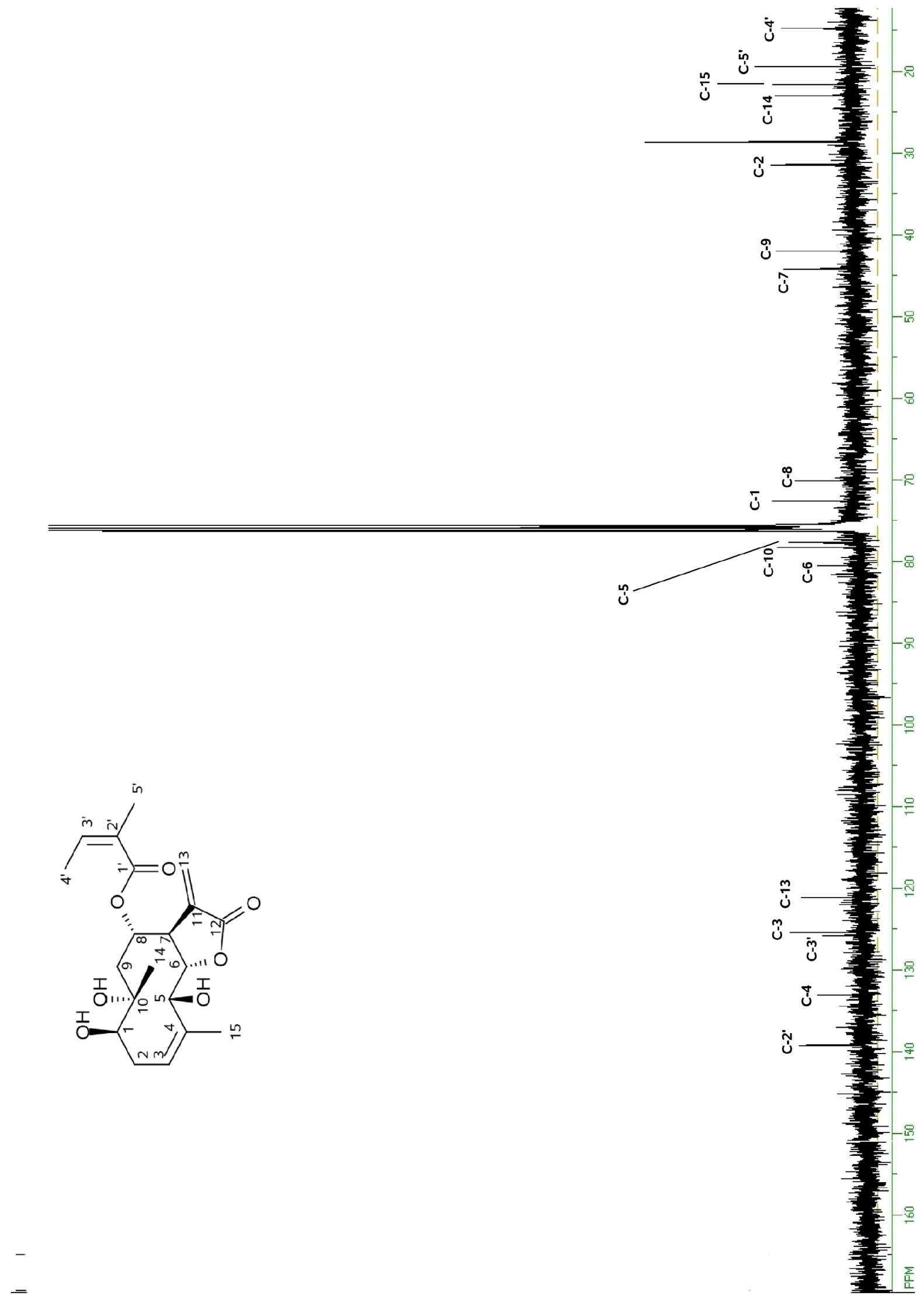


Apêndice VII - Espectro de RMN ${ }^{1} \mathrm{H}$ da substância $1 \alpha$-epoxiangeloilóxi-8 $\alpha$ hidróxi-4,15 $\alpha$-epóxi-eudesm-11,13-en-6 $\alpha, 12$-olido $\left(400 \mathrm{MHz}, \mathrm{CDCl}_{3}\right)$ 


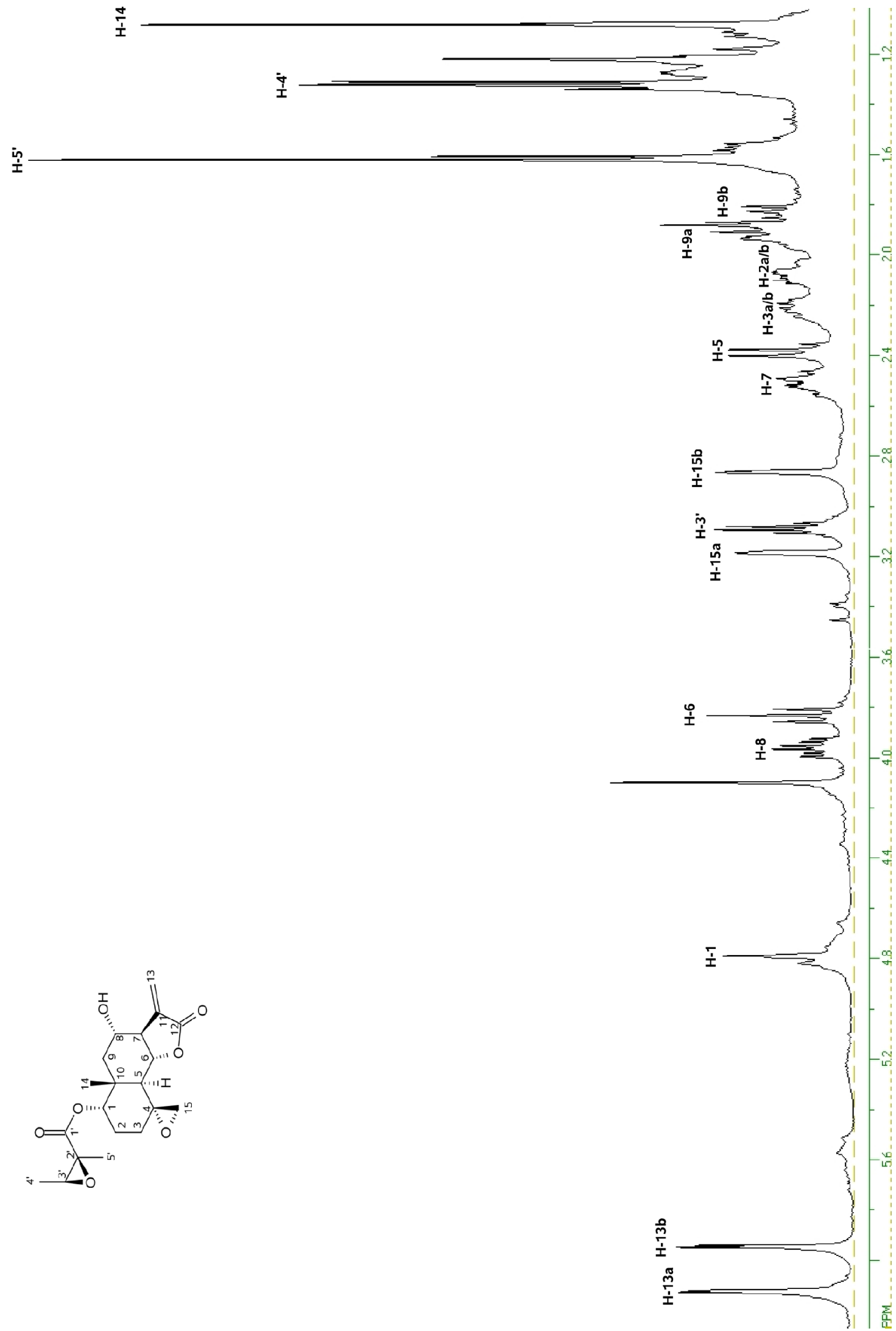


Apêndice IX - Espectro de RMN ${ }^{13} \mathrm{C}$ da substância $1 \alpha$-epoxiangeloilóxi-8 $\alpha$ -

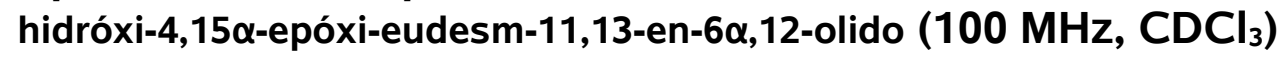

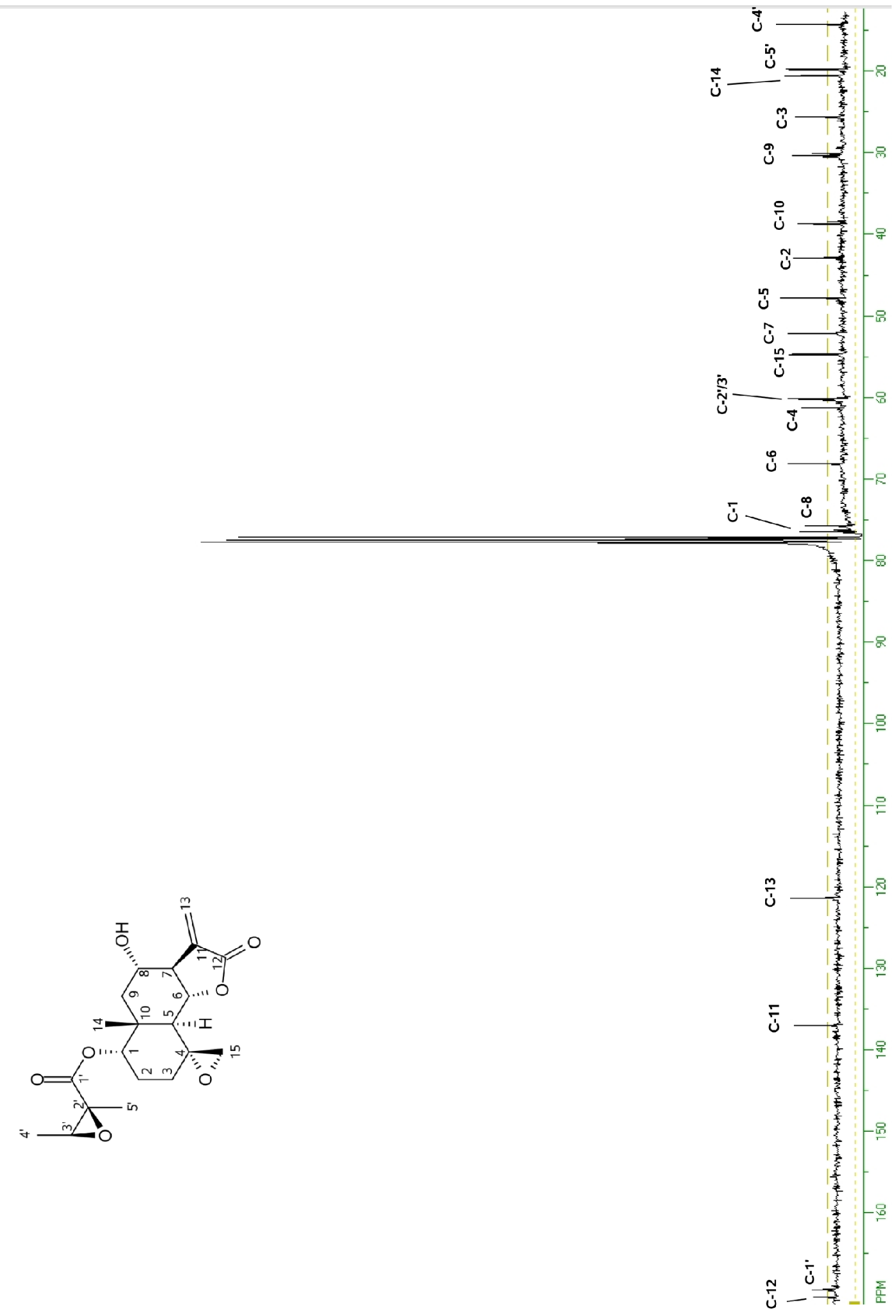


Apêndice $X$ - Espectro de RMN ${ }^{1} \mathrm{H}$ da substância $11 \alpha$-metacriloil-

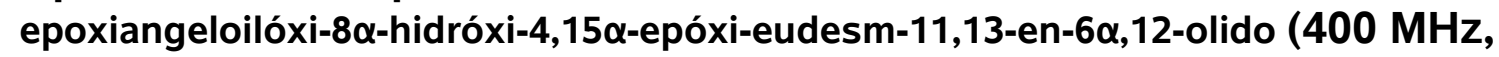
$\mathrm{CDCl}_{3}$ )

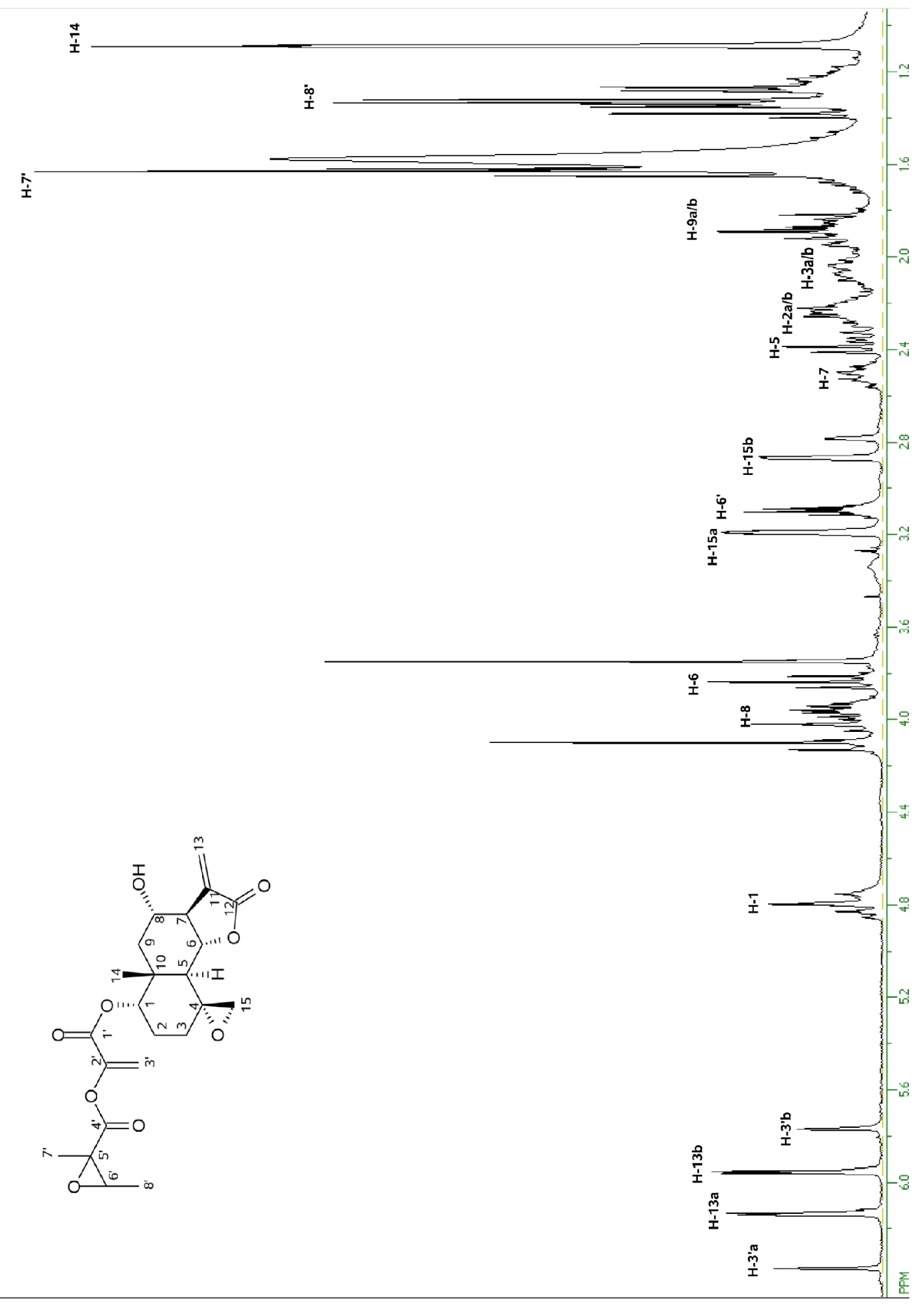




\section{Apêndice XII - Espectro de RMN ${ }^{1} \mathrm{H}$ da substância enidrina $(400 \mathrm{MHz}$, $\mathrm{CDCl}_{3}$ )}

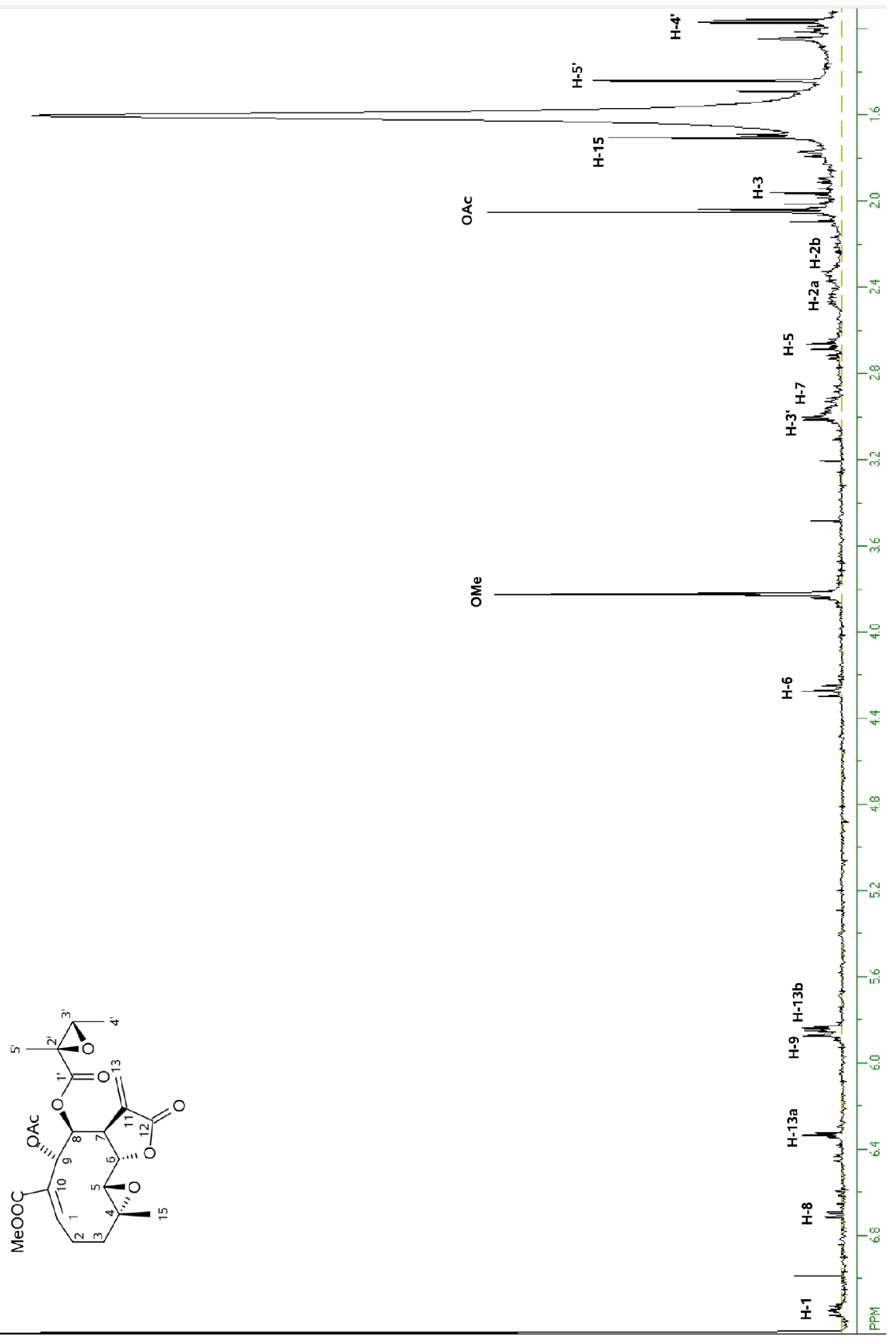




\section{Apêndice XIV - Espectro de RMN ${ }^{1} \mathrm{H}$ da substância $2 \alpha$-hidróxi- longipilina $\left(400 \mathrm{MHz}, \mathrm{CDCl}_{3}\right)$}

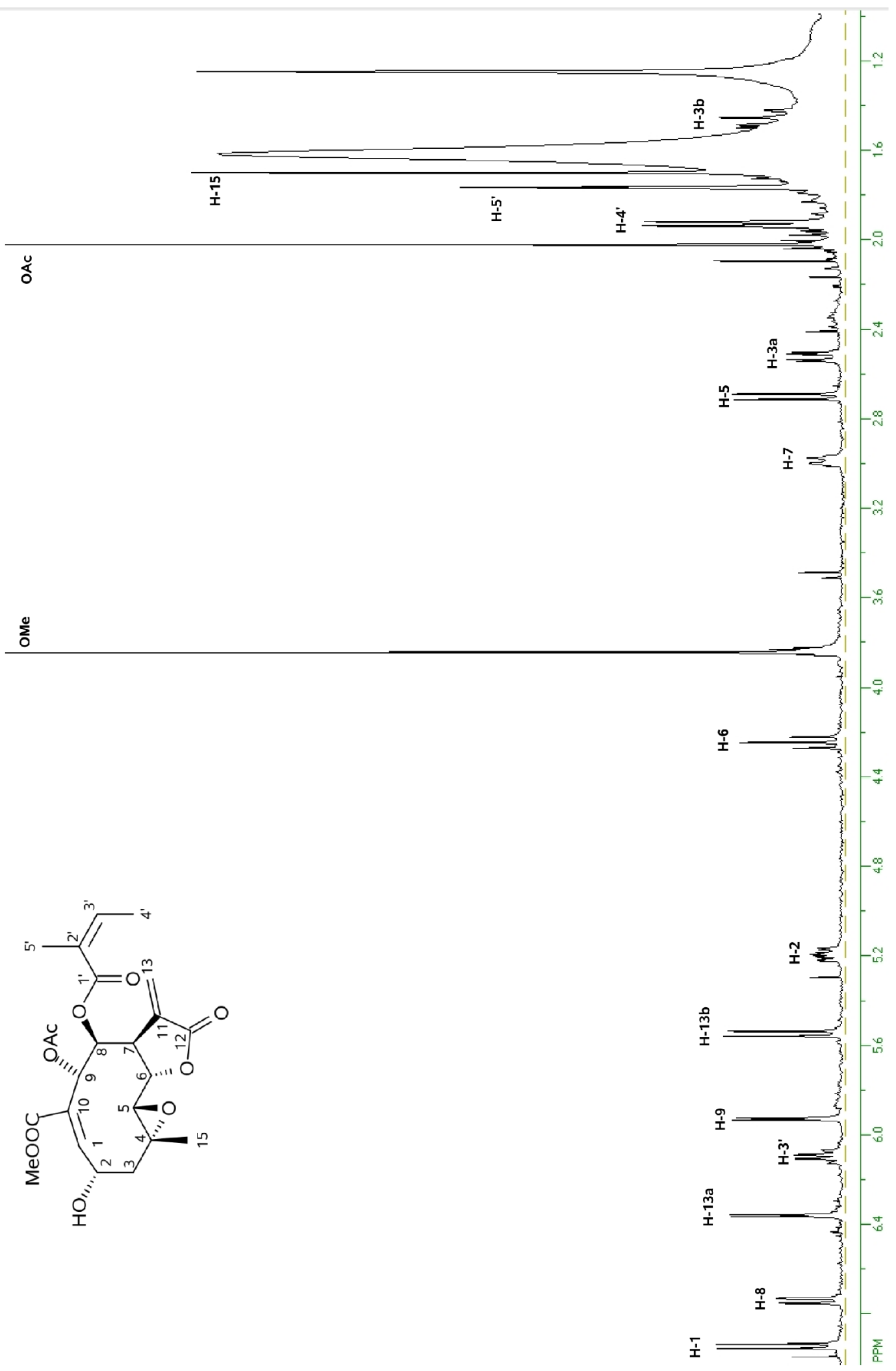

